\title{
Analysis of Glycans by Electrophoretic Approaches:
}

Highly Sensitive Capillary Electrophoretic Separation and Ion Mobility-Mass Spectrometric Structure Assignment 
Analysis of Glycans by Electrophoretic Approaches:

Highly Sensitive Capillary Electrophoretic Separation and Ion Mobility-Mass Spectrometric Structure Assignment.

ISBN 978-90-393-7325-5

All rights reserved. No part of this thesis may be reproduced or transmitted in any form or by any means without prior written permission from the author and publisher holding the copyrights of the published articles. 


\section{Analysis of Glycans by Electrophoretic Approaches:}

Highly Sensitive Capillary Electrophoretic Separation and

Ion Mobility-Mass Spectrometric Structure Assignment

\section{Analyse van Glycanen met Elektroforetische Methodieken: \\ Zeer Gevoelige Capillaire Elektroforetische Scheiding en \\ Ionenmobiliteit-Massaspectrometrische Structuurtoewijzing \\ (met een samenvatting in het Nederlands)}

\section{Proefschrift}

ter verkrijging van de graad van doctor aan de

Universiteit Utrecht

op gezag van de

rector magnificus, prof.dr. H.R.B.M. Kummeling, ingevolge het besluit van het college voor promoties in het openbaar te verdedigen op

maandag 28 september 2020 des middags te 2.30 uur

door

Javier Sastre Toraño

geboren op 6 augustus 1973

te Utrecht 
Promotor:

Prof. dr. G.J.P.H. Boons 
Voor Ana en Daniel 



\section{Preface / voorwoord}

This $\mathrm{PhD}$ thesis describes the development of methodologies for the analysis of glycans with capillary electrophoresis and ion mobility-mass spectrometry. The work is inspired by both the research in my former department of Biomedical Analysis and the work done in my current department of Chemical Biology and Drug Discovery. In the first chapter a general introduction is given on the analysis of glycans. The second chapter describes the developments in the field of capillary electrophoresis and the application for protein and glycan analysis. In the third chapter, the application of robust pre-concentration columns for capillary electrophoresis is described. The fourth and fifth chapters describe the identification of exact glycan structures with ion mobility-mass spectrometry.

During my $\mathrm{PhD}$ studentship, I was able to work with ample freedom on the development of the new analytical methodologies and it is good to notice that some of these approaches are now also being used in our laboratory. The combination of the research with my normal activities on the lab was not always easy, but thanks to the help of several people, we managed to keep all balls in the air. I would therefore wish to thank all the people whose assistance was important in the completion of this dissertation.

I wish to express my deepest gratitude to my supervisor Prof. G.-J. Boons for providing me the opportunity to complete my $\mathrm{PhD}$ thesis. In addition to the extensive knowledge of organic chemistry, glycans, biology, etc. etc., Geert-Jan also has a brought knowledge of analytical chemistry. His influence is therefore clearly reflected in the various chapters. Geert-Jan, thanks to your insight, 
overview, vision and confidence in me, the research went smoothly and we were able to publish our work in high profile journals.

I would also like to show my gratitude to my mentors Prof. G.W. Somsen and the late Prof. G.J. de Jong, without whom this thesis would not have been. Both Govert and Ad have been important in my analytical training and I think that their influence is also clearly reflected in this thesis.

I am also indebted to Oier Aizpurua Olaizaola and Victor Somovilla Busto. Oier and I took our first steps in glycan analysis together and he has made a major contribution to the measurements with ion mobility mass spectrometry. With Victor I have discussed a lot about the structure and behavior of glycans in the gas phase and he has also performed most of the modeling work described in this thesis. Both Oier and Victor have made a major contribution to the two manuscripts on ion mobility-mass spectrometry.

I wrote the first manuscript, about capillary electrophoresis for protein and glycan analysis, together with Rawi Ramautar and Ad de Jong. For the second capillary electrophoresis manuscript, I have been assisted by Xiufen Liu and the students of College of Pharmaceutical Sciences Kevin Hooijschuur, Anna Grootendorst and Ines Pieterman. The standards used in that chapter have been synthesized by $\mathrm{Na}$ Wei and Tiehai Li. Standards synthesized by Na Wei and Tiehai Li have also been used in the first ion mobility-mass spectrometry manuscript and modeling has been done by Victor Somovilla Busto in collaboration with Gonzalo JiménezOsés and Francisco Corzana. Luca Unione and Juan Falcon Perez also have worked on this manuscript. For the work described in the second ion mobilitymass spectrometry manuscript, I used standards that have been synthesized by Ivan Gagarinov, Gaël Vos, Frederik Broszeit and Apoorva Srivastava. Some of the measurements in that manuscript have been obtained on a cyclic ion mobilitymass spectrometer with the assistance of Martin Palmer and James Langridge. 
In addition to all the support in the laboratory, I have also received the necessary support from my parents and in-laws and, of course, from my anchor Linda. Ana and Daniel, this thesis is dedicated to you and I hope it will inspire and motivate you to get the most out of yourself.

I hope everyone will enjoy reading this thesis as much as I have had developing and writing it.

Javier Sastre Toraño, De Meern, August 19, 2020.

\section{Voorwoord}

Dit proefschrift beschrijft de ontwikkeling van methodieken voor het analyseren van glycanen met capillaire elektroforese en ionenmobilieit-massaspectrometrie. Het werk is geïnspireerd op zowel het onderzoek in mijn oude vakgroep Biomedische Analyse alsook het werk dat in mijn huidige vakgroep Chemical Biology and Drug Discovery wordt uitgevoerd. In het eerste hoofdstuk wordt een algemene inleiding gegeven over de analyse van glycanen. Het tweede hoofdstuk beschrijft de ontwikkelingen op het gebied van capillaire elektroforese en de toepassing voor eiwit- en glycaananalyse. In het derde hoofdstuk wordt de toepassing van robuuste preconcentreringskolommen voor capillaire elektroforese beschreven. Het vierde en vijfde hoofdstuk 
beschrijven de identificatie van exacte glycaanstructuren met ionenmobiliteitmassaspectrometrie.

Tijdens mijn AIO-periode heb ik met een grote mate van vrijheid aan de ontwikkeling van de nieuwe analytische methodieken kunnen werken en het is goed om te zien dat een deel van deze methodieken nu ook in ons laboratorium wordt gebruikt. De combinatie van het promotieonderzoek met mijn normale werkzaamheden op het laboratorium was niet altijd even makkelijk, maar dankzij de nodige hulp is het gelukt om alle ballen in de lucht te houden. Ik wil daarom iedereen bedanken die het mogelijk heeft gemaakt om dit proefschrift te maken.

Allereerst wil ik mijn promotor prof. dr. G.-J. Boons bedanken voor de mogelijkheid om dit proefschrift te kunnen maken. Naast de zeer uitgebreide kennis over organische chemie, glycanen, biologie etc. etc., heeft Geert-Jan ook veel kennis van de analytische chemie. Zijn invloed is dan ook duidelijk terug te vinden in de diverse hoofdstukken. Geert-Jan, door jouw inzicht, overzicht, visie en vertrouwen in mij is het onderzoek vlot en soepel verlopen en konden we ons werk publiceren in vooraanstaande vakbladen.

Ik wil ook mijn mentoren prof. dr. G.W. Somsen en wijlen prof. dr. G.J. de Jong bedanken, zonder wie dit proefschrift er ook niet was geweest. Zowel Govert als Ad zijn belangrijk geweest in mijn analytische vorming en ik denk dat ook hun invloed in dit proefschrift goed zichtbaar is.

Mijn speciale dank gaat uit naar Oier Aizpurua Olaizaola en Victor Somovilla Busto. Oier en ik hebben samen onze eerste stappen in de glycaananalyse gezet en hij heeft een grote bijdrage geleverd aan de metingen met ionenmobiliteitmassaspectrometrie. Met Victor heb ik veel over de structuur en gedrag van glycanen in de gasfase gediscussieerd en hij heeft ook het grootste deel van het modeleerwerk gedaan dat in dit proefschrift beschreven is. Zowel Oier als 
Victor hebben een grote bijdrage geleverd aan de twee manuscripten over ionenmobiliteit-massaspectrometrie.

Het eerste manuscript, over capillaire elektroforese voor eiwit- en glycaananalyse, is samen met Rawi Ramautar en Ad de Jong geschreven. Voor het tweede capillaire elektroforesemanuscript heb ik hulp gehad van Xiufen Liu en de studenten van College of Pharmaceutical Sciences Kevin Hooijschuur, Anna Grootendorst en Ines Pieterman. De standaarden die in dat hoofdstuk zijn gebruikt, zijn gesynthetiseerd door Na Wei en Tiehai Li. Voor het eerste ionenmobiliteitsmanuscript zijn standaarden gebruikt die ook zijn gesynthetiseerd door $\mathrm{Na}$ Wei en Tiehai Li en het modeleerwerk is gedaan door Victor Somovilla Busto i.s.m. Gonzalo Jiménez-Osés en Francisco Corzana. Aan dit hoofdstuk hebben verder ook Luca Unione en Juan Falcon Perez gewerkt. Voor het werk beschreven in het tweede ionenmobiliteitsmanuscript, heb ik gebruik gemaakt van standaarden die zijn gesynthetiseerd door Ivan Gagarinov, Gaël Vos, Frederik Broszeit en Apoorva Srivastava. Enkele metingen in dat manuscript zijn op een cyclische ionenmobiliteit-massaspectrometer gemeten met hulp van Martin Palmer en James Langridge.

Naast alle hulp op het laboratorium heb ik ook de nodige ondersteuning gekregen van mijn ouders en schoonouders en uiteraard ook van mijn steun en toeverlaat Linda. Ana en Daniel, dit proefschrift is aan jullie opgedragen en ik hoop dat het jullie zal inspireren en motiveren om alles uit jullie zelf te halen.

Ik hoop dat iedereen dit proefschrift met net zoveel plezier zal lezen als ik heb gehad met de ontwikkeling en het schrijven ervan.

Javier Sastre Toraño, De Meern, 19 augustus 2020. 



\section{Table of contents}

ACRONYMS AND SYMBOLS

\section{GENERAL INTRODUCTION AND OUTLINE}

1.1 Introduction

1.2 Glycans conjugated to proteins

1.3 Sample preparation

1.4 Glycan separation techniques and MS detection

1.4.1 LC-ESI-MS

1.4.2 CE-ESI-MS

1.4.3 IMS-MS

30

1.5 Glycan standards

33

2. ADVANCES IN CE FOR THE LIFE SCIENCES

2.2. Technology

2.2.1 CE modes 39

2.2.2 CE-MS 45

2.3 Selected applications in the life sciences 51

2.3.1 Biologicals 51

2.3.2 Glycans 58

2.3.3 Quantitative CE-MS for glycans 64

\section{HIGHLY SENSITIVE CE-IMS-MS OF GLYCANS USING IN-} LINE SAMPLE TRAPPING 
3.3 Results and discussion $\quad 74$

3.3.1 Trap column development $\quad 74$

3.3.2 Trapping, elution and CZE optimization $\quad 75$

$\begin{array}{ll}\text { 3.3.3 Characterization of trap columns } & 80\end{array}$

3.4 Conclusion $\quad 85$

\section{IDENTIFICATION OF ISOMERIC N-GLYCANS BY} CONFORMER DISTRIBUTION FINGERPRINTING USING IM-MS

$\begin{array}{ll}4.1 \text { Introduction } & 88\end{array}$

$\begin{array}{ll}4.2 \text { Experimental } & 90\end{array}$

4.3 Results and discussion $\quad 94$

4.3.1 CCS values for glycan identification $\quad 94$

4.3.2 ATDs for glycan identification 96

$\begin{array}{ll}4.4 \text { Conclusion } & 101\end{array}$

5. IMS CAN ASSIGN EXACT FUCOSYL POSITION IN

GLYCANS AND PREVENT MISINTERPRETATION OF MS

DATA AFTER GAS-PHASE REARRANGEMENT 103

$\begin{array}{ll}5.1 \text { Introduction } & 104\end{array}$

$\begin{array}{ll}5.2 \text { Experimental } & 105\end{array}$

$\begin{array}{ll}5.3 \text { Results and discussion } & 108\end{array}$

5.3.1 Determination of fucoside migration positions with MS/MS 108

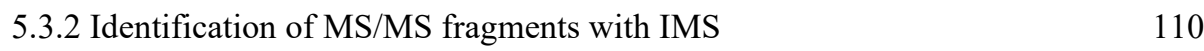

5.3.3 Cyclic IMS of $N$-glycan fragment ions 113

$\begin{array}{ll}5.4 \text { Conclusion } & 114\end{array}$ 
6.1 Capillary electrophoresis

6.2 Ion mobility-mass spectrometry

7. SAMENVATTING

123

CURRICULUM VITAE

LIST OF PUBLICATIONS 



\section{Acronyms and symbols}

$\Omega$

2-AA

2-AB

$\mathrm{ACN}$

ADAEB

ADC

Alloc

AMBER

ANTS

APTS

Asn

ATD

ATV

$\mathrm{BCC}$

BFS

BPE

$\mathrm{CCD}$

CCS

CCSD

$\mathrm{CD}$

CE

CEC

CGE

CID

CIEF
Collision cross section

2-amino benzoic acid

2-amino benzamide

Acetonitrile

4-amino- $N$-2(diethylamino)ethyl-benzamide

Antibody-drug conjugate

Allyloxycarbonate

Assisted model building with energy refinement

2-aminonaphthalene trisulfonate

Aminopyrene trisulfonate

Asparagine

Arrival time distribution

Aankomsttijdverdeling

Basal cell carcinoma

Bare fused silica

Base peak electropherogram

Charge-coupled device

Collision cross section

Collision cross section distribution

Conformation distribution

Capillary electrophoresis/capillaire elektroforese

Capillary electrochromatography

Capillary gel electrophoresis/capillaire gel elektroforese

Collision-induced dissociation

Capillary isoelectric focusing/ capillaire iso-elektrisch focusseren 
cIMS Cyclic ion mobility spectrometry

CMP Cytosine monophosphate

CV Capillary volume

CV Conformatie verdeling

CZE Capillary zone electrophoresis/capillaire zone elektroforese

DAR Drug-to-antibody ratio

DMSO Dimethyl sulfoxide

DMTMM 4-(4,6-dimethoxy-1,3,5-triazin-2-yl)-4-methylmorpholinium

DNA Deoxyribonucleic acid

$d p 1$

Degree of polymerization of preceding homooligomer peak

DTIMS Drift tube ion mobility spectrometry

DVB-NVP $\quad m$-divinylbenzene and $N$-vinylpyrrolidone copolymer

e Elementary charge

E $\quad$ Electric field

EOF Electroosmotic flow

EPO Erythropoietin

ESI Electrospray ionization

FA Formic acid

Fc Crystallizable region

Fmoc Fluorenylmethyloxycarbonate

Fuc Fucose

G2 Digalactosylated $N$-glycan

GAFF Generalized assisted model building with energy refinement force field

GAG Glycosaminoglycans

Gal Galactose

GalNac $\quad N$-acetylglucosamine

GC Gas chromatography

GDP Guanine diphosphate

Glc Glucose

GlcA Glucuronic acid

GlcN Glucosamine

GLcNAc $\quad N$-acetylglucosamine 


\begin{tabular}{ll} 
GU & Glucose unit \\
HAc & Acetic acid \\
HILIC & Hydrophilic interaction chromatography \\
HPMC & Hydroxypropylmethylcellulose \\
iCIEF & Imaging capillary isoelectric focusing \\
ID & Inner diameter \\
IdeS & Immunoglobulin G-degrading enzyme of Streptococcus pyogenes \\
IdoA & Iduronic acid \\
igG & Immunoglobulin G \\
IM & Ion mobility/ionenmobiliteit \\
IMS & Ion mobility spectrometry/ Ionenmobiliteisspectrometrie \\
ITP & Isotachophoresis \\
$k_{b}$ & Boltzmann constant \\
$K_{0}$ & Reduced mobility \\
$L$ & Length of the drift tube \\
LacNAc & sialosyl-fucosyl oligo- $N$-acetyllactosamine \\
LC & Liquid chromatography \\
LE & Leading electrolyte \\
Lev & Levulinoyl \\
LIF & Laser-induced fluorescence \\
M-B & Maxwell-Boltzmann probability distribution \\
$m_{I}$ & Mass of an ion \\
$m_{B}$ & Mass of the buffer gas \\
$m / z$ & Mass to charge ratio \\
mAbs & Monoclonal antibody \\
MALDI & Matrix-assisted laser desorption ionization \\
Man & Mannose \\
MAX & Mixed-mode strong anion exchange \\
MCE & Microchip capillary electrophoresis \\
MD & Molecular dynamics \\
MEKC & Micellar electrokinetic chromatography \\
MeOH & Methanol \\
\hline
\end{tabular}


MCX Mixed-mode strong cation exchange resin

MS

Mass spectrometry/massaspectrometrie

$N$

Density of buffer gas

Nap

2-naphthylmethyl

Neu5Ac

$\mathrm{N}$-acetylneuraminic acid (sialic acid)

OD

Outer diameter

$P$

Pressure in the drift tube

PA Procainamide

PAA Polyacrylamide

PB Polybrene

PE PolyE-323

PGC Porous graphitized carbon

pI Isoelectric point

PTFE Polytetrafluoroethylene

PVA Polyvinyl alcohol

QC Quality control

QTOF Quadrupole time of flight

RF Radio frequency

RP Reverse-phase

SCC Squamous cell carcinoma

SDS Sodium dodecyl sulfate

SDS-PAGE Sodium dodecyl sulfate-polyacrylamide gel electrophoresis

SL Sheath liquid

SPE Solid-phase extraction

$T \quad$ Temperature in the drift tube

$t A \quad$ Migration time of an unknown glycan

$t_{d} \quad$ Drift time

$t_{l}$ and $t_{2} \quad$ Migration times of homooligomers preceding and following the peak of an unknown glycan, respectively

TE Terminating electrolyte

TFA Trifluoroacetic acid

TIMS Trapped ion mobility spectrometry

tITP Transient isotachophoresis 


$\begin{array}{ll}\text { TMT } & \text { Tandem mass tag } \\ \text { TOF } & \text { Time-of-flight } \\ \text { TWIMS } & \text { Travelling wave ion mobility } \\ \text { UDP } & \text { Uridine diphosphate } \\ \text { USP } & \text { United States Pharmacopeia } \\ \text { UV } & \text { Ultraviolet } \\ \text { VFE } & \text { Vaste-fase extractie } \\ \text { WAX } & \text { Weak anion exchange } \\ \text { WCX } & \text { Weak cation exchange resin } \\ \text { Xyl } & \text { Xylose } \\ z & \text { Charge state of an ion } \\ \text { ZIC-HILIC } & \text { Zwitterionic hydrophilic interaction chromatography }\end{array}$





\section{General introduction and outline}

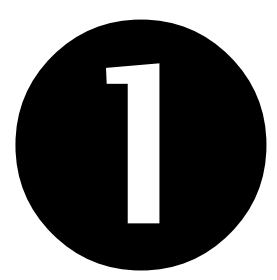

Modified from:

J. Sastre Toraño, R. Ramautar, G. de Jong, Journal of Chromatography B, Analytical technologies in the biomedical and life sciences, 1118-1119 (2019) 116-136.

And

O. Aizpurua-Olaizaola, J. Sastre Toraño, J.M. Falcon-Perez, C. Williams, N. Reichardt, G.J.

Boons, Trends in Analytical Chemistry, 100 (2018) 7-14. 


\section{General introduction and outline}

\subsection{Introduction}

Glycosylation is a common posttranslational protein modification and almost all eukaryotic cell surfaces and secreted proteins are modified by covalently linked glycans. The glycans play essential roles in different biological processes, such as protein folding, fertilization, neuronal development, hormone activity and the proliferation of cells and their organization into specific tissues. ${ }^{1,2}$ Eukaryotic protein glycosylation is performed in the endoplasmic reticulum and trans-Golgi Network and the process is dominated by genetic factors, age, gender and lifestyle, ${ }^{3}$ although it can also reflect specific pathological situations. In this context, glycosylation plays a relevant role in e.g. inflammation, innate immune responses, and the development of autoimmune diseases and cancer, which make glycans important as analytical biomarkers for several diseases. 2, 4, 5 Furthermore, many biologicals, such as monoclonal antibodies, are modified by complex glycans and their glycosylation determine biological activity and pharmacokinetic properties. ${ }^{6}$

Currently, the field of glycoscience is receiving considerable attention with the growing demand for glycan biomarkers for disease diagnosis and the vast growing market of biologicals. It is therefore essential to quickly and easily determine exact glycan structures in complex biological samples. Current analytical methods entail glycan release from proteins, derivatization and purification, followed by separation with capillary electrophoresis ${ }^{7}$ (CE) or liquid chromatography (LC) and fluorescence, matrix-assisted laser desorption/ionization (MALDI) as well as electrospray ionization (ESI) mass spectrometry (MS) detection. ${ }^{8}$ Accurate mass measurements are used for compositional assignment and additional MS/MS fragmentation experiments can provide more detailed structural information. However, the analysis and structural elucidation of glycans in biological samples is still very difficult due to their low abundance and detection sensitivity, structural complexity as well as the lack of well-defined standards, which is a major hurdle for the development of biologicals and discovery of biomarkers. 
In this thesis, new electrophoretic approaches for glycan analysis in the liquid and gas phase are described. An overview of CE for the analysis of glycans as well as proteins is given and a novel method, using CE-MS, is presented for sensitive glycan analysis. In this method, CE has been improved for sensitive glycan analysis using large volume injections with in-line sample trapping. In addition, new ion mobility spectrometry (IMS)-MS approaches, developed using welldefined standards, are described for accurate structural assignment of glycans. These approaches enable exact glycan structure elucidation, without further need for standards, by measuring the intrinsic gas phase conformer distribution of intact and collision induced fragment ions with IMS-MS. The developments described in this thesis, complement and enhance the current available analytical techniques, providing high sensitivity and distinct separation selectivity, with respect to LC, and improved exact glycan structure elucidation for their characterization in biological samples and biologicals.

\subsection{Glycans conjugated to proteins}

Glycans conjugated to eukaryotic proteins, consist of monosaccharide building blocks (Fig. 1) that are linked in different sequences and linkages. The chains can be linear or branched, yielding a large number of possible glycan structures including many isomers. In most glycoproteins and proteoglycans, the glycans are linked at the anomeric center to the protein by $N$ - or $O$-linkages of amino acids. $N$-glycans are linked to the nitrogen sidechain of asparagine (Asn) in an Asn-X-serine/threonine sequence and occasionally in an Asn-X-cysteine sequence, where $\mathrm{X}$ can be any amino acid except proline. $O$-glycans are linked through oxygen of the site chain of serine or threonine and glycosaminoglycans (GAGs) are linked to serine (Fig. 2A). $N$-linked glycans consist of a common Penta saccharide core composed of two $N$-acetylglucosamine (GlcNAc) and three mannose units and can be divided in three main groups based on further extension of residues (Fig. 2). $O$-glycans consist mainly of four cores, considering only the GalNAc linked type that can be extended with several glycan motifs, and GAGs consist of repeating sulphated disaccharide units linked to the protein by a tertrasaccharide linker consisting of a xylose, two galactose and one glucuronic acid unit (Fig.2). The GAG hyaluronan is not sulphated nor covalently linked to proteins but forms complexes with proteoglycans. 


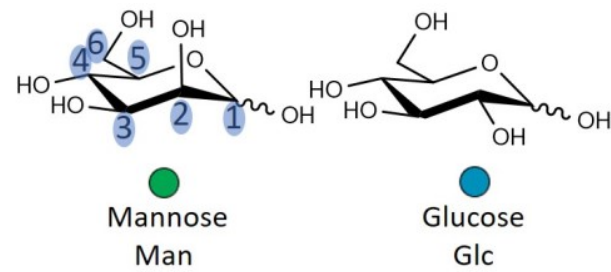

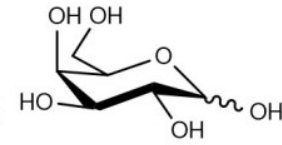

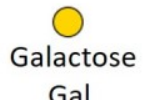

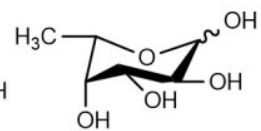

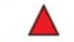

Fucose

Fuc<smiles>CC(=O)N[C@H](C(=O)O)[C@H](O)C(O)O</smiles>

$N$-acetylglucosamine

GIcNAc

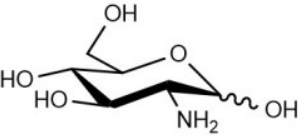

Glucosamine

GlcN

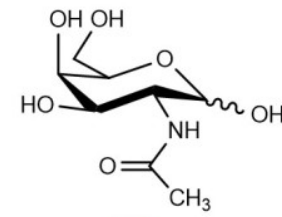

$N$-acetylgalactosamine GalNAc

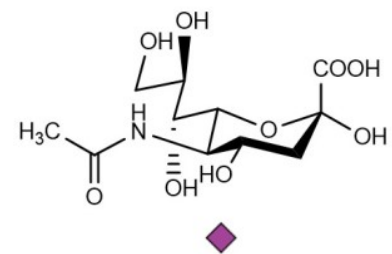

$\mathrm{N}$-acetylneuraminic acid Neu5Ac

Figure 1. Structures, symbols and letter codes of human protein monosaccharide building units. Carbon atoms are numbered according to the example given for mannose. Numbering starts at the anomeric center (number 1). The anomeric carbon is a stereocenter, where the attached hydroxyl can have an axial or an equatorial orientation, establishing the $\alpha$ - and $\beta$-form of the carbohydrate, respectively. When the anomeric carbon is not involved in a glycosidic bond, the ring can be converted into an open-chain form containing a reactive aldehyde group that can act as a reducing agent. Adapted from 9 with permission. 

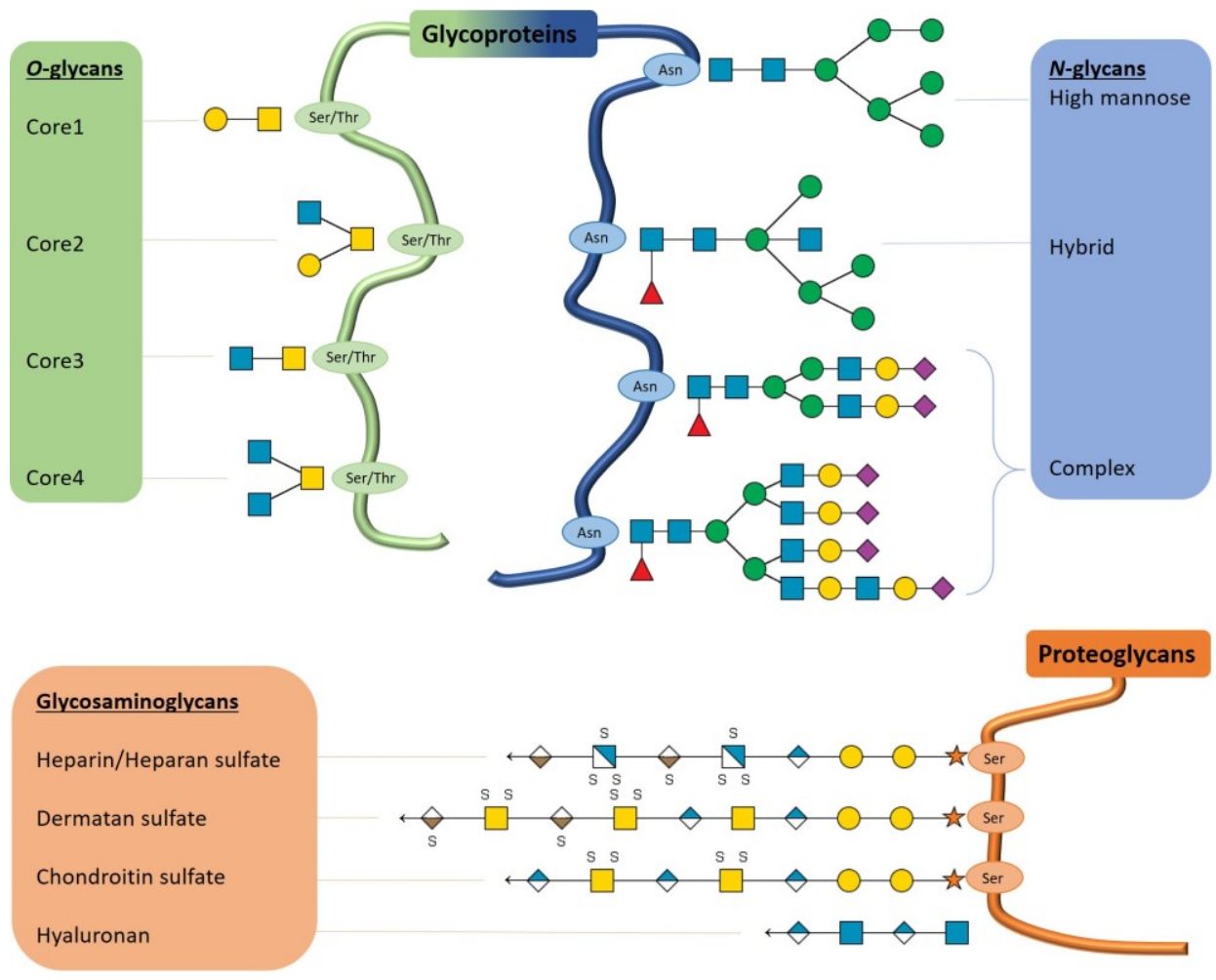

Figure 2. Structures of glycans conjugated to proteins. Adapted from 9 with permission.

\subsection{Sample preparation}

Glycans can be released from proteins enzymatically or chemically. $N$-glycans are usually released intact from isolated glycoproteins by denaturation of the protein and cleavage of the $N$-acetylglucosamine-asparagine bond by endoglycosidases such as peptide- $N$-glycosidase F (PNGase F) ${ }^{10}$ For $O$-linked glycans there is no universal enzyme-based cleavage procedure available and chemical cleavage is used instead. $\beta$-elimination at high alkaline $\mathrm{pH}$ is commonly used to release $O$-linked glycans, converting them thereby to the reduced form which makes the derivatization with a tag more complicated. ${ }^{11}$ Release with anhydrous hydrazine is also possible, but the peeling degradation of glycans increases compared to the reducing $\beta$-elimination approach and more modified carbohydrate residues are obtained. ${ }^{12}$ 
Since most glycans do not contain an UV-active chromophore, labeling of released glycans is often required. ${ }^{13}$ Furthermore, if no $\mathrm{N}$-acetylneuraminic acid (Neu5Ac) or other chargeable group is present, it is difficult to charge glycans for electrophoretic separation or electrospray ionization (ESI) and therefore an ionizable group needs to be attached. Several derivatization reagents for glycan analysis are described in chapter 2.

The reagents for glycan release and derivatization are often added in large excess for quantitative release and labeling. Since these additives and matrix components can interfere with the further analysis, they are removed after the respective reactions. Native and derivatized glycans can be purified and concentrated using solid-phase extraction methods such as with reversed phase (RP) ${ }^{14}$ gel filtration, size exclusion, porous graphitized carbon $(\mathrm{PGC})^{15}$ and hydrophilic-interaction chromatography (HILIC). ${ }^{16}$

\subsection{Glycan separation techniques and MS detection}

Glycans are usually analyzed with a separation technique, followed by ESI-MS. ${ }^{17}$ The separation is often necessary to reduce MS spectrum complexity and minimize ion suppression. Common separation techniques include LC, such as RP, PGC and HILIC as well as CE and IMS. All these separation techniques can be coupled to MS to obtain compositions, using accurate mass measurement, and exact structures using multi-stage MS. ${ }^{18}$

\subsubsection{LC-ESI-MS}

LC-ESI-MS analysis of released glycans is probably the most widely used analytical technique to obtain comprehensive glycan profiles. For RP chromatography, glycans are derivatized with a hydrophobic label to obtain retention on the stationary phase. The separation of glycans is highly dependable on the hydrophobicity of the label, but also on the positions and linkage types of the carbohydrate residues, ${ }^{19}$ although isomeric separation is limited compared to HILIC or PGC-LC.

For HILIC, a large variety of stationary phases can be used for glycan analysis, such as silica-based, zwitterionic and amide modified materials. Retention times 
are based on the hydrophilicity of the molecule, which accounts for differences in properties that depend on size, charge, composition, structure, linkage and branching. As a result, HILIC-based approaches are more appropriate for the analysis of complex mixtures than RP-LC, as many structural isomers can be separated prior to MS analysis. ${ }^{20}$

Porous graphitized carbon (PGC) chromatography is often used because it has a strong retention capacity for glycans, in particular for charged species. ${ }^{15}$ The elution patterns are based on the size and carbohydrate sequence and linkage configuration, which makes this technique appropriate for the separation of complex isomeric glycans. ${ }^{21}$

\subsubsection{CE-ESI-MS}

$\mathrm{CE}$ is an established analytical technique for biomolecules with unique separation characteristics. Chapter 2 presents an overview of different CE mode principles, recent developments in CE instrumentation and CE-MS interfacing. Examples are shown of $\mathrm{CE}$ applications for the analysis of intact proteins and for the analysis of protein-released glycans in the characterization of biologicals and discovery of glycan biomarkers in biological samples.

CE coupled to laser-induced fluorescence (CE-LIF) has allowed for highly sensitive glycomics since the early 1990s. ${ }^{22}$ Despite improvements in instrumentation and methods based on MS, capillary gel electrophoresis (CGE)LIF is still the major CE technique for glycan profiling. This is due to the extraordinary limits of detection offered by LIF detection and the high resolution and migration time repeatability obtained with CGE, allowing for the separation of many structural isomers and structure assignment through the application of glucose unit ladders for intact and exoglycosidase-digested fragments. Although the separation with CGE and detection with sensitive LIF provides a very useable analytical platform, only molecules for which standard migration times have been determined can be identified. Therefore, a universally applicable identification methodology that provides detailed structural information, such as MS, is more appropriate.

Despite the improved limits of detection of CE-MS, due to interface developments that lead to a better ionization efficiency, the low injectable sample 
volumes in $\mathrm{CE}$ is a major stumbling block. Various attempts to inject larger sample volumes into CE have been made in the past. ${ }^{23-25}$ These methods are mostly based on solid-phase materials to concentrate analytes in-line before CE separation. Most of these in-house prepared constructs are difficult to prepare and create an impermeable layer after a few runs due to caking of the stationary phase, which makes it impossible to use this method routinely. In Chapter 3, a new sample trapping construct is described which uses mixtures of solid-phase extraction (SPE) material and diatomite, also known as kieselguhr. The combination of SPE materials with these rigid and highly porous silica particles, creates a low-pressure permeable trap column and ensures its use over a longer period of time without increasing backpressures. The SPE constructs were applied to the analysis of protein-released $N$-glycans, using large volume injections.

\subsubsection{IMS-MS}

IMS-MS is a fast developing technique with many possible applications. ${ }^{26}$ This method is used to separate gas-phase ions by their mobility through a buffer gas under the influence of a weak electric field, which results in different ion arrival times at the end of the mobility cell. The mobility of ions in the gas phase is, just as with CE in the liquid phase, based on their shape, size and charge, which makes IMS suitable for separation of isomers ${ }^{27,28}$ and for acquisition of structural information, as was obtained for the discrimination between $\alpha 2-3$ and $\alpha 2-6$ sialic acid linkages. ${ }^{29}$ Moreover, rotationally averaged collision cross section (CCS) values can be obtained for identification. The CCS is an intrinsic value of the ion and reflects the two-dimensional projection of the randomly rotating ion in the gas phase.

Several types of IMS analyzers have been coupled to MS, such as travelling wave (TW)IMS, trapped (T)IMS and drift tube (DT)IMS. The first commercial TWIMS-MS instrument was released by Waters in 2006. In TWIMS, ions are directed through a cell filled with a static gas using series of ring electrodes. By increasing the voltage on periodically spaced electrodes and then transferring the potential along the ring electrodes, travelling waves are generated. An additional radio frequency $(\mathrm{RF})$ potential is applied to confine the ions. Ions with lower interaction with the drift gas will "surf" the waves, and as a result have lower CCS values (Fig. 3C). With the second generation TWIMS instruments, resolutions of $\sim 40 \Omega / \Delta \Omega$ can be obtained. Recently, an improved TWIMS 
instrument, using a cyclic ion mobility (cIM) cell, was developed. ${ }^{30}$ This instrument contains a closed loop TWIMS cell positioned orthogonally to the main ion optical axis (Fig. 4D), which provides increased resolution, selectable by the number of passes through the cIM cell, and additional features such as mobility selection and activation. ${ }^{30}$

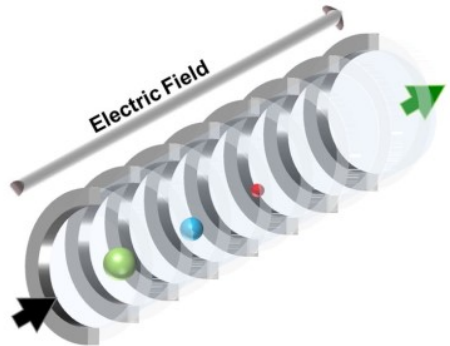

A

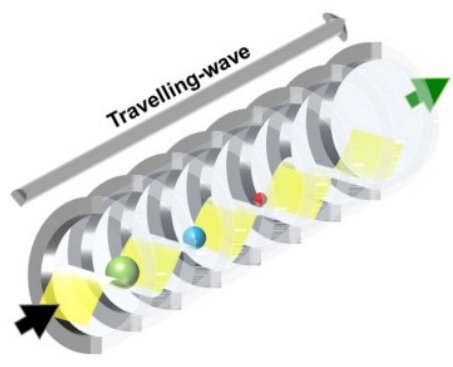

C

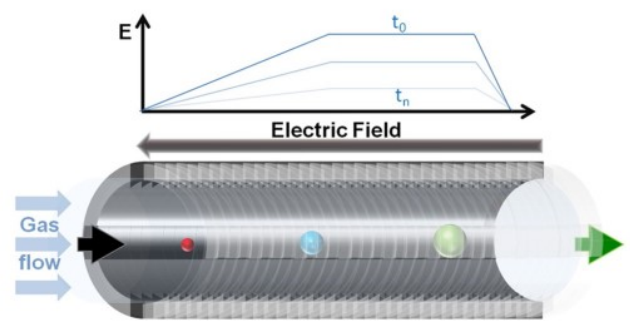

B

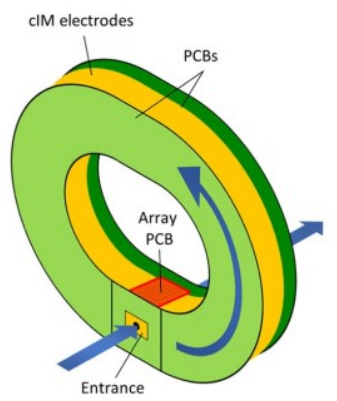

D

Figure 3. Mobility cells for drift tube (A), trapped (B), travelling wave (C) and cyclic (D) IMS. Ions with increasing CCS are depicted as red, blue and green spheres. Black arrows (A-C) show where the ions enter the cell and green arrows show where they exit the cell. Blue arrows (D) show the direction of ions towards the time-of-flight MS and in the cyclic IM device. Adapted from reference 27 and 30 with permission.

The first commercial IMS-MS instrument based on TIMS technology was released by Bruker. In this instrument, ions enter the TIMS cell with a flow of drift gas with an electric field opposing the gas flow to trap ions (Fig. 3B). During TIMS, ions are confined in the cell by applying an RF potential. The electric field 
is then gradually lowered and ions migrate, ranging from high CCS values to low CCS values. With this technology, resolutions of $>250 \Omega / \Delta \Omega$ can be obtained.

Both TWIMS and TIMS analyzers operate under low field conditions, which allow for CCS value determination from the mobility data, although CCS values can only be derived directly with DTIMS, without the need of structurally related standards with known CCS values. ${ }^{27}$ There are few glycan analysis studies with DTIMS-MS, but the number is expected to increase after the recent release of the first commercial instrument, the Agilent 6560 ion mobility- quadrupole time-offlight MS. This instrument uses an $80 \mathrm{~cm}$ drift tube to obtain a resolution of $\sim 60 \Omega / \Delta \Omega$. In this instrument, ions are introduced into a cell filled with a static drift gas, in which a weak electric field is applied causing the ions to move through the cell. Larger ions undergo more interactions with the drift gas and are slowed down, resulting in reduced mobilities and higher drift times and as a result have higher CCS values (Fig. 3A). The reduced mobility $\left(K_{0}\right)$ of an ion can be calculated with the following equation: ${ }^{27}$

$$
K_{0}=\frac{L}{t_{d} E} \frac{P}{760} \frac{273.2}{T}
$$

where $L$ the length of the drift tube, $t_{d}$ the drift time, $E$ the electric field, $P$ the pressure in the drift tube and $T$ the temperature in the drift tube. The CCS value $(\Omega)$ can be derived from the reduced mobility with the Mason-Schamp equation: ${ }^{27}$

$$
\Omega=\frac{1}{K_{0}} \frac{(18 \pi)^{\frac{1}{2}}}{16} \frac{z e}{\left(k_{b} T\right)^{\frac{1}{2}}}\left[\frac{1}{m_{I}}+\frac{1}{m_{B}}\right]^{\frac{1}{2}} \frac{1}{N}
$$

where $k_{b}$ is the Boltzmann constant, $m_{I}$ the mass of the ion, $m_{B}$ the mass of the buffer gas, $z$ the charge state of the ion, $e$ the elementary charge and $N$ the density of the buffer gas. ${ }^{27}$ The linear relationship between $K_{0}$ and $\Omega$ applies only at low field conditions $(E / N<2 \mathrm{Td})$, where the effect of ion-heating is neglectable. 
Several glycans can be identified unambiguously by their CCS values, but these values are often not distinctive enough to discriminate between isomeric $\mathrm{N}$-glycan structures. Chapter $\mathbf{4}$ describes a new approach to identify glycan isomers, based on their DTIMS arrival time distributions (ATDs) rather than on single CCS values. The ATDs reflect the intrinsic glycan conformers in the gas phase, which depend on the branching and linkage of the different carbohydrate residues. These conformer distribution fingerprints were used for exact structure assignment of $\mathrm{N}$-glycans derived from proteins, using an ATD database which was obtained by measuring well-defined glycan standards with DTIMS. Furthermore, a computational model, based on molecular dynamics simulations, was used to predict the ATDs of $N$-glycans.

Besides the structural assignment of intact glycans, IMS-MS can also be used to assign exact glycan structures by measuring ATDs of fragments after collisional activation. Chapter 5 shows the application of IMS-MS for the exact native fucosyl position determination in glycans after gas-phase rearrangement. Fragments of well-defined $\mathrm{N}$-glycan standards, obtained after collisional activation dissociation, were measured with IMS, which rendered unique ATDs to discriminate between fragments with naturally linked and rearranged fucosyl residues.

\subsection{Glycan standards}

Data analysis and MS spectra interpretation are still the main bottleneck for high throughput glycomics, as obtaining complete structural elucidation of complex isomeric glycan mixtures is still challenging. It is expected that glycan standards will play a major role in the near future for structural identification and database development, but also for separation method development and quantification using isotopically labeled standards.

The synthesis of glycans used in this thesis (chapter 3-5) has been performed with an chemoenzymatic approach developed by Boons and co-workers. ${ }^{31-34} \mathrm{An}$ example of this approach is shown in figures 4-5. This approach uses orthogonally protected core pentasaccharide 1 and glycosyl donors 2-4 (Fig. 4) to obtain oligosaccharide precursor 6 (Fig. 5) by selectively removal of a protection group of $\mathbf{1}$ and followed by a chemical glycosylation using an appropriate donor 2-5. Compound 6 can then be selectively extended by glycosyltransferases using sugar-nucleotide substrates, to give complex 
asymmetrical $N$-glycans such as 7-13 (Fig. 5). This approach also makes it possible to prepare other oligosaccharide precursors from $\mathbf{1}$ to obtain different bi-, tri-, and tetra-antennary oligosaccharide precursors that can be extended by glycosyltransferases. ${ }^{31}$
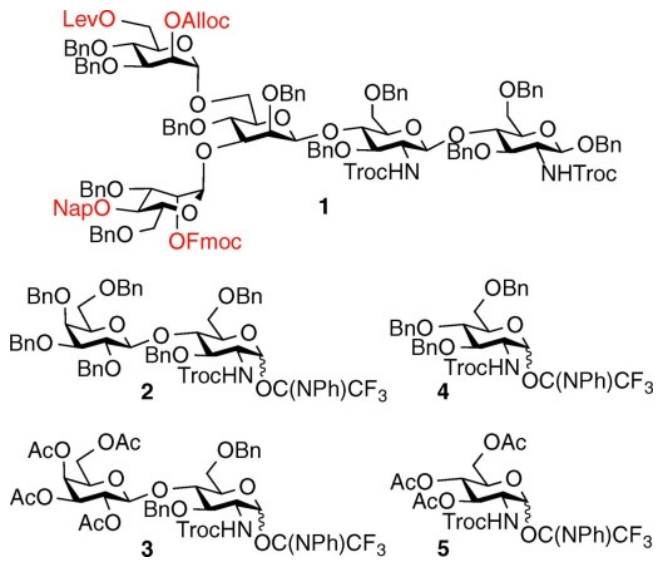

Figure 4. Structure $\mathbf{1}$ is modified at positions where branching points can occur by selectively removing the protecting groups levulinoyl (Lev), allyloxycarbonate (Alloc), 2-naphthylmethyl (Nap) or fluorenylmethyloxycarbonate (Fmoc) and attaching a glycosyl group from glycosyl donors (2-4) at this position. Reproduced from reference 31 with permission.

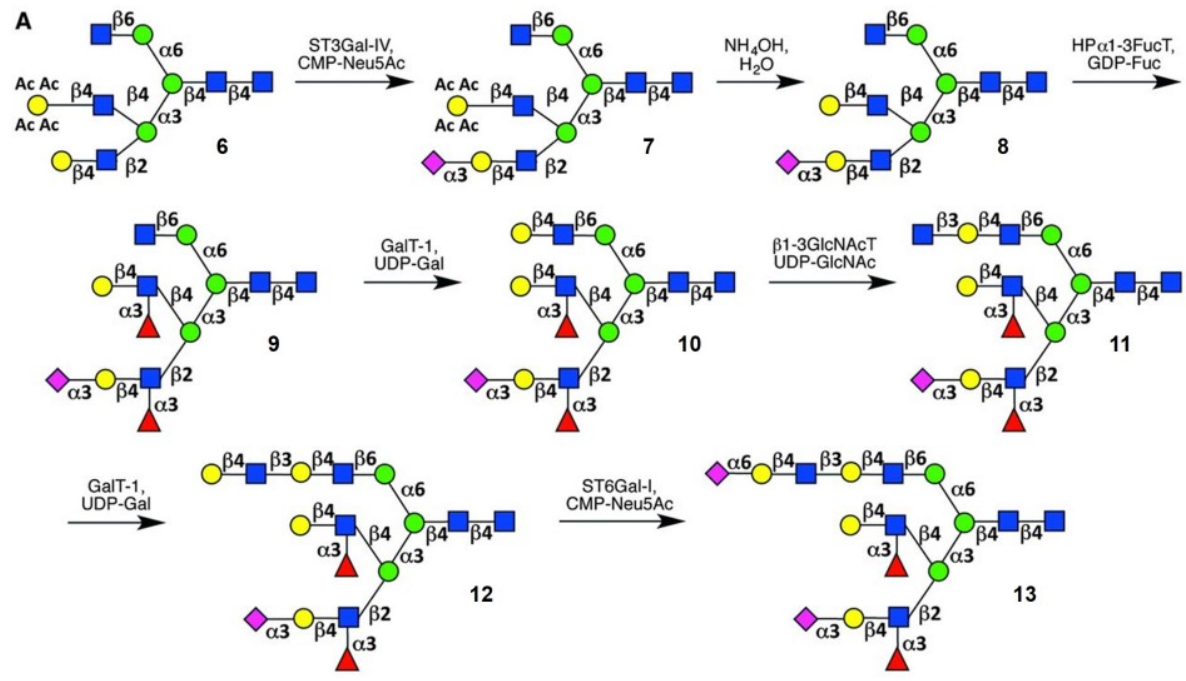

Figure 5. Chemoenzymatic synthesis of $N$-glycans from oligosaccharide precursor $\mathbf{6}$. Adapted from reference 31 with permission. 
To further speed up synthesis, an automated platform has been developed for the preparation of glycans..$^{35,36}$ These glycans provide unique opportunities for development of analytical methods to determine exact structures of glycans in complex biological samples, based on chromatographic and electrophoretic properties, MS fragmentation, CCS values and IMS conformer distributions.

A summary and conclusion on the research described in this thesis are given in Chapter 6. 



\section{Advances in CE for the life sciences}

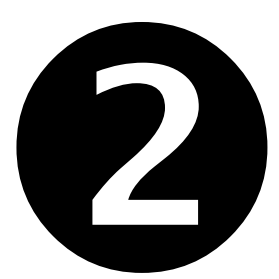

Modified from:

J. Sastre Toraño, R. Ramautar, G. de Jong, Journal of Chromatography B, Analytical technologies in the biomedical and life sciences, 1118-1119 (2019) 116-136. 


\section{Advances in $\mathrm{CE}$ for the life sciences}

\subsection{Introduction}

After a long development, capillary electromigration techniques are now very strong in various fields. ${ }^{37}$ Their separation is mainly based on charge-to-size ratio and high efficiencies can be obtained with short separation times. Next to the use of capillary zone electrophoresis (CZE) for different types of application, capillary isoelectric focusing (CIEF) and capillary gel electrophoresis (CGE) are powerful for the analysis of biopolymers. The reproducibility and robustness of capillary electrophoresis (CE) was less than that of liquid chromatography (LC) and gas chromatography (GC) but during the last decades this has been improved by reliable injection and stable electroosmotic flows (EOF) in the capillaries. Furthermore, the development and commercialization of suitable automated instruments played an important role in the progress of CE.

Electrophoresis has been known for a long time and different principles have been developed. ${ }^{38}$ In 1937 Tiselius described protein separations using an U-tube ${ }^{39}$ but only a separation of two components was obtained and the applicability was still limited. Separation efficiency was rather low due to thermal diffusion and convection. It should be noted that the thesis of Tiselius on electrophoresis as an analytical technique already appeared in 1930. For this work in separation science, Tiselius was awarded with the Nobel Prize. In the following years a few new developments and applications were published. A main contribution was offered by Martin who obtained an efficient separation of chloride, acetate, aspartate and glutamate using displacement electrophoresis (isotachophoresis, ITP).$^{40}$

Convection was considered a major drawback and its suppression was obtained by carrier materials in the separation tube and plates containing gels. A successful approach was the use of capillaries of 0.1-0.5 mm i.d. which were useful for gel electrophoresis. Initial work in open-tube electrophoresis was presented by Hjerten ${ }^{41}$ using capillaries rotated along their longitudinal axis to minimize the effects of convection. Everaerts et al..$^{42}$ applied capillaries with similar diameters made from glass and Teflon for ITP. Subsequently, the diameter was further 
reduced for the optimization of heat dissipation. In 1981, Jorgenson and Lukacs ${ }^{43}$ showed the potential of bare fused silica (BFS) capillaries smaller than $100 \mu \mathrm{m}$, which is considered a real breakthrough in the development of CE. The role of the electroosmotic flow (EOF) as driving force was stressed and a stable EOF could be obtained. Just as in capillary GC, these capillaries increased the possibilities of $\mathrm{CE}$ for routine analysis. At the end of the last century, much attention was paid to $\mathrm{CE}$ and promising results were shown. However, the competition with existing high-performance separation techniques such as LC was hard. In the last decades the real value of $\mathrm{CE}$ has been demonstrated, especially for the life sciences.

Based on developments in the past, this chapter presents the state of the art and advances of CE in life sciences. In the technology section the different principles are described and attention is paid to instrumentation. Since the combination of $\mathrm{CE}$ and mass spectrometry (MS) is now mature, ${ }^{44}$ contributing to the complementarity of CE to LC and LC-MS, this technique is discussed in a separate section. CE is very suitable for the separation of polar and ionogenic compounds and the applicability in main fields of the life sciences, like biologicals (therapeutic proteins) and glycans, is shown. Advanced systems and perspectives of $\mathrm{CE}$ are also discussed, and some figures illustrate that $\mathrm{CE}$ is now a strong technique in life sciences.

\subsection{Technology}

\subsubsection{CE modes}

In this section different $\mathrm{CE}$ modes are shortly discussed, and important developments are described that stress the versatility of CE. In the CZE part, related capillary electromigration techniques are also mentioned. Special attention is paid to the progress in microfluidics CE. 


\subsubsection{CZE}

Separations in CZE are obtained by differences in electrophoretic migration of analytes in an electric field, based on their charge-to-size ratio. The application of high voltages leads to fast analysis, as the migration of analytes is proportional to the voltage. Generally, the mobility of analytes also depends on the EOF, which is caused by the charged silanol groups of the BFS capillary. The high separation efficiency of $\mathrm{CE}$ is due to the flat EOF profile and low diffusion. Basically, only longitudinal diffusion, i.e. the B-term of the Van Deemter equation, is contributing to band broadening, which makes this technique wellsuited for highly efficient and selective analysis of polar and charged compounds. Since the separation efficiency is inversely proportional to the diffusion coefficient of the solute, large biomolecules, which have small diffusion coefficients, will be particularly suited to CZE analysis, providing highly efficient separations with high plate numbers. Solvent consumption in CE is small as flowrates are very low (nL/min range) and aqueous buffers are mostly used as background electrolyte (BGE). This latter aspect means that the technique is biocompatible and suitable for the native analysis of intact proteins.

Neutral compounds can also be separated by using micelles in the buffer solution (micellar electrokinetic chromatography, MEKC). This important extension of CZE was developed by Terabe et al. ${ }^{45}$ The micellar solution is called a pseudostationary phase as compounds can partition between the micelles and the solution outside the micelles. The use of different surfactants (also volatile) and other methodological innovations have made MEKC a powerful technique. ${ }^{46}$ Other additives that can offer special selectivity through molecular interaction in CZE are e.g. cyclodextrins for chiral separations. ${ }^{47}$ The chiral separation of drugs and amino acids is one of the main application fields of $\mathrm{CE}$ where it outperforms other separation techniques.

Capillary electrochromatography (CEC) with packed and open-tubular columns has also been developed for the analysis of charged and neutral compounds. ${ }^{48-50}$ Here, separation is based on differences in electrophoretic mobility and the partition between stationary and mobile phase. The mobile phase flows through the column by the EOF, generated by the silanol groups of the stationary phase. Neutral analytes move through the packed column by the EOF and are separated by partition between the stationary and mobile phase, while charged analytes 
progress through the packed column with the additional contribution from the electrophoretic mobility of the analytes.

For protein analysis, a special aspect plays an important role: electrostatic interactions induce protein adsorption on the capillary inner wall due to the presence of negatively charged silanols. This can result in the total collapse of the EOF as well as peak broadening or even peak deformation. Modification of the surface of the capillary wall with a dynamic or permanent coating is a successful strategy to prevent these phenomena. ${ }^{51,52}$ Dynamic coating of the capillary with a buffer additive, such as hydroxypropyl-methylcellulose (HPMC) or polybrene, are commonly used for the characterization of biologicals. Figure 1 shows the effect of dynamic coatings on the separation of peptides and the correspondence between precoated and self-coated capillaries. ${ }^{53}$ Polymers adsorb on the capillary wall minimizing the interaction between proteins and silanols, which increases the repeatability of the EOF. This coating can be released, requiring regeneration steps in-between runs. As an alternative, modification of the capillary wall by covalent bonding of neutral or charged polymers is a good option. Various coatings have been applied for the separation of proteins but also for the analysis of complex samples containing small cationic and anionic compounds, such as in metabolomics. ${ }^{54}$ Many coating procedures are described in the literature, but modified capillaries are also commercially available. It should be noted that positively charged coatings change the direction of the EOF and the CE polarity should be reversed to move analytes towards the detector.

Microchip CE (MCE) is an important development to miniaturize CE methods. ${ }^{55,56}$ The properties of microchips (e.g. rectangular channel of about 10 $100 \mu \mathrm{m}$ in width and height and 10-100 mm in length) make MCE an efficient and fast separation system with separation times $<1$ min. Joule heating and radial dispersion of the analytes are reduced with respect to capillaries with larger diameters. MCE-UV is frequently used for monoclonal antibodies (mAbs) charge heterogeneity analysis using a dynamic coating with HPMC. ${ }^{57,58}$ More recently, Ramsey et al. introduced an MCE-MS device based on a surface coating procedure with chemical deposition of an aminopropylsilane layer and modification with polyethylene glycol. ${ }^{59,60}$ The design is shown in figure 4 and the separation and detection of intact mAbs variants are demonstrated in the biologicals section (2.3.1). 

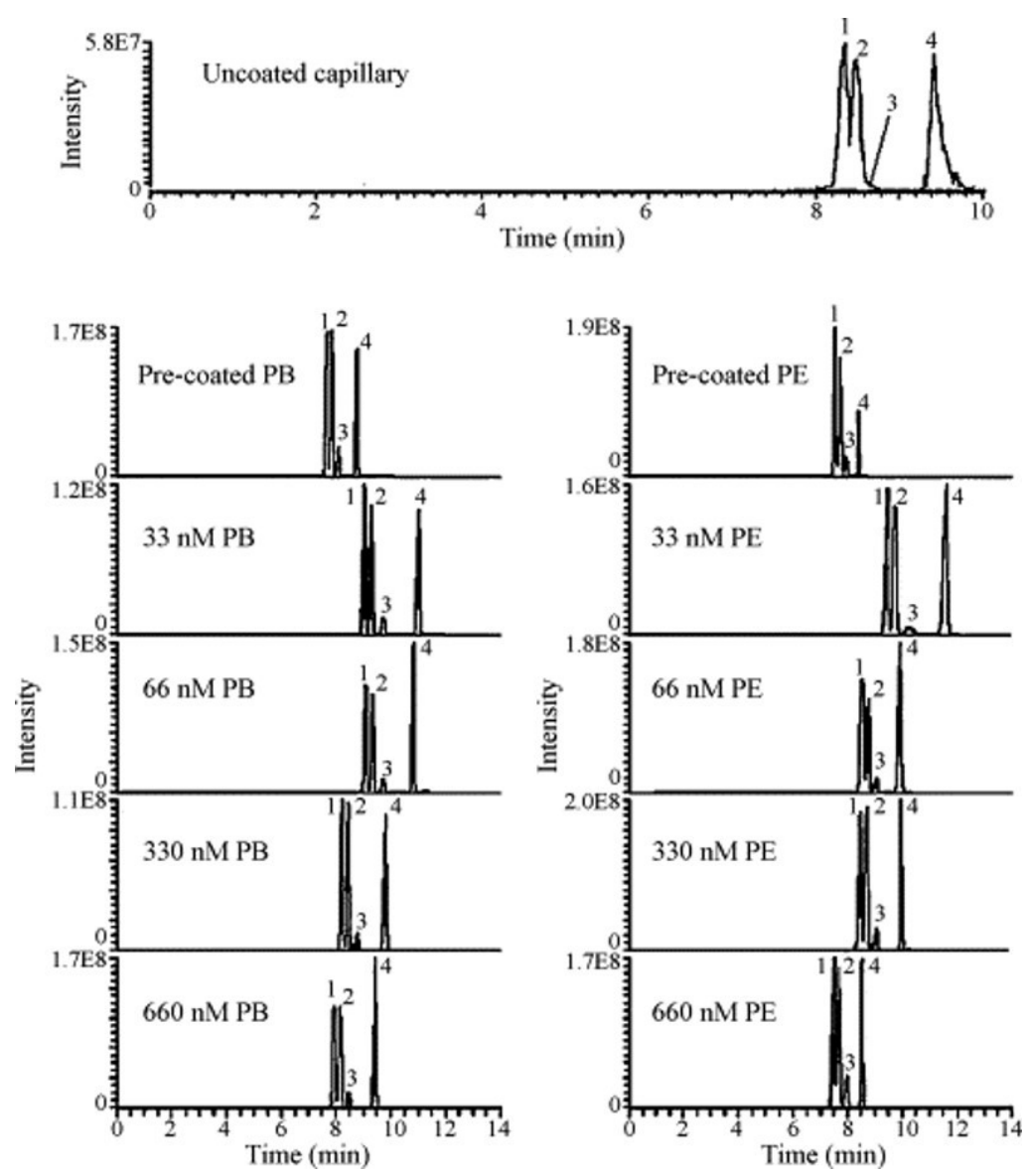

Figure 1. Comparison of CE-MS analyses of peptide standard using an uncoated capillary (top panel), polybrene (PB) and PolyE-323 (PE) pre-coated capillary, and self-coated capillary using 33-660 nM PB and PE (from top to bottom). Reproduced from reference 53 with permission.

\subsubsection{CGE}

The principle of CGE is the separation of biomacromolecules in a sieving medium. For proteins, sodium dodecyl sulfate (SDS) is added to the BGE to denature them. The charge homogeneity of SDS-protein complexes allows separation based on their hydrodynamic radius. CGE adapts SDS-polyacrylamide gel electrophoresis (SDS-PAGE) to a miniaturized design that reduces the drawbacks of SDS-PAGE, such as a long separation time, limited 
reproducibility and low resolution. The traditional slab gel has been replaced by soluble polymers employed as replaceable gels allowing the efficient separation of deoxyribonucleic acid (DNA) fragments and proteins. ${ }^{61,62}$ Highly automated CGE array systems have been developed, which increased the sample throughput considerably. ${ }^{63}$

The use of a sheath-flow fluorescence detector with intercalating dyes was also an important step in this field. ${ }^{64}$ The rapid progress in the human genome project was enabled by this technique and the elucidation of the complete genetic blueprint was an important step in the history of biology. ${ }^{65}$ In CGE, the EOF must often be suppressed and several procedures for neutral coatings have been described, using e.g. polyacrylamide (PAA) hydroxypropyl cellulose, polyvinyl alcohol (PVA) and some other (commercial) coating agents. ${ }^{66}$ Since the end of the $80 \mathrm{~s}$ of the previous century, CGE methods have been used for protein separations and characterization. With the development of commercial sieving kits, CGE has become a high-throughput method for quality control of biologicals and more specifically for glycan analysis.

\subsubsection{CIEF}

CIEF is a CE separation mode that provides a high resolution separation of proteins according to their isoelectric point (pI) and has mainly been applied for the analysis of charge heterogeneity of biologicals. ${ }^{67,68}$ In CIEF, a mixture of ampholytes and sample fills the capillary. A basic catholyte, generally sodium hydroxide, is placed at the cathode and an acidic anolyte, e.g. phosphoric acid, is placed at the anode. Due to the ampholyte properties, a $\mathrm{pH}$ gradient is established in the capillary under influence of the electric field. Proteins are focused in the region where the $\mathrm{pH}$ and the $\mathrm{pI}$ of the protein are equal. At this point, the net charge of the protein is zero and the migration stops. In the next step, the individual components are transported to the detector by electrophoretic or hydrodynamic mobilization. The position of the detector at the capillary end makes the mobilization step necessary, which may cause negative effects on the resolution due to possible peak broadening. To prevent this effect, whole-column imaging CIEF (iCIEF) was developed to provide faster separations with higher resolution, better reproducibility, and reduced sample volume consumption. ${ }^{69}$ iCIEF uses short capillaries $(5 \mathrm{~cm})$ with CCD camera detection and enables monitoring of the focusing process. Therefore, no mobilization step is necessary in iCIEF for protein detection. 

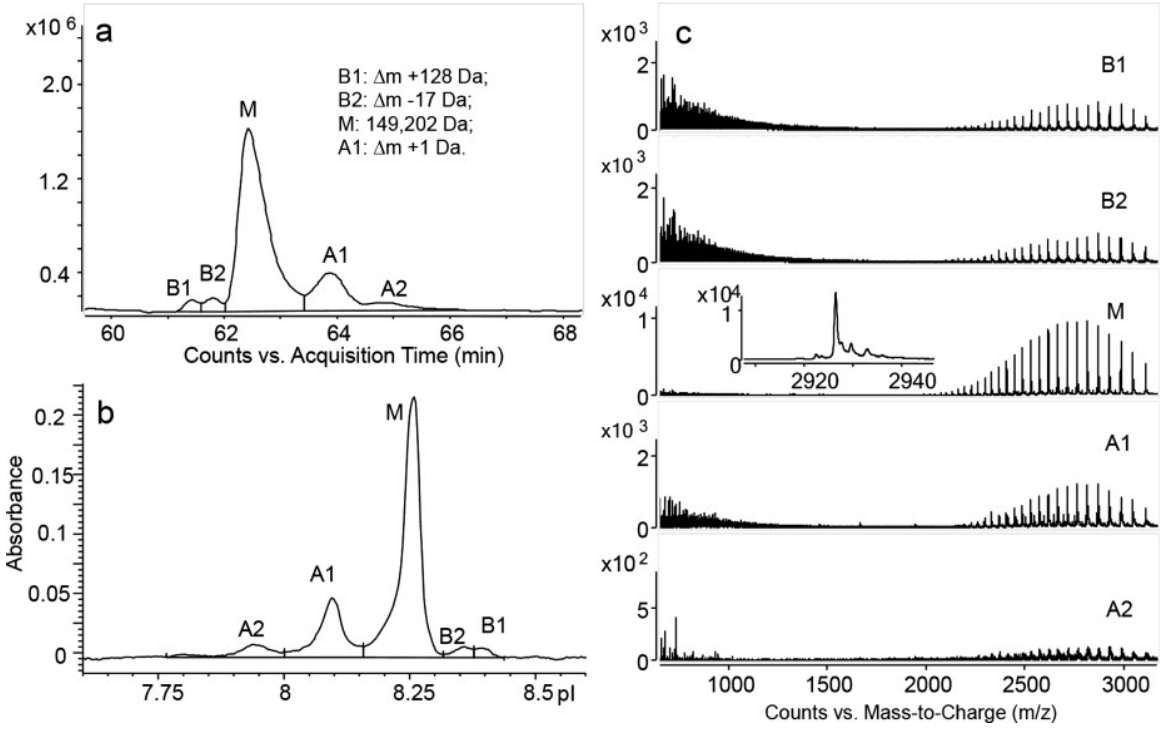

Figure 2. Bevacizumab CIEF-MS analysis in comparison with iCIEF-UV: (a) CIEF-MS extracted ion electropherogram showing basic variants $\mathrm{B} 1$ and $\mathrm{B} 2$, main peak $\mathrm{M}$, and acidic variants $\mathrm{A} 1$ and A2; (b) iCIEF-UV electropherogram; (c) CIEF-MS mass spectra of major variants. The insert in part $\mathrm{c}$ is the expanded view of the main peak in the mass spectrum. Reproduced from reference 70 with permission.

Concerning detection modes, UV detection at $280 \mathrm{~nm}$ represents almost all applications described to date. For structural information, MS detection coupled with CIEF allows identification based on $\mathrm{m} / \mathrm{z}$ value. However, the potential of CIEF-MS coupling is limited by the presence of salts and ampholytes. A recent paper shows the possibilities of CIEF-MS using special conditions for CIEF and MS interfacing. ${ }^{71}$ Figure 2 shows a promising application including the comparison with iCIEF-UV. Two-dimensional CE consisting of CIEF and CZE or CGE was developed for complex protein samples. Ampholytes were removed after the CIEF separation and different interfaces were optimized. ${ }^{70}$ Presently, CIEF is a reference method for the characterization of biotherapeutics. Similar to CGE, CIEF became an important technique in the biopharmaceutical industry with the development of commercial kits and instruments. 


\subsubsection{CE-MS}

The coupling of CE and MS is indispensable to obtain a complementary technique to LC-MS. CE-MS provides high resolution separation under more physiological conditions, detailed structural information and lower limits of detection compared to UV. To fully use the combined potential, it is important to have access to robust CE-MS interfaces. Electrospray ionization (ESI) ${ }^{72}$ is most often used to interface liquid-based separation techniques to $\mathrm{MS}^{73}$. It effectively ensures that dissolved molecules can enter the MS analyzer as gas-phase ions. For CE however, coupling is not that straightforward since there is no outlet vial nor an electrode at the capillary outlet to close the electrical circuit. Furthermore, the separate electrical circuits of CE and MS are not easily combined as currents used in $\mathrm{CE}$ are much higher than those encountered in ESI. In addition, the low liquid flow in $\mathrm{CE}$, ranging from zero to sub $-\mu \mathrm{L} / \mathrm{min}$, hampers stable electrospray formation.

\subsubsection{Sheath liquid interface}

CE and MS were successfully coupled by connecting the outlet of the capillary with a stainless steel ESI needle, using it as both a capillary outlet and ESI emitter electrode. ${ }^{74}$ In this way direct electrical contact was accomplished with the CE effluent. This approach was further developed by increasing the flow rate of the sprayed liquid with a co-axial sheath-liquid (SL) interface, thereby ensuring a more effective electrospray (Fig. 3A). ${ }^{75}$ In this setup a regular CE capillary was encompassed by a conductive SL establishing electrical contact between the metal sprayer and BGE at the sprayer tip. ${ }^{76}$ The SL acted as outlet vial and provided electrical contact at the capillary outlet to ensure a stable and independent CE flow. In this way the electrospray was created directly at the capillary outlet.

The material of the spray needle has a significant effect on the measurement, especially on the signal of anions. Stainless steel needles can oxidize and corrode when using reverse CE polarity due to electrolysis and anionic compounds can complexate with the iron oxides, reducing detection intensity. ${ }^{77}$ The application of platinum ESI needles however, prevented oxidation and needle corrosion. This resulted in limit of detection improvements up to 63 fold for anions, better reproducibility and improved capillary lifetime, compared to a stainless steel needle. ${ }^{77}$ Another way to circumvent the issue with oxidation and corrosion of the stainless steel ESI needle is to analyze anionic compounds in normal polarity $\mathrm{CE}$ mode at high $\mathrm{pH}$ separation conditions. 
The SL interface is often used with MS instruments that use a grounded sprayer needle, delivering the ESI voltage from the MS inlet and ensuring two separate and adjustable current flows for CE and MS. This allows for independent optimization of the BGE and the SL composition. The liquid used in the co-axial SL interface typically consists of a mixture of volatile organic solvents and water with volatile acidic or alkaline additives to facilitate ion formation. The additives in the SL however, can also be used to facilitate chemical reactions upon mixing capillary effluent. This concept was used to obtain additional structural information in the analysis of phenolic compounds using stable free radicals, and in the determination of the number of exchangeable hydrogens in analytes by adding deuterated solvents to the SL. ${ }^{78}$ SL flows are typically several $\mu \mathrm{L} / \mathrm{min}$ to ensure a stable spray. This results in dilution of the CE effluent, depending on the EOF rate, and thus a lower signal intensity. Furthermore, suction effects caused by the sheath-liquid flow can cause a laminar flow inside the CE capillary which results in band broadening if the pressure is not compensated through the inlet vial. ${ }^{79}$ On the other hand, non-volatile BGE additives that provide effective separation but are in principle not compatible with MS can be used in low amounts without causing too much ion-suppression. Non-volatile buffers were applied in the BGE for protein analysis with CE-ESI-MS. ${ }^{80}$ Sodium phosphate strongly suppressed ionization, but $25 \mathrm{mM}$ ammonium borate could be used without compromising signal intensities. Phosphate could be used for the analysis of antihistamines, applying it in the BGE and SL in low concentrations. Minimal ion-suppression was observed by using an interface with low SL flow and performing the analysis under acidic conditions to ensure mobility of phosphate ions towards the capillary inlet. ${ }^{81}$ For the analysis of drugs of abuse, the application of ammonium phosphate in the BGE also showed high ionization performances and good resolution. In contrast, tris(hydroxymethyl)aminomethane and borate as BGE constituents, could not be used in this case due to severe ion suppression. ${ }^{82}$ Apparently, low concentrations of non-volatile buffers can be used with SL interfaces, but applicability may be dependent on analyte characteristics and SL composition.

The SL interface has been widely applied, proven to be very robust and is considered the standard for CE-MS. Recent adjustments to the SL sprayer tip, in combination with ESI source and sprayer positioning modifications, even improved spray quality, ionization efficiency and signal intensity. It is therefore expected that this interface will continue to be used extensively. 

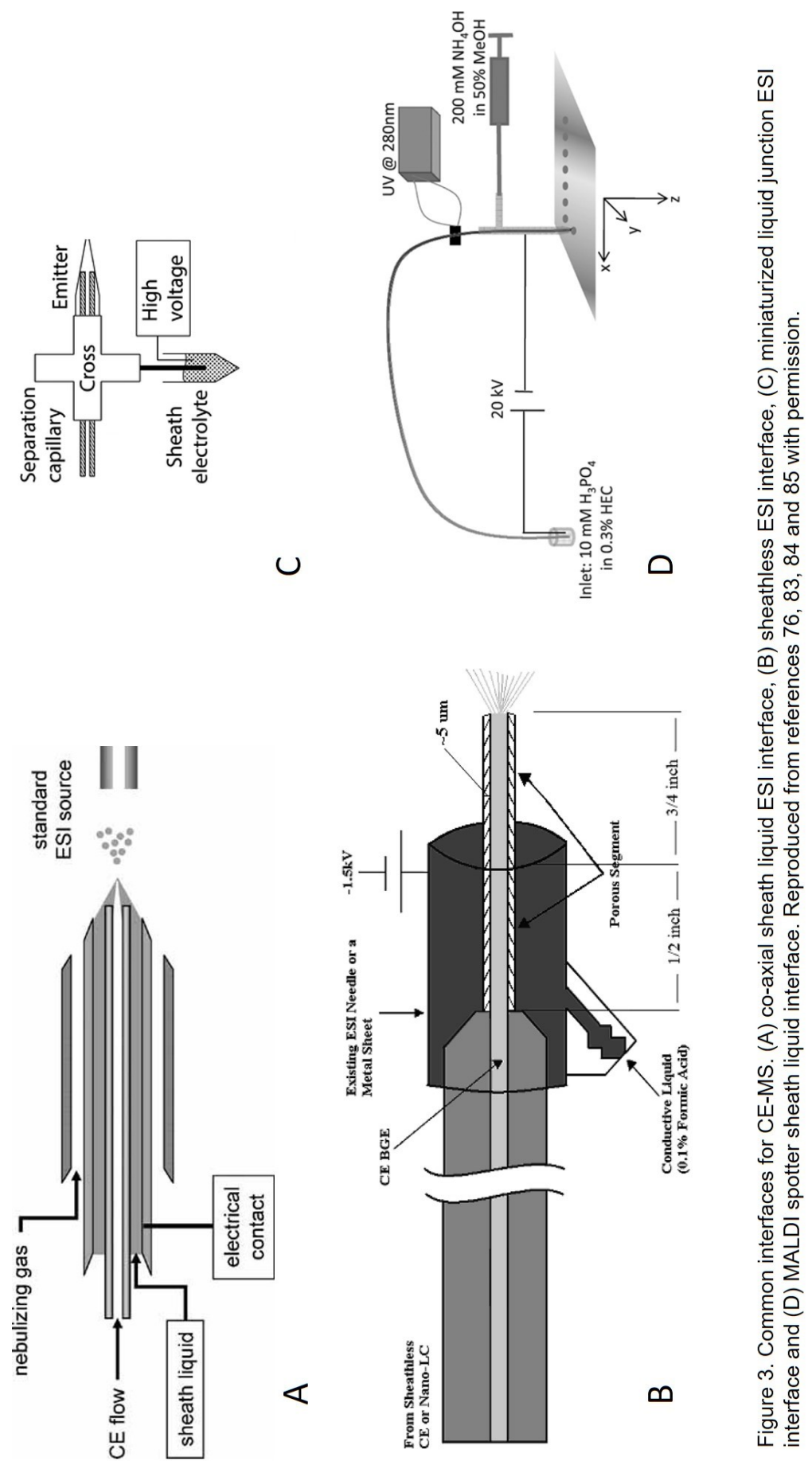
The SL interface was recently miniaturized for working in the nanoflow range to further improve ionization efficiency, while retaining the benefits of the SL. ${ }^{83} \mathrm{In}$ this setup, the capillary end was encompassed by a thin grounded metal needle. The SL was pumped through the needle at a flow rate of $1 \mu \mathrm{L} / \mathrm{min}$ using a $\mathrm{T}$-connection and contacted the CE effluent at the capillary end. Due to the lower SL flow rate in this setup, no nebulizing gas was required for effective ESI, which eliminated the suction effect. To improve the stability of this interface, the outer diameter of the separation capillary and the inner diameter of the needle were further reduced, allowing SL flow rates of $300 \mathrm{~nL} / \mathrm{min}$. This resulted in a smaller Taylor cone and minimized peak broadening by the ESI process. Better separation efficiency was obtained with this setup, while maintaining comparable limits of detection as with the conventional SL interface. ${ }^{84}$

\subsubsection{Sheathless interface}

To completely avoid dilution of the $\mathrm{CE}$ effluent a porous tip sheathless interface was used (Fig 3B). The end of the CE capillary was etched with hydrofluoric acid to obtain a porous capillary end to provide a passage for ions and electrons. ${ }^{85}$ The capillary end was encompassed by a metal cylinder that acted as outlet vial and electrode. In this way the BGE inside the capillary was in contact with the BGE surrounding the outside of the capillary. The end of the capillary protruded slightly from the metal cylinder and acted as sprayer tip. Relative standard deviations of $1-3 \%$ were achieved for migration time repeatability ${ }^{86}$ and a stable and more effective ESI was obtained ${ }^{87}$ which resulted in a 5 to 140 fold improvement of limit of detection for proteins ${ }^{88}$ and 8 to 30 fold for selected metabolites, ${ }^{89}$ compared to the SL interface. The sheathless interface is universal and can be used with all types of ESI-MS instruments, independent of the electrical circuit of the MS. Although, specially treated and relatively expensive capillaries are required for this commercialized interface, which can only be obtained from the manufacturer. Furthermore, a CE device from the same manufacturer is needed and, therefore, it is difficult to predict whether this interface will receive widespread attention. 


\subsubsection{Liquid junction interface}

Liquid junction is a third, common type of interface that uses, like the SL interface, the principle of mixing the $\mathrm{CE}$ effluent with an outlet electrolyte that is connected to a ground electrode. The electrolyte is added through a T-connection to the CE effluent before ESI and usually has the same composition as liquids used in SL interfaces..$^{90}$ The CE effluent and the outlet electrolyte are combined between the MS emitter and the CE capillary end. This causes peak broadening and hence lower resolution. Furthermore, analytes are still diluted, just like with the SL interface, and therefore compromising intensity. On the other hand, the liquid junction interface is universally applicable and can also be used with MS instruments with ESI potential on the sprayer tip.

The liquid-junction approach has been used in a miniaturized device using a flowthrough microvial to combine $\mathrm{CE}$ effluent and outlet electrolyte. This nanoflow ESI interface ${ }^{91}$ used a stainless steel hollow needle with asymmetrical geometry. ${ }^{92}$ The needle enclosed the CE capillary and acted as outlet electrode and vial, through which the outlet electrolyte was pumped. The outside tip of the needle acted as electrospray emitter. An electrolyte flow rate of $\geq 100 \mathrm{~nL} / \mathrm{min}$ through the needle ensured minimal $\mathrm{CE}$ effluent dilution using normal size capillaries. This approach was also applied for interfacing cIEF-ESI-MS by supplying catholyte and mobilization solutions through the microvial.${ }^{93}$ Recently, a similar miniaturized liquid-junction interface, but using an electrokinetically pumped outlet electrolyte and a borosilicate glass emitter, was developed (Fig. 3C). The emitter had a $15-35-\mu \mathrm{m}$ diameter tip and a $20-\mu \mathrm{m}$ spacing between the separation capillary and the emitter tip. ${ }^{94}$ This geometry resulted in an EOF of approximately $50 \mathrm{~nL} / \mathrm{min}$ in the emitter, while the EOF in the CE capillary was around $20 \mathrm{~nL} / \mathrm{min}$, resulting in minimal dilution of the CE effluent before MS analysis, compared to SL and regular liquid-junction interfaces. ${ }^{94}$ With this nanoflow ESI liquid junction interface an approximately 20 -fold improvement for limits of detection was obtained, compared to the regular SL interfaces. The interface was recently commercialized, and it is therefore expected that its application will increase significantly in the future. In view of the wide applicability, regarding the choice of CE capillaries and CE-MS instruments, in combination with the improvement in signal intensity, the miniaturized liquidjunction interface could well become a potential new standard in CE-MS interfacing. 
MCE devices have been used to miniaturize CE systems. It allows for high speed analyses, the possibility to combine different $\mathrm{CE}$ separation modes and the integration of ESI in one device. An integrated microfluidic CE-ESI device, combined with MS detection, was recently demonstrated (Fig. 4). ${ }^{95}$ The device incorporated, beside the CE part, an integrated ESI emitter and electroosmotic pump to assist ESI. Junctions between individual components were absent and therefore no dead volumes were present. This CE-ESI was commercialized and applied successfully to the analysis of biomolecules. ${ }^{59,96}$

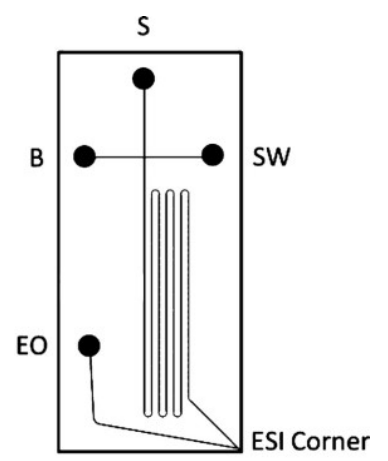

Figure 4. MCE-ESI device. $\mathrm{S}=$ sample reservoir; $\mathrm{B}=\mathrm{BGE}$ reservoir; SW: sample waste reservoir; EO: electroosmotic pump reservoir. Adjusted from reference 95 with permission.

\subsubsection{CE-MALDI MS}

CE can also be coupled indirectly to matrix assisted laser desorption/ionization (MALDI)-MS, which is less prone to ion-suppression by non-volatile BGE additives compared to ESI. Both CE separation and MS detection can be optimized without compromising each other, as the instruments are not directly coupled. SL interfacing is most commonly used for CE-MALDI-MS ${ }^{97}$ in combination with a spotting device to deposit analytes on a MALDI target plate (Fig. 3D). The MALDI matrix can be added through the SL before or after sample spotting. In another approach, liquid free interfacing was used with a silver-coated tip for connection to ground. Droplets of solution were redeposited on the MALDI plate to receive the analytes upon contact with the capillary. ${ }^{98}$ A sheathless interface was obtained by coupling the CE and a separate spotting capillary through a porous polymer. This provided a passage for ions and electrons. ${ }^{99}$ The porous joint was encompassed by a reservoir containing the outlet BGE to ensure a closed electrical circuit. MALDI is more tolerant to nonvolatile additives than ESI and can therefore be used with CE modes that are less 
compatible with ESI-MS. The analysis of proteins with cIEF-MALDI-MS for example, could be performed in the presence of ampholytes, detergents and viscosity increasers, using a SL interface which provided the catholyte solution. ${ }^{97}$ A big disadvantage of CE-MALDI however, is the loss of resolution after deposition. Therefore, this combination is mainly used for identification of peaks. Given the many developments in ESI-MS instrumentation and CE-ESI-MS interfaces and the few new developments in CE-MALDI-MS, the use of the latter is likely to decrease rapidly.

Recent developments in CE-MS coupling focus on miniaturization using universally applicable and nanoflow ESI interfaces that provide the lowest possible dilution of $\mathrm{CE}$ effluent and most efficient ionization. ${ }^{100,}{ }^{101}$ The application of non-volatile BGE constituents however, is more limited with these interfaces and $\mathrm{CE}$ separation often has to be performed at lower currents, ${ }^{94}$ reducing the freedom in the choice of constituents and concentrations of the BGE. On the other hand, it is the expectation that miniaturized liquid junction interfaces will become more important in the future, as they allow the measurement of lower concentration levels and the use of regular separation capillaries.

\subsection{Selected applications in the life sciences}

\subsubsection{Biologicals}

Biologicals are biomolecules (nucleic acids, peptides, proteins) used for therapeutic purpose. These products have emerged at an exceptional speed and several important products are now on the market. They are mainly produced using recombinant technologies, which enable the production of proteins on a large scale. Biological products include different types of biomolecules, e.g. hormones such as insulin and growth factors (erythropoietin, EPO), interferons, interleukins (IL-2), vaccines, mAbs and related products, e.g. bispecific antibodies and antibody-drug conjugates. Characterization of biologicals requires a combination of several techniques in order to investigate the different structural properties of biomolecules. Analytical techniques used are separation methods such as $\mathrm{CE}$ and $\mathrm{LC}$ which allow separation of the main isoform from variants and impurities. Since the introduction of modern CE, capillary electromigration techniques have shown to be very suitable for the separation of 
biomolecules. The advantages of CE are its high separation efficiency and the use of aqueous buffers which is favorable to preserve the higher order structure of proteins.

Therapeutic peptides and proteins are typically charged molecules. Their modification often induces a change in the net charge and/or hydrodynamic radius. Therefore, electrokinetic separations using CE-based techniques with sensitive detection techniques, including laser-induced fluorescence (LIF) and MS, are well suited for the separation of biologic variants. ${ }^{102}$ The characterization of biologicals has been described using different CE separation modes such as CZE, CGE and CIEF. In this section, the possibilities of each separation mode for characterization of biologicals are stressed and a few relevant figures are shown.

\subsubsection{CGE}

The size heterogeneity of proteins is influenced by modifications such as post translational modifications (PTMs) and fragmentation. A shift of the profile toward acidic forms (deamidation, sialylation, glycation) or basic forms (succinimide formation, C-terminal lysine heterogeneity) ${ }^{103}$ can be observed and this may influence the safety and efficacy of the product. ${ }^{104}$ PTMs can be effectively mapped with CGE and therefore Salas-Solano et al. optimized a generic CGE-LIF method for quality control (QC) and stability monitoring of mAbs. The validation of this method under the guidelines of the International Committee on Harmonization demonstrates that the method determines the consistency of mAb manufacturing. ${ }^{105}$ Han et al. also proposed a CGE-LIF method for $\mathrm{mAb}$ separation and their method was transferred to the QC laboratory for lot release testing of therapeutic antibodies. ${ }^{106}$ As CGE proved to be very suitable for mAbs characterization, the United States Pharmacopeia (USP) released a general protocol for the CGE-UV characterization of mAbs. However, it was shown that the USP method induced fragmentation for three mAbs under non-reducing conditions. This extent of fragmentation was not found using an inhouse developed method, ${ }^{107}$ demonstrating that molecule-specific methods can be essential to minimize artifacts, as was reported in several publications. ${ }^{108}$

Further improvements in the performance of CGE have been made by Szekely et al., proposing a generally applicable multicapillary SDS-CGE-LIF method for high-throughput quality control analysis of mAbs with reducing conditions, ${ }^{109}$ 
and Kubota et al., demonstrating the analysis of a mAb and cleaved fragments using orthogonal analytical methods, including CGE-UV (Fig. 5). ${ }^{110}$ Progress in CGE instrumentation to reduce separation times have focused on MCE with SDS. While MCE-SDS is an attractive alternative to conventional CE-SDS for protein analysis, there are still opportunities for improvement, e.g. higher resolution to separate product variants of similar sizes. Smith et al. validated an MCE-SDS method with LIF detection for analysis of mAbs by separation and quantitation of size variants. The method is suitable for good manufacturing practice release and stability studies. ${ }^{111}$
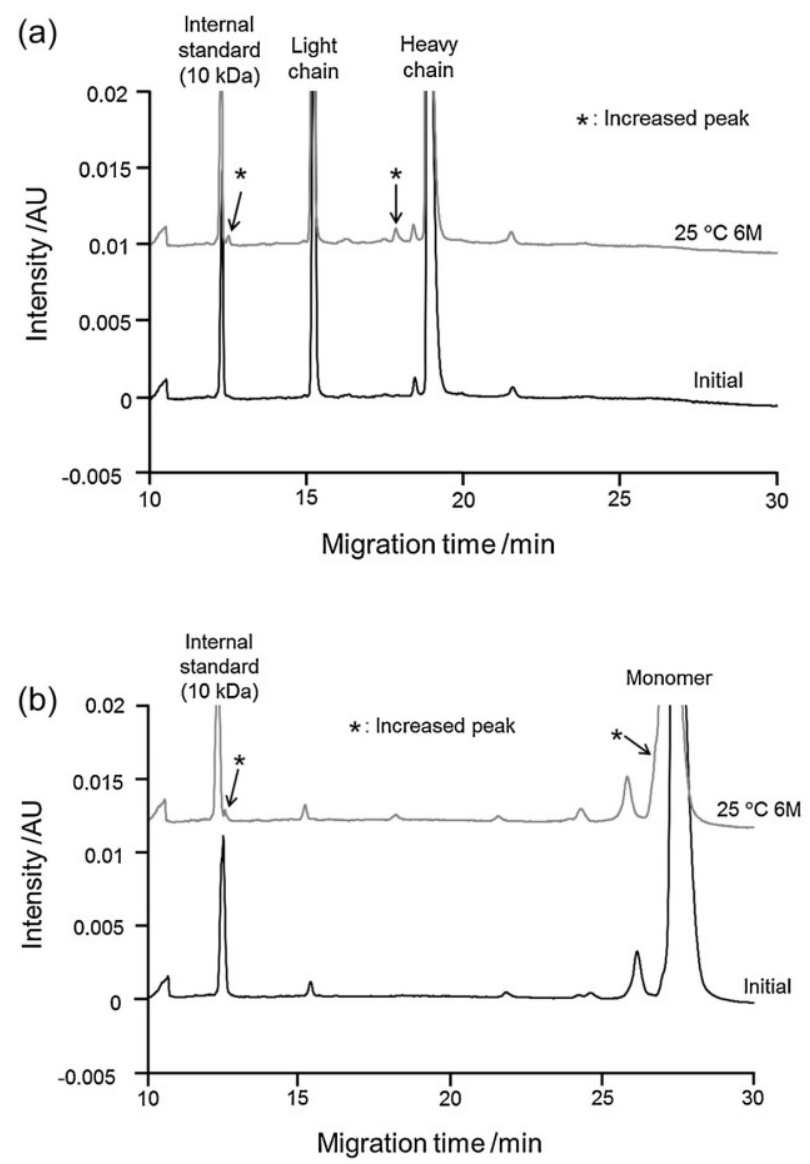

Figure 5. Electropherograms of the mAb-A initial sample (lower trace) and degradation sample (upper trace) obtained by SDS-CGE (a) reduced and (b) non-reduced conditions. The internal standard peak, light chain peak, heavy chain peak, monomer peak, and increased peaks are indicated. Reproduced from reference 110 with permission. 


\subsubsection{CIEF}

The charge heterogeneity of biologicals is an important quality parameter. Charge heterogeneity profiles can also be influenced by modifications such as PTMs and fragmentation. CIEF and iCIEF with UV detection are fully implemented in QC laboratories and have become reference methods for the characterization of charge heterogeneity. Identification of intact and reduced therapeutics and PTMs can be realized using this CE mode. Many papers describe the potential of CIEF- and iCIEF-UV as useful tools in the process development of biotherapeutics. ${ }^{112,113}$ Suba et al. validated a CIEF-UV method for identification testing of $\mathrm{mAb}$ drug products with a $\mathrm{pI}$ between 7.0 and 9.0. The CIEF method provided a good $\mathrm{pH}$ gradient for internal calibration $(\mathrm{R} 2>0.99)$ and good resolution between all isoforms. These authors also found CIEF-UV to be an accurate analytical method to confirm protein identity in QC and release tests in the biologicals industry, especially with the use of commercial standardized kits. ${ }^{114}$ CIEF- and iCIEF-UV methods are also suitable for the characterization of mAbs-related products. An improved method for the characterization of acidic and basic variants of an antibody used a preparative immobilized $\mathrm{pH}$ gradient for fractionation and the fractions were further characterized by CGE-UV and LCMS. ${ }^{115}$ To demonstrate the accuracy of CIEF- and iCIEF-UV methods as references for charge variants characterization, Salas-Solano et al. organized interlaboratory studies. ${ }^{116}$ An international group of 12 laboratories from biopharmaceutical companies was formed to evaluate the precision and robustness of CIEF- and iCIEF-UV to determine the charge heterogeneity of mAbs. This has stimulated the application of CIEF- and iCIEF-UV methodologies both in process development and QC of biopharmaceutical companies. The coupling of (i)CIEF with MS would further increase the possibilities of CIEF, but efficient hyphenation is still difficult (see section 2.2.2).

Further improvement of separation time was obtained by the development of microchip CIEF. Kinoshita et al. reported a comparison between microchip CIEF-UV and conventional CIEF-UV methods for the evaluation of mAbs charge heterogeneity. ${ }^{117}$ A 10-fold decrease in separation time and an excellent correlation of calculated $\mathrm{pI}$ values and the relative amounts of the charge variants were observed. Automation of the microchip method is still limited, but this strategy is promising and improvements are expected in the future. 


\subsubsection{CZE-MS}

CZE can be easily coupled with MS and structure information of products can be obtained. For CZE, middle-up analysis is most often performed, which is the characterization of therapeutic proteins after limited proteolysis, generating peptides usually larger than $10 \mathrm{kDa}$. Proteolytic treatment is performed with enzymes such as pepsin, papain and streptococcal cysteine proteinase. The use of a limited digestion is interesting as it reduces the complexity of the sample in order to focus the analysis on specific parts of the investigated protein. As a consequence, it is mainly employed for the analysis of highly complex proteins like mAbs, especially because specific enzymes for Immunoglobulin ( $\operatorname{IgG}) 1$ proteolysis are available. ${ }^{118}$ The analysis of mAbs after reduction of disulfide bridges was developed using online CE-ESI-MS. ${ }^{119}$ Results showed the separation of the mAbs heavy $(\mathrm{H})$ chain and light $(\mathrm{L})$ chain in a mixture of reduced mAbs. CE-ESI-MS has been used for the characterization of biologicals with different sample pretreatments. The complete separation of the mixture composed of $\mathrm{mAbs} \mathrm{H}$ chain, L chain, and fragments produced by IdeS (igGdegrading enzyme of Streptococcus pyogenes) digestion was demonstrated. In addition, the different lysine variants for the fragment crystallizable region $(\mathrm{Fc})$ fragments were identified. The various applications of CE-ESI-MS middle-up characterization demonstrate that $\mathrm{CE}$ is suitable for the separation of large protein fragments. Biacchi and coworkers developed an off-line CE-MALDI/ESI-MS method for the analysis of different fragments produced from the IdeS digestion of cetuximab. They demonstrated the baseline separation of Fc lysine variants and the independent characterization of the $\mathrm{N}$-glycosylation sites present of the protein. ${ }^{120}$

For characterization of biologicals, the analysis of intact proteins is the main goal. A useful protocol for rapid CZE method development for top-down and middleup analysis of mAbs was presented by Suba et. al. ${ }^{121}$ An efficient separation before MS increases the information obtained from the spectra, which offers an additional high level of structural information. CE-ESI-MS with a sheathless interface was used to develop a method for the characterization of human EPO (Fig. 6). This method provided fractionation and subsequent characterization of many EPO glycoforms in a single analysis. The separation of isoforms prior to MS improved sensitivity and significantly increased the number of identified isoforms ${ }^{87} \mathrm{CE}-\mathrm{ESI}-\mathrm{MS} / \mathrm{MS}$ analysis was also used for the characterization of intact interferon- $\beta 1$. This approach allowed the identification of glycoforms and modified variants by electron transfer dissociation and high-energy collision 
dissociation fragmentation. ${ }^{122}$ In another approach, CE-MALDI-MS was applied for the separation and detection of intact charge variants of trastuzumab. ${ }^{123} \mathrm{CZE}$ MS has also been applied for intact protein stability studies, wherein deamidation and oxidation products have been identified. Time-of-flight (TOF) MS was found to be very suitable for this type of analysis as small mass differences can be observed. ${ }^{124,125}$
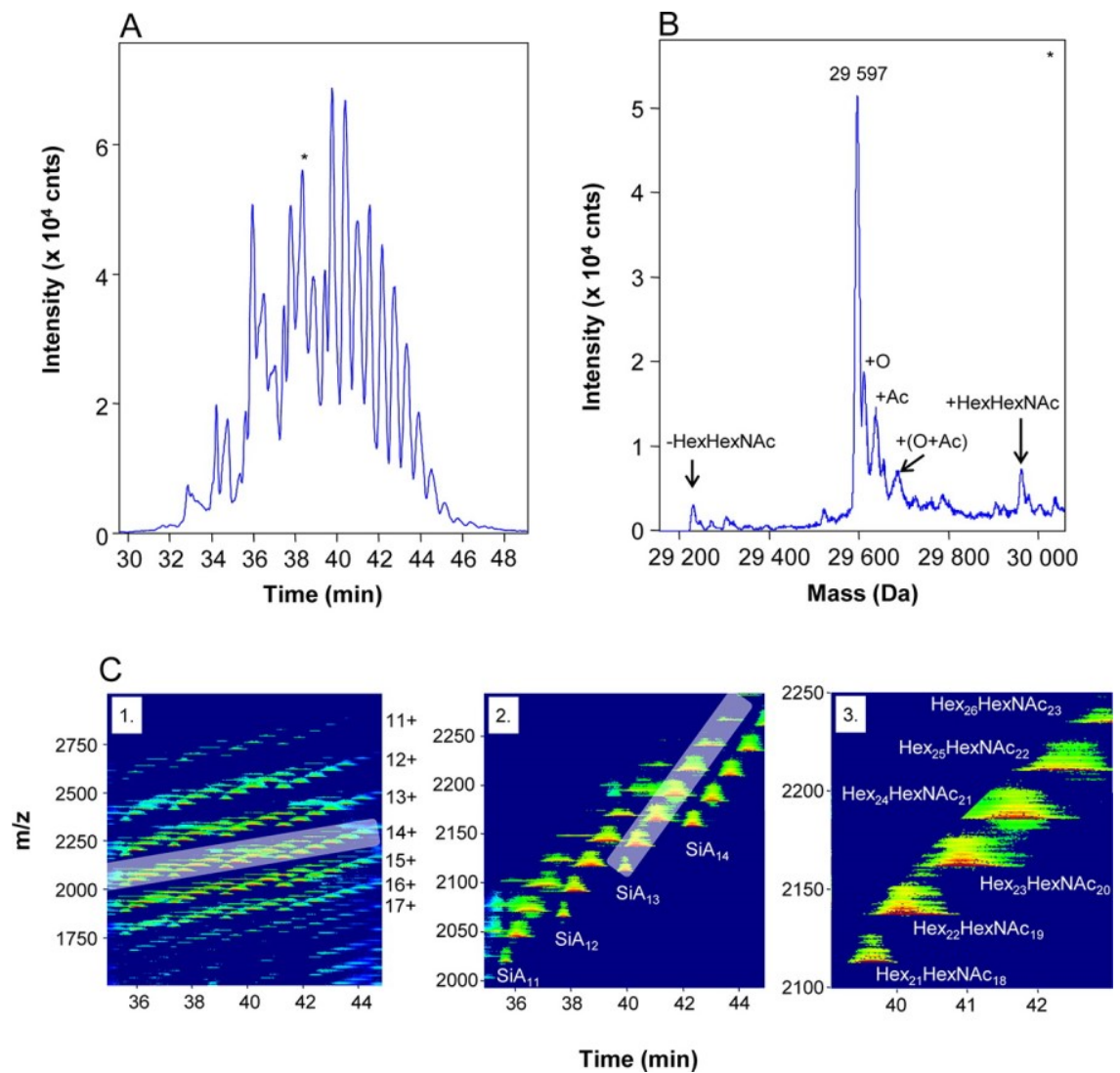

Figure 6. Sheathless CE-MS of recombinant human EPO $(200 \mu \mathrm{g} / \mathrm{mL})$ employing a neutrally coated capillary. (A) BPE; (B) deconvoluted mass spectrum obtained at the apex of the peak migrating at $38.0 \mathrm{~min}$; (C1) contour plot with zooms of (C2) the 14+ charge state of the glycoforms and $(\mathrm{C} 3)$ the SiA13 sialoforms of the $14+$ glycoforms. Reproduced from reference 87 with permission. 
A CE-nano ESI-MS microchip was used for the analysis of intact infliximab. ${ }^{59}$ Lysine variants were successfully separated and identified by MS (Fig. 7). The same system was used for the characterization of intact antibody drug conjugates (ADCs). The microchip MS analysis demonstrated the possibility to determine the drug-to-antibody ratio (DAR). ${ }^{126}$ ADCs are complex samples in the field of therapeutic protein products. Said and coworkers developed an analytical methodology for ADCs analysis on the peptide, middle-up, and intact level. This workflow is mainly based on sheathless CE-ESI-MS. It enables the characterization of the amino acid sequence, to localize the different conjugation sites to estimate the relative conjugation levels for each site and obtain the glycoprofile of the protein. ${ }^{127}$ Because the ESI ionization yield is relatively low for intact proteins, CE-ESI-MS methods for intact proteins will profit from the development of more sensitive CE-MS coupling. The characterization of intact therapeutic proteins using CE-MS however remains a challenge.
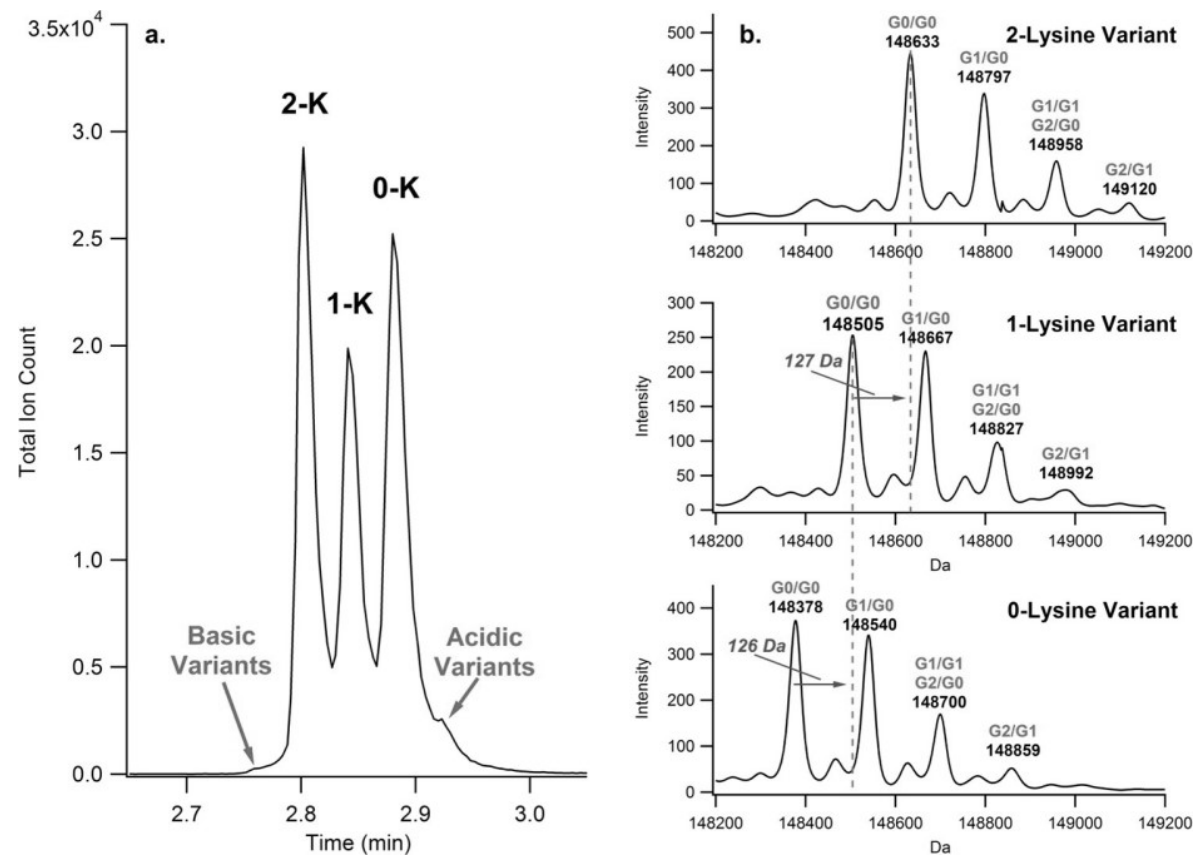

Figure 7. (a) Separation of intact Infliximab charge variants by MCE-MS. Identified lysine variants are labeled as 2-K, 1-K and 0-K. (b) Deconvoluted mass spectra for each lysine variant. Reproduced from reference 59 with permission. 


\subsubsection{Glycans}

\subsubsection{CE-LIF of glycans}

The combination of CZE or CGE with very sensitive LIF detection has been used for the analysis of glycans in clinical samples since many years and has become an important tool in the biopharmaceutical industry ${ }^{66}$ By using multicapillary CE-LIF analyzers, multiplexing can be performed for high-throughput analysis of glycans. ${ }^{128}$ CGE-LIF makes use of replaceable sieving matrices like PAA and cellulose derivatives. ${ }^{129}$ Furthermore, neutral capillary coatings like PAA ${ }^{130}$ or the more hydrophilic PVA ${ }^{131}$ are used to reduce the EOF while preserving the liquid sieving matrix in the capillary. These systems can be used to obtain separation of polydisperse intact polysaccharides, with a resolution of 1 carbohydrate unit, ${ }^{132}$ and oligosaccharide hydrolysates derivatized with 2-aminonaphthalene trisulfone (ANTS). ${ }^{133}$

By partially hydrolyzing an oligosaccharide derived from glucose monomers, a mixture of chains consisting of different numbers of glucose units is obtained. The high resolution CGE analysis allows the baseline separation of this oligosaccharide ladder that can be used for the identification of unknown glycans using glucose unit (GU) calculation. GU values can be obtained from the migration times of separated homooligomers (oligomer consisting of identical monomers) and calculated for the unknown glycan using the closest migrating homooligomers with the following equation: ${ }^{134}$

$$
G U_{A}=d p_{1}+\frac{t_{A}-t_{1}}{t_{2}-t_{1}}
$$

where $d p_{1}$ is the degree of polymerization of the preceding homooligomer peak, $t_{A}$ is the migration time of the unknown glycan and $t_{1}$ and $t_{2}$ are the migration times of the homooligomers preceding and following the peak of the unknown glycan, respectively. ${ }^{134}$ Structural elucidation, including linkage and position information of carbohydrates is possible by removing carbohydrates stepwise from the nonreducing end with exoglycosidase enzymes, subsequential analysis with CGE and identification using GU values. ${ }^{135}$ 
CE-LIF was recently used for $N$-glycan profiling of human serum proteins to discover and evaluate biomarkers for several diseases: in hepatocellular carcinoma abundance alterations of two fucosylated bi- and triantennary glycans were found, ${ }^{136}$ gastric cancer could be diagnosed by using one specific triantennary glycan and observing an overall decrease in core-fucosylation ${ }^{137}$ and a decrease in corefucosylation could be related to all known subtypes of congenital disorders. ${ }^{138}$ Additionally, $\mathrm{N}$ - and $O$-glycans originating from skin cells were analyzed to screen for basal cell carcinoma (BCC) and squamous cell carcinoma (SCC) biomarker. An increase in high-Man $\mathrm{N}$-glycans and core $2 \mathrm{O}$-glycans was observed on carcinogenic cells, while $\alpha 2-3-N e u 5$ Ac levels were decreased in SCC but not in BCC. ${ }^{139}$

Microchip CE-LIF was used in the analysis of serum $N$-glycans ${ }^{140}$, where Neu5Ac residues were derivatized with methylamine to neutralize the charge. All $\mathrm{N}$-glycans were then labeled with aminopyrene trisulfonate (APTS), separated using the microchip device and detected with LIF. In combination with separate MALDI-TOF analysis, a total of 52 different glycans were identified in serum samples, including linkage and positional isomers (Fig. 8). The same approach was used for the analysis of serum samples from patients with colorectal cancer, revealing an increase in the abundance of several fucosylated tri- and tetra-antennary glycans. ${ }^{141}$ As described above, a change in fucosylation is characteristic for several different forms of cancer, but by applying high-resolution MCE separation it was possible to assign alterations in different fucosyl isomers specifically to colorectal cancer. ${ }^{141}$ CE-LIF has not only made its way in clinical research as described above, but has also become a widely used technique for glycan analysis in the biopharmaceutical industry. ${ }^{142}$ The technique has been used for the characterization of glycans on $\mathrm{mAbs}^{143}$ (Fig. 9A) and on influenza A virus glycoproteins used in vaccine manufacturing. ${ }^{144}$

$\mathrm{CE}$ became an established technique for glycan analysis after it was coupled to LIF as it offers high resolution with good reproducible migration times and peak areas $^{66}$ together with unrivaled detection sensitivity for the analysis of glycans. The technique is nowadays applied in clinical biomarker analysis and pharmaceutical quality control. However, for identification purposes, well-defined glycan standards or the application of several exoglycosidase digestion steps are necessary. Correspondingly, multiple $\mathrm{CE}$ analyses are required to elucidate single glycan structures using exoglycosidases and although high-throughput analyzers can be used, this approach is more difficult for the identification in biological 
samples containing high number of different and co-migrating (isomeric) glycans. ${ }^{66}$ Mass spectrometry can be a suitable complement for identification.

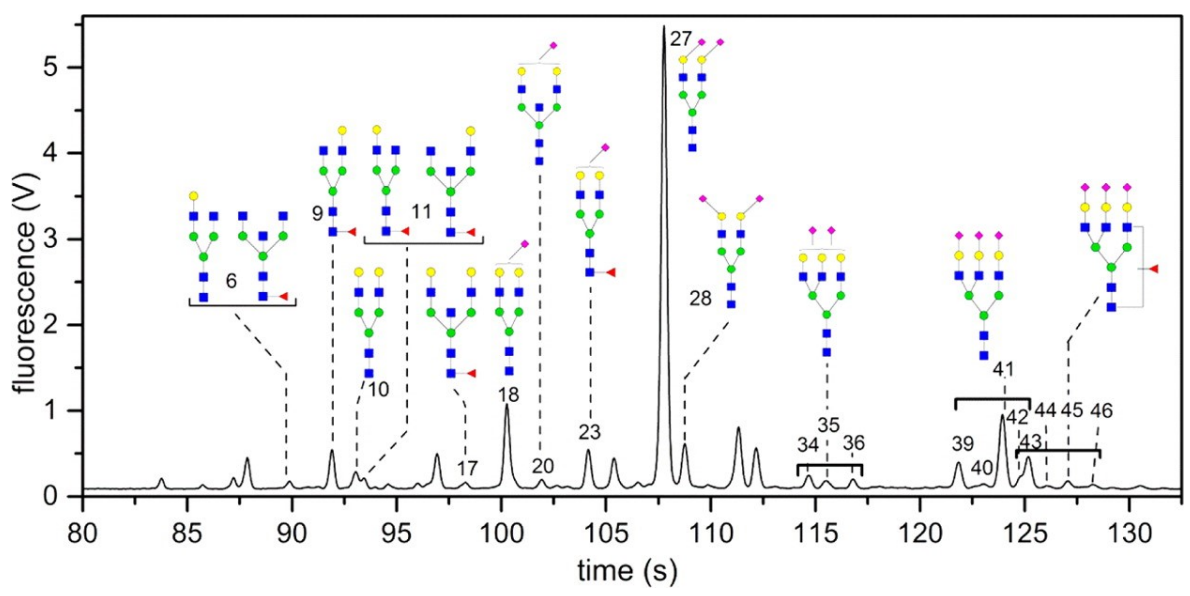

Figure 8. MCE of methylamidated serum $N$-glycans from a colorectal cancer patient. Separation efficiencies were up to 700,000 theoretical plates. Annotated peaks correspond to statistically different glycans between control and pathological samples. Adjusted from reference 141 with permission.

\subsubsection{CE-MS of glycans}

Although limits of detection measured with CE-LIF are lower than with CE-MS, the latter offers the possibility to easily determine glycan composition using accurate mass measurements and to obtain linkage information by multi-stage fragmentation experiments. ${ }^{145}$ SL interfacing is most often used with CE-MS and to obtain high detection sensitivity in negative MS mode, an alkaline SL is commonly applied. This can influence glycan separation as was shown by the application of triethylamine as a SL additive; In the reverse CE polarity mode, positively charged ions from the SL enter the CE capillary and improve the separation efficiency by creating moving ion boundaries and ion interactions. ${ }^{146}$ 
The separation of negatively chargeable glycans in CE-MS is almost always performed in reverse CE polarity with a neutrally coated capillary to suppress the EOF and ensure a larger separation window. ${ }^{131}$ Both permanent (e.g. PVA or PAA) and dynamic coatings (e.g. based on soluble PAA) can be used to suppress the EOF and their application results in similar CE glycan profiles. ${ }^{146}$ A PVA coating was employed for the study of $O$-acetylation on Neu5Ac residues of $\mathrm{N}$-glycans obtained from fish serum. Separation was performed in reverse CE polarity mode at low $\mathrm{pH}$ and a flow-through microvial was used for interfacing with MS. The analysis revealed up to three different $O$-acetylated isomers for disialylated bi- and triantennary glycans. ${ }^{147}$ The same method was used for the analysis of unlabeled $\mathrm{N}$-glycans released from human $\mathrm{IgG}$ and recombinant human EPO expressed in Chinese hamster ovary cells. ${ }^{148}$ Neutral glycans migrated with the low EOF and were not separated, while several sialylated glycans were separated in the window before the EOF. ${ }^{148}$ To obtain a more robust coating and repeatable migration times, a multilayer PVA coating was applied for the analysis of $\mathrm{N}$-glycans, which was reported to be superior in both separation efficiency and detection sensitivity over single-layer coated PVA capillaries. Several $\mathrm{N}$-glycans released from human serum were separated and identified using MS with a SL interface. $^{14}$

In a different approach, phospholipids were applied as semi-permanent inner wall coatings, using 1,2-dimyristoyl-sn-glycero-3-phosphocholine and 1,2-diheptanoyl-sn-glycero-3-phosphocholine in a 1:2 concentration ratio. These quaternary ammonium components with long alkyl tails self-assemble on the inner surface of the capillary, thereby forming a stable zwitterionic bilayer with a zero net charge while reducing the EOF. ${ }^{149}$ Two APTS-labeled, isomeric triantennary $\mathrm{N}$-glycans consisting of the same monosaccharide units and containing three galactose (Gal) residues were released from asialofetuin, treated with the exoglycosidase enzyme $\beta 1-4$ galactosidase and analyzed using a co-axial SL sprayer as interface. The analyzed glycans differed in the linkage of one terminal Gal residue ( $\beta 1-3$ instead of $\beta 1-4$ linkage) in the middle antenna of one glycan. All terminal Gal residues were removed by the enzyme, except for the $\beta 1-3$ linked Gal, yielding two different compounds that could be baseline separated. ${ }^{149}$ 

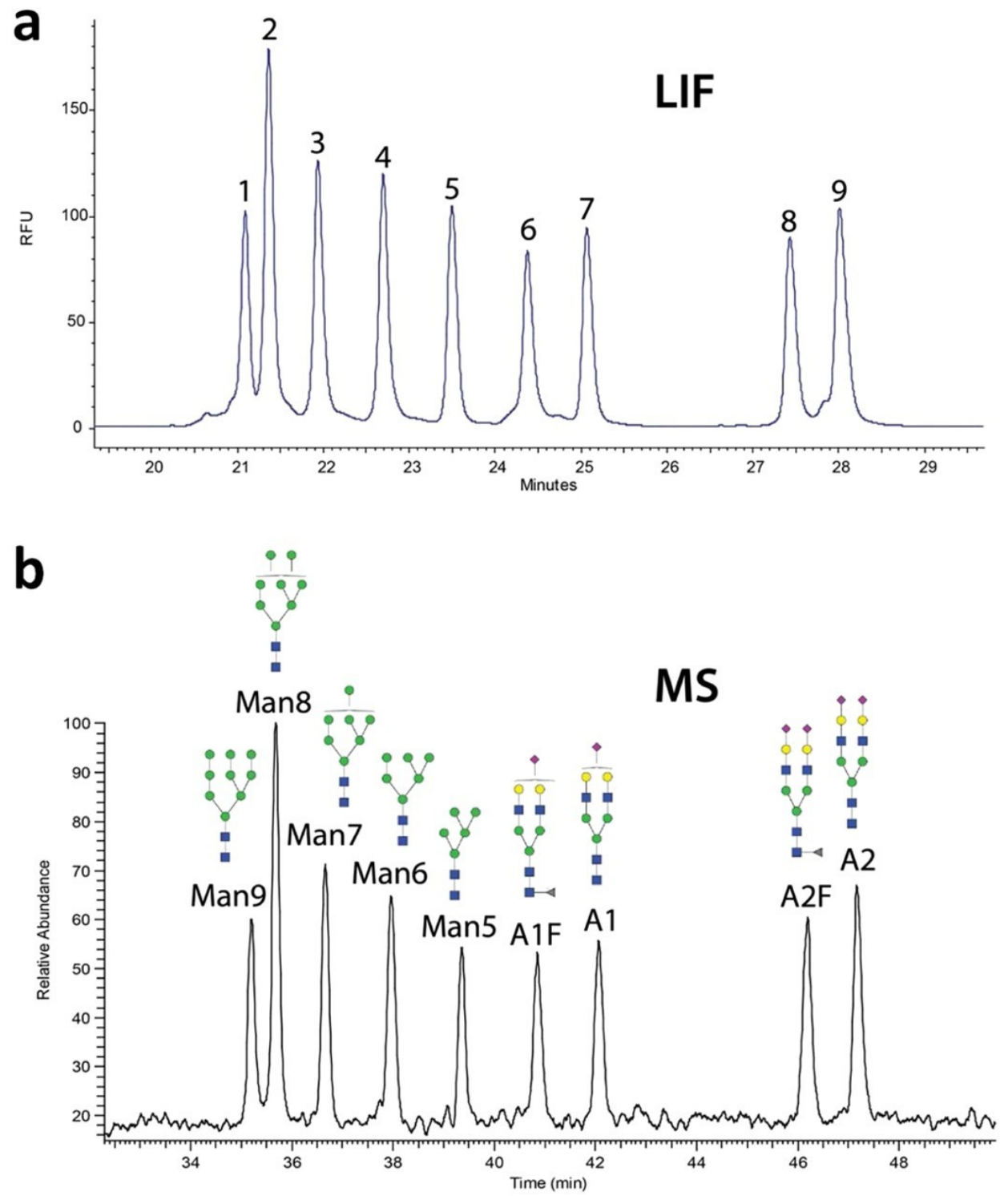

Figure 9. Electropherograms obtained with CZE-LIF (a) and CZE-MS (b). The extracted ion electropherogram and LIF trace show the analysis results of common $N$-glycans $(1.25 \mathrm{nmol} / \mathrm{mL})$ observed on mAbs, labeled with Teal ${ }^{\mathrm{TM}}$ and separated using a high methanol content in the BGE. The signal to noise ratio of the LIF trace is clearly superior to the ratio of the MS trace. Reproduced from reference 150 with permission. 
New labeling strategies have been applied for glycan analysis with CE-MS to further improve limits of detection and gain structural information. $\mathrm{N}$-glycans derivatized with $\mathrm{Teal}^{\mathrm{TM}}$ were analyzed using an electrokinetic pump-based nanospray SL ion source with high methanol content in the BGE for separation and ESI support (Fig. 9B). ${ }^{150}$ Several glycan structures were separated using the Teal $^{\mathrm{TM}}$ reagent and similar signal intensities were obtained, compared to APTS labeling. ${ }^{150}$ In addition to derivatizing at the reducing end, Neu5Ac residues can be labeled to prevent their loss during analysis, to neutralize their charge or to obtain detailed structural information during MS analysis. Therefore, Neu5Ac residues on $\mathrm{N}$-glycans were derivatized with 4-(4,6-dimethoxy-1,3,5-triazin-2-yl)4-methylmorpho-linium (DMTMM) to amidate $\alpha 2,6$-linked Neu5Ac and form lactones with $\alpha 2,3$-linked Neu5Ac residues. This reaction labeled each type of Neu5Ac with a unique mass to determine specific linkages on sialylated $\mathrm{N}$-glycans. ${ }^{145} \mathrm{~N}$-glycans were derivatized with DMTMM and APTS and analyzed with both CE-MS, using a sheathless interface, and a microfluidic device using a linear PAA coating to minimize the EOF and prevent sample adsorption. A number of $77 \mathrm{~N}$-glycan structures derived from human serum were detected, differentiating between specific linkages on sialylated isomers. ${ }^{145}$

Due to the small injection volumes used in CE (typically $\sim 5-20 \mathrm{~nL}$ ) the sensitivity of CE-MS is often not sufficient to analyze low abundant glycans in biological samples. For the analysis of APTS-labeled $N$-glycans anion-exchange sorbent beads were used in an solid-phase extraction (SPE)-CE set-up consisting of an inlet, an SPE and separation capillary joined with a polymeric sleeve. ${ }^{151}$ The inner diameter of the inlet and separation capillaries were smaller than the SPE beads diameter and the SPE capillary, effectively trapping the beads between inlet and separation capillary. By introducing $90 \mu \mathrm{m}$ particles into a $100 \mu \mathrm{m}$ capillary, a single bead strain was created that better prevented the SPE column from clogging than with the application of a multi-layer bead packing. A $10-\mu \mathrm{L}$ injection volume of the glycan sample led to an 800 -fold increase in detection sensitivity compared to a CE-MS analysis using a regular injection volume. However, the flow through the capillary for loading and eluting of analytes needed to be adjusted continuously to the gradually changing backpressure of the SPE construct. Unfortunately, the robustness of SPE-CE is still low and therefore this approach cannot yet be applied routinely. 


\subsubsection{Quantitative CE-MS for glycans}

Till now, most CE-MS analyses methods for glycans are focused on identification, since the quantitative determination is complicated by the lack of reliable standards. Therefore, other approaches that are more generally applicable for relative quantification have been developed. One of those methods is stable isotope labeling of glycans to compare concentrations of glycans between different samples. ${ }^{152}$ For one sample a normal label is used and for the other sample a heavier label containing a stable isotope. Glycans existing in one sample are detected as single ions, whereas common glycans are detected as paired ions with a normal and heavy label. Stable isotope twoplex labeling with ${ }^{12} \mathrm{C}$ and ${ }^{13} \mathrm{C}$ 2-aminobenzoic acid (2-AA) isotopes was used for the analysis of $\mathrm{N}$-glycans released from a mAb. ${ }^{153}$ With CE-MS using a PVA coating and an SL interface it was possible to quantify several glycans in two different drug product lots of a commercial $\mathrm{mAb} .{ }^{153}$ Quantitative analysis has also been reported using tandem mass tags (TMTs) for multiplexed semiquantitative MS/MS of identical analytes in different samples. The TMTs have a modular structure consisting of a reactive group to attach the tag to the analyte, a reporter group that can be modified with different stable isotopes for multiplexing and a balance group to counterbalance the different masses of the reporter ion to ensure that all tags have the same mass prior to fragmentation. Analytes are labeled with TMTs with different reporter ion masses for each different sample. The samples are mixed and analyzed with a separation method and tandem MS. During separation single peaks are obtained for each analyte in the mixed sample. These peaks consist of analytes with isobaric tags and therefore have the same mass in MS. Upon fragmentation in the second MS step unique known reporter ion masses are obtained for each sample that can be used to distinguish the different samples and to determine the relative concentration of analytes in each. Recently, TMTs were modified with a carbonyl-reactive aminooxy group to make the tag suitable for glycan analysis. ${ }^{154}$ The applicability of this TMT was demonstrated by the characterization of $N$-linked glycosylation profiles of human colon carcinoma cells with MS, revealing down-regulation of high-mannose glycans in the metastatic cell line. ${ }^{154}$ The TMT contains a tertiary amine that provides electrophoretic migration and ESI under acidic conditions and therefore it could also successfully be applied in CE-MS quantification of $N$-glycans released from bovine fetuin. ${ }^{155}$ In another application, a microfluidic system with integrated liquid-junction MS interface was used for the quantification of $N$-glycans in positive $\mathrm{CE}$ and MS mode. ${ }^{96}$ Capillary surfaces were coated with an aminopropyl silane reagent to minimize EOF and glycans were derivatized with aminooxy-TMT to introduce a positive charge for electrophoretic migration and to enable multiplexing 
in multi-stage MS experiments. Neu5Ac residues were derivatized to prevent interaction with the positively charged capillary surface coating and to obtain linkage-specific mass-shifts for sialylated glycans. The authors claimed that the application of this chip-based CE method improved glycan separation compared to frequently used chromatographic methods. ${ }^{96}$

CE-MS is an attractive technique that has developed into an alternative to HILICand PGC-MS for glycan separation and identification. Different developments in CE-MS interfacing have resulted in improved signal intensities, however detection limits in CE-MS of glycans remain an issue to be dealt with. In recent years, progress in the $\mathrm{CE}$ field has been made regarding injectable volumes to increase sensitivity and stable, MS compatible capillary coatings to obtain better resolution and migration time repeatability. Furthermore, several new derivatization strategies were developed to increase identification and quantification possibilities. It is expected that these new technologies will contribute to further developments in the glycomics field that will expand the application of CE-MS and make it an even more indispensable technique in the field next to LC-MS 



\section{Highly sensitive CE-IMS-MS of glycans using in-line sample trapping}

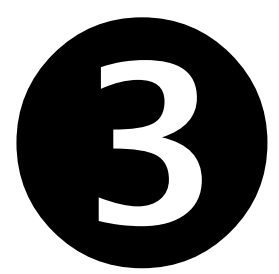

J. Sastre Toraño, X. Liu, K. Hooijschuur, A. Grootendorst, I. Pieterman, G. J. Boons, In preparation. 


\section{Highly sensitive CE-IMS-MS of glycans using in-line sample trapping}

\subsection{Introduction}

Capillary electrophoretic (CE) techniques have played an important role in developments in the life sciences. They provide efficient separation of small polar metabolites as well as of large biomolecules, such as DNA and proteins. ${ }^{156}$ The coupling with mass spectrometry (MS) has ensured a broader application of CE in the life sciences, offering additional structural information, such as for glycans. ${ }^{9}{ }^{157}$ MS offers the possibility to determine glycan compositions using accurate mass measurements and linkages through multistage MS measurements. More recently, ion mobility spectrometry (IMS)-MS has been commercialized. This combination facilitates isomeric glycan separation and characterization by collision cross section (CCS) values as well as by arrival time distributions (ATDs). ${ }^{27,} 158$ The coupling of capillary zone electrophoresis (CZE) with IMSMS creates a synergy in which efficient separations can be obtained with identification based on mass, CCS value and IMS ATDs. On the other hand, a CE-IMS-MS system also compromises detection sensitivity due to a lowered duty cycle in IMS, in particular with drift-tube (DT)IMS, while the sensitivity with CE-MS is already lower compared to liquid chromatography (LC)-MS methods, due the low $\mathrm{nL}$ injection volumes used in CZE. ${ }^{9,27}$ The application of larger injection volumes in CZE could overcome the sensitivity problems, but injection volumes in CE are usually limited to $1-2 \%$ of the capillary volume to ensure fieldamplified sample stacking, which provides the typical efficient electrophoretic peaks. ${ }^{159}$ To inject larger volumes while maintaining efficient peaks, several high-volume injection techniques can be applied, based on stacking ${ }^{159}$ or chromatographic techniques. ${ }^{24}$ Stacking techniques, such as large-volume sample stacking, offer a limited enrichment factor and they often require an outlet background electrolyte (BGE) vial, which is missing in a conventional CZE-MS setup. Chromatographic fritless in-line solid-phase extraction (SPE) trap columns with packed polymeric sorbent beds, have been used to obtain a better sample enrichment ${ }^{151}, 160,161$ and are easier implementable with CZE-MS. Several microliters of sample can be injected, depending on the capacity of the column, which leads to preconcentration factors of more than 100. Fritless trap columns 
contain particles that are larger in diameter than the preceding inlet capillary and the outlet separation capillary, which ensure that particles remain trapped in the columns during analysis. ${ }^{160}$ However, it is difficult to fill these trap columns, due to caking and wedging of particles, leading to hollow spaces and irreproducible as well as incomplete filling of the trap column. Furthermore, the formation of a dense cake and compression of particles increases backpressure over time, which leads to irreproducible results, electric current break downs, impermeable columns at low pressure and short trap column durability. ${ }^{151}$ The low robustness of SPE-CE so far has ensured that this approach has yet not been applied routinely.

Here we show robust in-line sample trapping for CE, using trap columns with commercially available polymeric SPE particle sorbents, blended with diatomite. Diatomite, also known as diatomaceous earth or kieselguhr, consist of natural amorphous silica formed from fossils of unicellular organisms, that form intricately shaped and highly porous particles. It is used as a filter aid to form a highly permeable and incompressible layer in filters ${ }^{162}$, as a solid support in automated liquid-liquid extraction ${ }^{163}$ and it played an important role in the development of stationary phases for gas chromatography and LC. ${ }^{164-166}$ It is also used as an anticaking agent and glidant in the pharmaceutical and food/feed industry to improve the flow of solid powders. ${ }^{167}$ The combination of diatomite with several types of polymeric SPE particles allowed for smooth and consistent filling of trap columns, and for the formation of an incompressible and permeable chromatographic cake, which allows sustained low-pressure driven flow rates for large volume injections in CE. The trap columns, with cation or anion exchange particles or combinations thereof were applied to enrich samples for $\mathrm{N}$-glycan analysis with CZE-DTIMS-MS using a conventional and robust CE-MS sheath liquid sprayer interface. ${ }^{9}$ Trap columns could be used up to 340 sample runs, using several microliter volume injections, without affecting their characteristics and performance, which demonstrates the robustness that is necessary for routine $\mathrm{CE}$ analysis. 


\subsection{Materials and method}

\subsubsection{Chemicals}

Methanol (MeOH; LC-MS grade) and acetonitrile (ACN; LC-MS grade) were obtained from Biosolve (Valkenswaard, The Netherlands). Ultra-pure water was generated by a Synergy UV water purification system (Burlington, MA, US) and Oasis SPE sorbents were obtained from Waters (Milford, MA, US). All other chemicals were purchased from Sigma-Aldrich (St. Louis, MO, US).

\subsubsection{Release of glycans from ribonuclease $B$ and glycan labeling}

High-mannose $N$-glycans were released from ribonuclease B (RNAse B) by PNGase F treatment: A 200- $\mu$ g amount of RNAse B was dissolved in $75 \mu \mathrm{L}$ water with $12.5 \mu \mathrm{L}$ denaturing buffer $(0.5 \%$ sodium dodecyl sulfate and $40 \mathrm{mM}$ dithiothreitol). The solution was heated at $100{ }^{\circ} \mathrm{C}$ for 10 minutes and after cooling to room temperature, $12.5 \mu \mathrm{L} 50 \mathrm{mM}$ sodium phosphate $\mathrm{pH} 7.5,12.5 \mu \mathrm{L}$ NP-40 solution and $2.5 \mathrm{U}$ PNGase $\mathrm{F}$ were added. The mixture was incubated at $37{ }^{\circ} \mathrm{C}$ overnight and then passed through a $\mathrm{C}_{18} \mathrm{SPE}$ cartridge to remove the proteins, eluting the glycans with $1 \mathrm{~mL} 5 \%$ ACN:95\% water with $0.05 \%$ TFA (\% v/v). After evaporation of the eluate under a nitrogen stream, the residue was dissolved in water and subsequently desalted with porous graphitized carbon (PGC) SPE (HyperSep Hypercarb, Thermo Scientific, Waltham, MA, US) by first washing with $1 \mathrm{~mL} 0.05 \%$ TFA in water, $1 \mathrm{~mL}$ ACN:water 5:95 (\%v/v) containing 0.05\% TFA (\%v/v) and finally eluting with $1 \mathrm{~mL}$ of ACN:H2O 1:1 (v/v) containing $0.1 \%$ TFA. The sample was evaporated under a nitrogen stream. Glycans were then labeled by adding $10 \mu \mathrm{L}$ water and $10 \mu \mathrm{L}$ labelling mixture (50 $\mathrm{mg} / \mathrm{mL}$ 4-amino- $N$-2-(diethylamino)ethyl-benzamide (procainamide, PA) and $50 \mathrm{mg} / \mathrm{mL}$ sodium cyanoborohydride in 10:3 (v/v) DMSO/acetic acid). This solution was incubated at $65^{\circ} \mathrm{C}$ for 2 hours and cleaned up using the previously described PGC SPE method. The sample was dried under a nitrogen stream and reconstituted in $20 \mu \mathrm{L}$ water before analysis. The derivatization procedure was also applied to glycan standards, using several different derivatization agents. 


\subsubsection{Preparation of trap columns}

Diatomite (Celite 545, 20-100 $\mu \mathrm{m}$ particles; Merck KGaA, Darmstadt, Germany) and both strong as well as weak anion and cation exchange Oasis SPE particles $(\sim 60 \mu \mathrm{m})$ were dried at $65^{\circ} \mathrm{C}$ and sieved through steel powder sieves to obtain particles ranging from 52 to $90 \mu \mathrm{m}$. This procedure was repeated several times until all diatomite and SPE particles $<52 \mu \mathrm{m}$ were removed. Diatomite and SPE particles were mixed in different ratios and dry packed in $4 \mathrm{~mm}$ length bare fused silica (BFS) capillaries (200 $\mu \mathrm{m}$ internal diameter (ID), $365 \mu \mathrm{m}$ outer diameter (OD, Biotaq, Gaithersburg, MD, US) by applying vacuum on one side of the capillary. ${ }^{160}$ The combined capillary was assembled by connecting one side of the trap column to a $10 \mathrm{~cm}, 50 \mu \mathrm{m}$ ID inlet and the other side to a $60-100 \mathrm{~cm}$, $50 \mu \mathrm{m}$ ID outlet BFS capillary through a sleeve to ensure a tight connection (Fig. 1). ${ }^{160}$ The sleeve consisted of a $1.5 \mathrm{~cm}$ long, $1.58 \mathrm{~mm}$ OD and $0.3 \mathrm{~mm}$ ID Teflon tube (Sigma-Aldrich). The ID of the sleeve was slightly increased by first passing through a $10 \mathrm{~cm}$ long, 365 um OD BFS capillary, to allow capillaries to be connected more easily and to prevent the scraping of Teflon pieces of the inside of the sleeve, which could clog the combined BFS capillary during assembly. Besides uncoated BFS capillaries, in- and outlet BFS capillaries with fluorocarbon (FC) polymer coating (Agilent Technologies, Santa Clara, CA, US) were used for CE-IMS-MS.

The sample trapping on the trap columns was performed with 4 different polymeric SPE materials and chemoenzymatically synthesized $\mathrm{N}$-glycan standards, ${ }^{31,35,36}$ with anomeric tags attached through reductive amination. ${ }^{9}$ All derivatized compounds were purified using the previously described PGC SPE method. Four different tags and sorbents were used in the trap columns: Girard's reagent-T tag in combination with weak cation exchange resin (WCX; $m$-divinylbenzene and $N$-vinylpyrrolidone copolymer (DVB-NVP) containing carboxylic acid substituents), PA tag with strong cation exchange resin (MCX; DVB-NVP with sulfonic acid substituents), 2-aminobenzoic acid tag with strong anion exchange resin (MAX; DVB-NVP with quaternary amine substituents) and aminopyrene trisulfonate tag with weak anion exchange resin (WAX; DVB-NVP modified with piperazine substituents). 


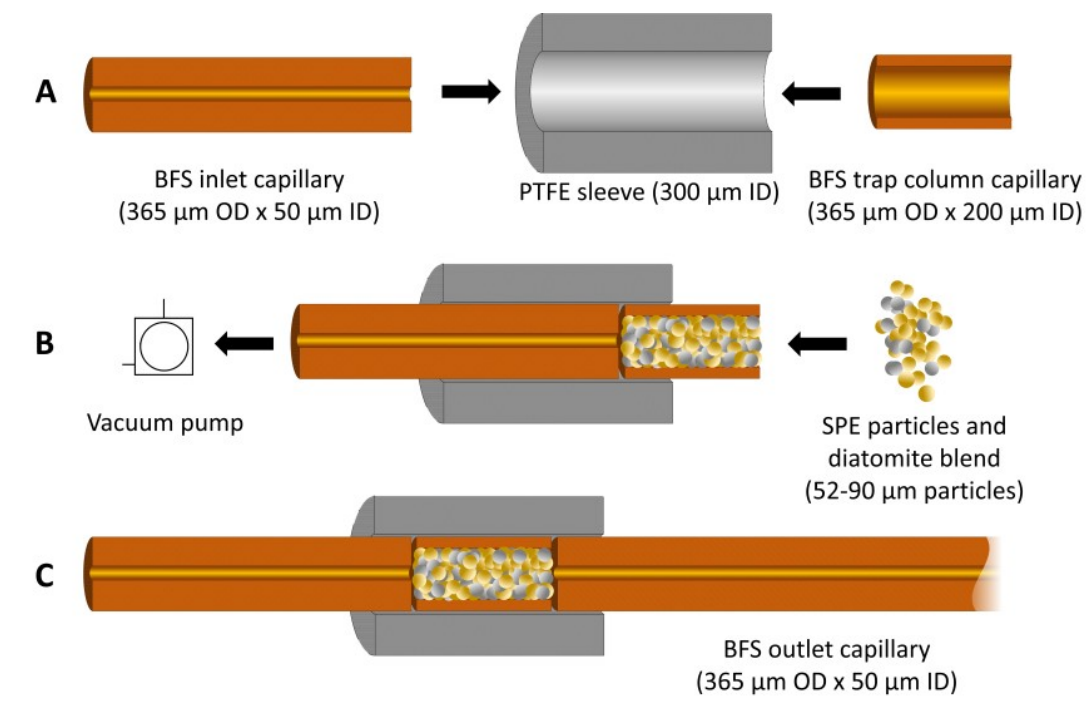

Figure 1. Schematic overview of the construction of the trap column. A) Cross sections of bare-fused silica (BFS) capillaries in a polytetrafluoroethylene (PTFE) sleeve. The capillaries have an outer diameter (OD) that matches the inner diameter (ID) of the sleeve. B) They are inserted into the sleeve and thereafter sorbent particles, with a larger diameter than the in- and outlet capillaries, are introduced into the SPE capillary by applying a vacuum through the inlet capillary. C) The packed SPE capillary is pushed to the center of the sleeve with a BFS capillary and the outlet capillary is connected.

\subsubsection{CE-ISM-MS system}

The capillaries with SPE trap columns were used in a 7100 CE instrument and connected to a 6560 DTIMS-mass spectrometer through a coaxial sheath liquidjet stream electrospray interface (Agilent Technologies), using an optimized sheath liquid of $\mathrm{MeOH}$ :water 70:30 (v/v) with $20 \mathrm{mM}$ formic acid (FA) at a flow rate of $5 \mu \mathrm{L} / \mathrm{min}$. The optimal CE-MS interface conditions were: a capillary voltage of $1725 \mathrm{~V}$, a drying gas temperature of $250^{\circ} \mathrm{C}$, a drying gas flow rate of $3 \mathrm{~L} / \mathrm{min}$, a nebulizer pressure of $6 \mathrm{psi}$, a sheath gas temperature of $195^{\circ} \mathrm{C}$ and a sheath gas flow of $3.5 \mathrm{~L} / \mathrm{min}$. 
Instrument settings for IMS and CE were optimized with $\mathrm{N}$-glycans for optimal selectivity and signal response. For CE, the background electrolyte (BGE) composition and $\mathrm{pH}$ was optimized in combination with the elution solvent for the trap column as these solvents affected both CZE as well as elution of glycans. Flushing times of these solvents at specific pressures were dependent on flow rate through the capillary and trap column. This flow rate was determined daily by flushing an aqueous solution of glucose, which is not retained on the column, through the capillary at a specific pressure and by determining the arrival time at the CE capillary exit with MS. The consecutive volumes of optimized flushing solutions, with an outlet capillary of $88 \mathrm{~cm}$, were: 3 capillary volumes $(6 \mu \mathrm{L}) 50$ mM FA to condition the trap column, 6.8 capillary volumes sample injection (up to $13.6 \mu \mathrm{L}), 1$ capillary volume $(1.5 \mu \mathrm{L}) 50 \mathrm{mM}$ FA to remove sample solvent, 2 trap column bed volumes ( $175 \mathrm{~nL}$ ) of eluent and $2 \mathrm{M}$ acetic acid (HAc, $290 \mathrm{~nL}$ ) as BGE and solvent to push the eluent plug through the trap column. The elution plug was moved back and forth several times through the trap column to ensure an efficient desorption and then pushed into the separation capillary with $250 \mathrm{~nL}$ 2 M HAc for CE separation. For outlet capillaries with a different length, the flushing volumes for the BGE were adjusted to displace equal capillary volumes of solvents. Separations were performed at $25^{\circ} \mathrm{C}$ and at a separation voltage of $30 \mathrm{kV}$, with both FC coated and uncoated BFS capillaries.

IMS separation was performed in a drift tube operated at an entrance voltage of $1700 \mathrm{~V}$ and exit voltage of $250 \mathrm{~V}$, using nitrogen as drift gas. The trap funnel pressure was maintained at 3.85 Torr and drift tube pressure at 4.00 Torr. Maximum drift time was set at $60 \mathrm{~ms}$, with a trapping time of $20000 \mu \mathrm{s}$ and a release time of $150 \mu \mathrm{s}$. 


\subsection{Results and discussion}

\subsubsection{Trap column development}

Trap columns were filled with blends of MCX, WCX, MAX or WAX Oasis SPE particles with diatomite. These columns have a reduced capacity, compared to columns with pure SPE sorbents. To obtain sufficient sorbent surface area, trap columns with a length of $4 \mathrm{~mm}$ and $200 \mu \mathrm{m}$ ID were used, which are larger than in previously optimized systems. ${ }^{160,161}$

The powder density of diatomite is approximately half of the powder density of the SPE particles. Given the difficulty to determine accurate powder volumes, the corresponding amounts of diatomite and SPE particles were determined by weight to obtain repeatable blends. To establish the optimal diatomite:SPE particle sorbent ratio, diatomite and SPE particles were mixed in ratios ranging from 1:4 to $4: 1(\mathrm{~m} / \mathrm{m})$. When the percentage of diatomite in blends was less than $50 \%(\mathrm{~m} / \mathrm{m})$, the dry packing of trap columns was difficult, leading to incomplete filling and impermeable columns after solvent flushing at a pressure of 1 bar. With a $50 \%$ or higher diatomite percentage $(\mathrm{m} / \mathrm{m})$, a complete filling was accomplished within seconds and the packed columns could be flushed at a pressure of $1 \mathrm{bar}$, demonstrating the positive effect of diatomite blends on the flow of SPE particles into the trap column and solvent flow through the packed bed. The 4 different SPE sorbents, containing $50 \%(\mathrm{~m} / \mathrm{m})$ diatomite were tested by trapping a digalactosylated $\mathrm{N}$-glycan (G2), containing the corresponding anomeric tag, washing the trap column with water and eluting with 1 bed volume $(88 \mathrm{~nL})$ of the generally recommended Oasis SPE elution solvents, at a pressure of 1 bar. The eluted G2 standard was flushed further through the outlet capillary to the MS detector with $50 \mathrm{mM} \mathrm{FA}$. The four different types of sorbents all successfully retained G2, with the combination of MCX strong cation exchange sorbent and PA tag yielding the highest MS response for G2. Therefore, this combination was used for further optimization and characterization of trap columns with diatomite blends. The PA tag, which also has strong fluorescent properties, is predominantly protonated due to the presence of a tertiary amine (pKa 9.2) and can be multiply charged under acidic conditions due to the primary amine (pKa 3.3), ensuring sufficient charge for sample trapping, electrophoretic migration and MS detection. At these low $\mathrm{pH}$ conditions, the electroosmotic flow in BFS capillaries is suppressed, which provides a larger separation window for glycans. 


\subsubsection{Trapping, elution and CZE optimization}

To determine the flowrate through the capillary with trap column at $100 \mathrm{mbar}$ and 1 bar pressures, a $1 \mathrm{mM}$ aqueous solution of unlabeled glucose (which is not retained by the column) was flushed through the capillary and detected by MS. The arrival time at the MS detector was used to calculate the flowrate to adjust pressure application times and ensure accurate flushing, injection and elution volumes. As there was no difference in signal intensity when applying equal volumes during injection and elution steps at 100 mbar or 1 bar (data not shown), all pressure applications in the method were performed at 1 bar.

A trap column, connected to a $100 \mathrm{~cm}$ BFS outlet capillary, was conditioned with $50 \mathrm{mM} \mathrm{FA}$, and a- $100 \mathrm{~nL}$ volume of $6 \mu \mathrm{M}$ G2-PA was injected hydrodynamically into the column at a pressure of 1 bar. Injections of G2-PA dissolved in acidified solutions and organic solvents resulted in sample loss, while G2-PA was retained on the trap column when water was used as solvent. Therefore, all sample injections were performed with water as solvent.

The elution of G2-PA from the column was optimized in three steps by first optimizing the BGE solvent composition, which is important to prevent sample breakthrough of injected sample during capillary filling with BGE. Then the elution solvent composition was optimized by flushing 2 bed volumes $(175 \mathrm{~nL})$ of different eluent compositions through the trap column and finally the optimal elution plug volume was determined by eluting with different bed volumes.

After flushing with one capillary volume $(2.3 \mu \mathrm{L})$ of $2 \mathrm{M}$ FA or $2 \mathrm{M}$ acetic acid (HAc), most of the trapped G2-PA was eluted by these high ionic strength solutions. During flushing with 1 capillary volume of $10 \mathrm{mM} \mathrm{HAc}$, still approximately $50 \%$ sample was eluted, probably caused by favorable ion-paring of G2-PA and acetate, while during flushing with 4 capillary volumes of up to $100 \mathrm{mM}$ FA, all G2-PA was still retained on the trap column. To maintain a safe margin, 50 mM FA was used to fill the separation capillary after sample injection. 

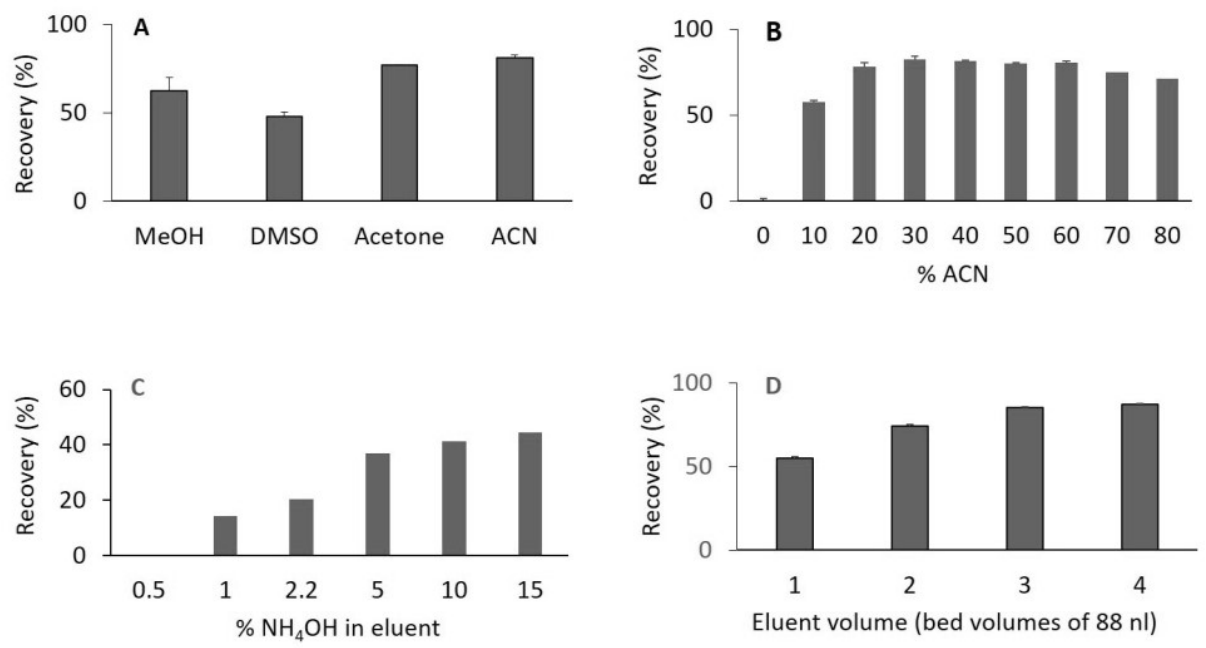

Figure 2. Optimization of trapping and elution. A) Recovery of G2-PA after elution with $175 \mathrm{~nL}$ of organic solvent with $50 \%(\% \mathrm{v} / \mathrm{v})$ water and $5 \%(670 \mathrm{mM})$ concentrated ammonium hydroxide $(25 \% \mathrm{v} / \mathrm{v})$. B) Recovery of G2-PA after elution with $175 \mathrm{~nL}$ of solvents with different ACN:water ratios (v/v), containing 5\% ammonium hydroxide. C) Recovery of G2-PA after elution with ACN:water 30:70 (v/v) solvents, containing different percentages of concentrated ammonium hydroxide. D) Recovery of G2-PA after elution with different bed volumes of ACN:water 30:70 $(\mathrm{v} / \mathrm{v})$, containing $5 \%$ concentrated ammonium hydroxide.

Next, the optimal eluent composition was determined, by applying different organic solvents in a ratio of $1: 1(\mathrm{v} / \mathrm{v})$ with $5 \%$ concentrated ammonium hydroxide $(670 \mathrm{mM})$. Ammonium hydroxide was selected as it provides a high $\mathrm{pH}$ and high ionic strength for the elution of weak cations from the MCX sorbent. Furthermore, ammonium ions can also act as leading electrolyte (LE) in transient isotachophoresis (tITP) in a system with acidic solutions as terminating electrolyte (TE). ${ }^{168}$ Figure $2 \mathrm{~A}$ shows that the elution was most efficient with ACN, with a minimum of $10 \%(\mathrm{v} / \mathrm{v})$ needed to elute $\mathrm{G} 2-\mathrm{PA}$, and $30-60 \%(\mathrm{v} / \mathrm{v})$ yielding the highest recovery (Fig. 2B). For further optimization, the ammonium hydroxide concentration was varied in the ACN:water 30:70 (v/v) elution solvent. High concentrations of ammonium hydroxide ( $>5 \%)$ showed best elution of G2- 
PA (Fig. 2C). Elution with larger bed volumes $(>2)$ also resulted in higher G2-PA recovery (Fig. 2D). To further improve the recovery, while applying lower elution volumes, eluent plugs with different ammonium hydroxide concentrations and bed volumes were passed back and forth through the trap column by applying consecutively positive and negative pressures on the $\mathrm{CE}$ inlet vial. A maximum recovery was obtained by eluting with $5 \%$ ammonium hydroxide in ACN:water 30:70 (v/v), with an elution plug of 2 bed volumes and by passing the eluent two times back and forth through the trap column. This way, the eluent plug is passed five times through the trap column, which ensures maximum desorption of G2-PA. Nevertheless, when the CE capillary was flushed with eluent, after applying the complete elution protocol and pushing the elution plug out of the CE capillary, additional peaks of G2-PA eluted out of the capillary. This was probably due to G2-PA adsorption to the BFS capillary wall. To prevent this adsorption, an FC-coated capillary was used as inlet and outlet capillary, resulting in elution of all G2-PA in the eluent plug, without the detection of additional peaks for G2-PA after additional flushing with eluent. Therefore, FC coated capillaries were used to further optimize the CZE step.

The ammonium ions in the elution plug served as leading electrolyte (LE) for tITP and several volatile BGEs were used to optimize the terminating electrolyte (TE). FA and HAc at high (2-4 M) and low molarities (10-100 mM) were flushed through the capillary after the eluent plug, to fill the inlet side of the capillary with TE, which also served as BGE. After passing the eluent back and forth two times, the plug was moved into the outlet capillary and $30 \mathrm{kV}$ was applied to the capillary to start the ITP process. The separation was assisted by pressure to ensure the migration of G2-PA out of the capillary before the transition to CZE. FA as TE resulted in broad peaks for G2-PA in the electropherograms, without effectuating ITP, probably caused by the high mobility of protons in the TE. The protons in HAc have a lower mobility due to the higher buffering capacity of the solution, and the application of this weaker acid resulted in more concentrated analyte zones. ${ }^{168}$ All HAc TE solutions effectuated ITP, but low HAc concentrations slowed down the transition from ITP to CZE, resulting in poor separation between unreacted PA and G2-PA. A TE of $2 \mathrm{M} \mathrm{HAc}$, in combination with $670 \mathrm{mM}$ ammonium hydroxide as LE, ensured ITP and provided subsequent separation of G2-PA and unreacted PA with CZE (Fig. 3). To demonstrate the requirement of ammonium ions to create a concentrated G2-PA ITP zone, an elution plug with $30 \% \mathrm{ACN}$ and sodium hydroxide was used, with similar ionic strength and $\mathrm{pH}$ as the optimized ammonium hydroxide elution plug. The sodium 
hydroxide solution ensured elution of G2-PA from the trap column, but at the same time impeded ITP, which resulted in very broad and smeared G2-PA and unreacted PA peaks. This result indicates that the sharp zone is not created by $\mathrm{pH}$ differences in the discontinuous BGE, but by ITP with ammonium ions as LE, although an additional $\mathrm{pH}$-induced stacking effect for G2-PA cannot be excluded completely.

An overview of the optimized injection and elution procedure is shown in figure 4. This procedure was used to characterize the trap-column and analyze additional glycan standards and samples with CZE-DTIMS-MS.

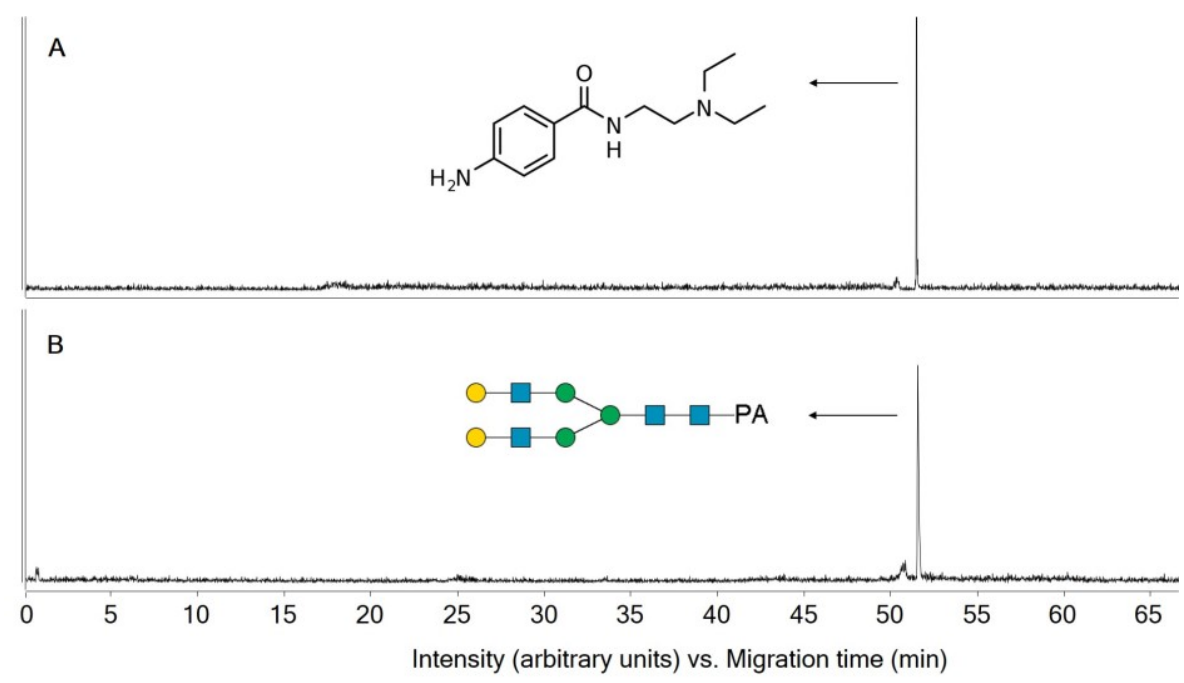

Figure 3. Extracted ion electropherograms during ITP-MS of unreacted PA (A; at $\mathrm{m} / \mathrm{z} 236$ ) and 600 nM G2-PA (B; at $m / z$ 930). A $100 \mathrm{~cm}$ BFS outlet capillary was used, with a $10-\mu \mathrm{L}$ volume injection on the cation exchange trap column, elution with $30 / 70$ (v/v) ACN/670 mM ammonium hydroxide and a separation voltage of $30 \mathrm{kV}$ with additional pressure on the inlet vial during ITP. Ammonium ions from the elution solution served as leading electrolyte and protons from acetic acid (2 M) as terminating electrolyte. 
1- Conditioning with $50 \mathrm{mM}$ FA (3 capillary volumes) at 1 bar

3

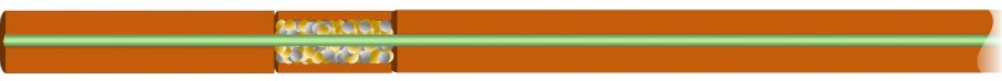

2- Injection of analyte in water at 1 bar

3
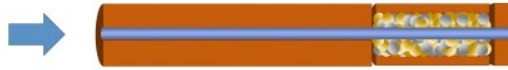

3- Capillary refill with 50 mM FA BGE (1 capillary volume) at 1 bar
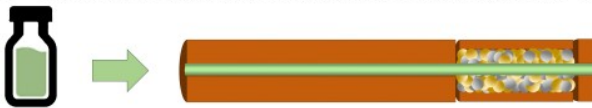

4- Flush with $670 \mathrm{mM} \mathrm{NH}_{4} \mathrm{OH}: \mathrm{ACN}$ (70:30) eluent (2 trap column bed volumes) at 1 bar
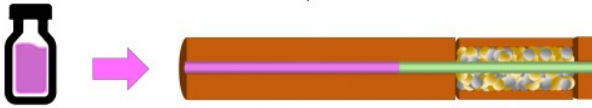

5- Flush with $2 \mathrm{M} \mathrm{HAc} \mathrm{BGE} \mathrm{(1} \mathrm{inlet} \mathrm{capillary} \mathrm{volume} \mathrm{+} 1$ trap column bed volume) at 1 bar

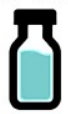

\section{Fueconicind}

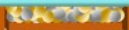

6- Flush $2 x$ back and forth ( 2 trap column bed volumes) at -100 mbar and 1 bar, respectively
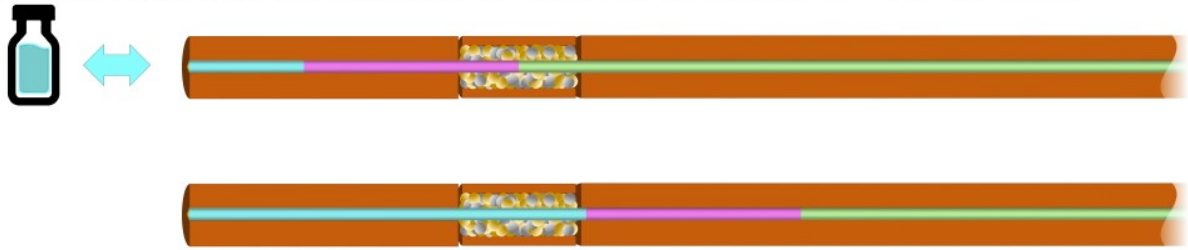

7- Flush with $2 \mathrm{M} \mathrm{HAc}$ ( 1 trap column bed volume past trap column) at 1 bar
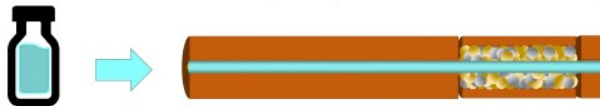

Figure 4. Injection and elution steps for $N$-glycans on a trap column with MCX cation exchange sorbent. 


\subsubsection{Characterization of trap columns}

A number of 8 trap columns, with strong cation exchange resin and diatomite blends, were successfully prepared on 8 different days. All columns were used for at least 100 and up to 340 sample runs, without affecting the flow rate through the columns. The flow rate at $100 \mathrm{mbar}$, using $50 \mathrm{mM} \mathrm{FA}$, was $10.27 \pm 0.03$ times lower than at 1 bar ( $n=6$, measured over 67 days), showing a linear response between flowrate and pressure. At a pressure of 1 bar, a flow rate of $10.7 \pm 0.3$ $\mathrm{nL} / \mathrm{s}$ was obtained (Fig. $5 ; \mathrm{n}=23$, measured over 40 days), using an outlet capillary of $100 \mathrm{~cm}$, which demonstrates the consistent flow properties through the trap column, that is needed for reproducible injection procedures and robust analyses.

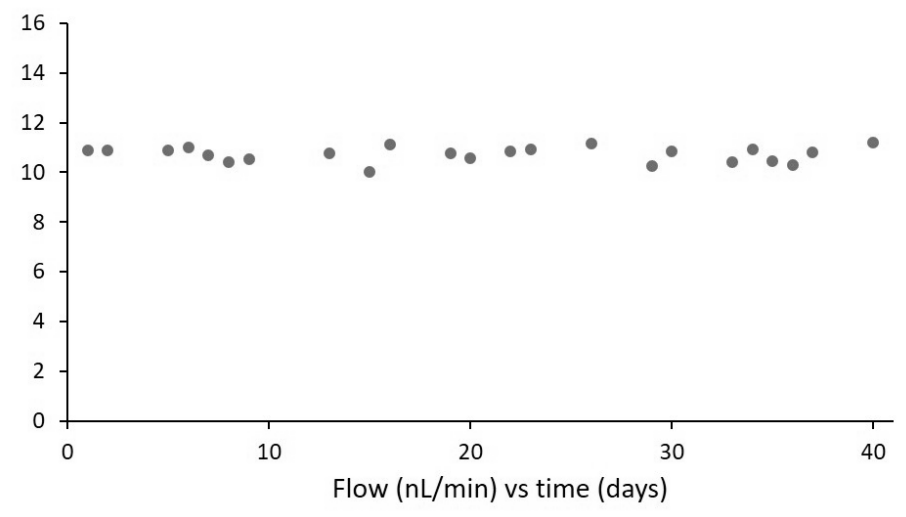

Figure 5. Flow through the CE capillary, determined by flushing glucose in water through the capillary with known dimension, at a pressure of 1 bar, and determining the arrival time at the capillary exit. The capillary with trap column used an inlet capillary length of $10 \mathrm{~cm}$ x $50 \mu \mathrm{m}$ and an outlet capillary length of $100 \mathrm{~cm}$ x $50 \mu \mathrm{m}$ with a total capillary volume of $2.2 \mu \mathrm{L}$.

To determine if the sample capacity of the trap column was sufficient for highvolume injections, different volumes of maltoheptaose (G7)-PA were injected onto the column. The injection volume was gradually increased with decreasing G7-PA concentration to obtain equal absolute amounts of analyte on the trap column for all injections. Figure 6 shows that 1.7-13.6 $\mu \mathrm{L}$ injection volumes, corresponding to $1.7 \mathrm{pmol}$ amounts on column, provide similar signal intensities for equal injected absolute amounts, demonstrating the high sample capacity of the trap column, with a breakthrough volume $>13.6 \mu \mathrm{L}$. The largest injection 
volume is a 1000-fold higher than normally used in CE, which should ensure the analysis of low abundant glycans in biological samples. The improved injection capacity allowed for the CE-MS analysis of G2-PA with a limit of detection (LOD) of $35 \mathrm{nM}$, using a $10-\mu \mathrm{L}$ injection volume. With a $2 \%$ injection volume $(15.6 \mathrm{~nL})$ on a $70 \mathrm{~cm}$ BFS capillary without trapping column and CZE with a $2 \mathrm{M}$ HAc BGE, an LOD of $18.5 \mu \mathrm{M}$ could be obtained for G2-PA. The absolute amount injected for the LOD determination on the trap column system is approximately $80 \%$ of the absolute amount injected in the system without trap column, which shows the high retaining capacity of the trap column.

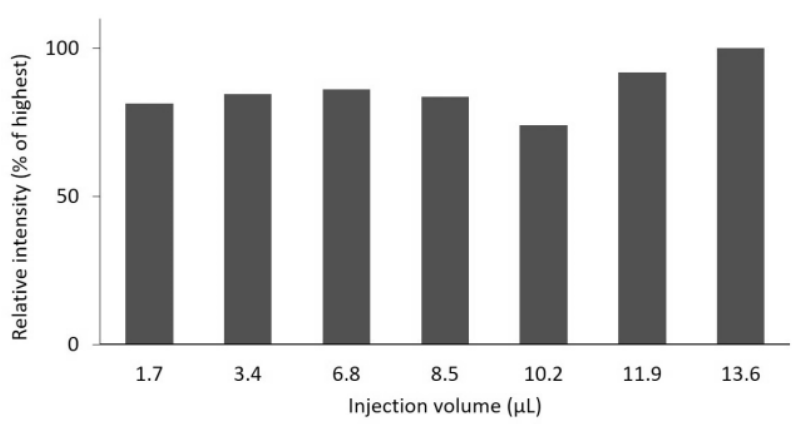

Figure 6. Signal intensities for different injection volumes of G7-PA solutions. The solutions were diluted in order to inject equal absolute amounts of analyte (1.7 pmol) on the trap column for each injection volume.

The developed in-line sample trapping method, using cation exchange/diatomite blends, was applied to the CZE-IMS-MS analysis of high-mannose $\mathrm{N}$-glycans released from $200 \mu \mathrm{g}$ ribonuclease B. The glycans were derivatized with PA and a $5 \mu \mathrm{L}$ sample was injected for CZE with sample trapping. The enriched glycans were partly separated by their size in the CZE dimension and showed good resolution in the ion mobility dimension (Fig. 7). Broader CZE peaks are obtained for the traces in fig. 7C and 7D, showing the presence of multiple isomers, which is also confirmed by their ion mobility ATDs (Fig. 7H and 7I). 


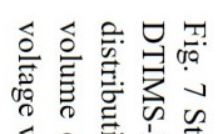

迆串家完

है है

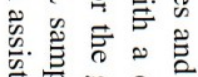

官突祭

¿

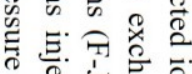

○

ज令

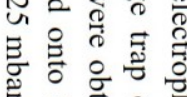

के

है 苍. ᄋ

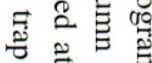

局吉

官官艺。

志芯突

言岕芯

ह क

运透

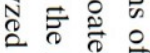

\& 哭 。

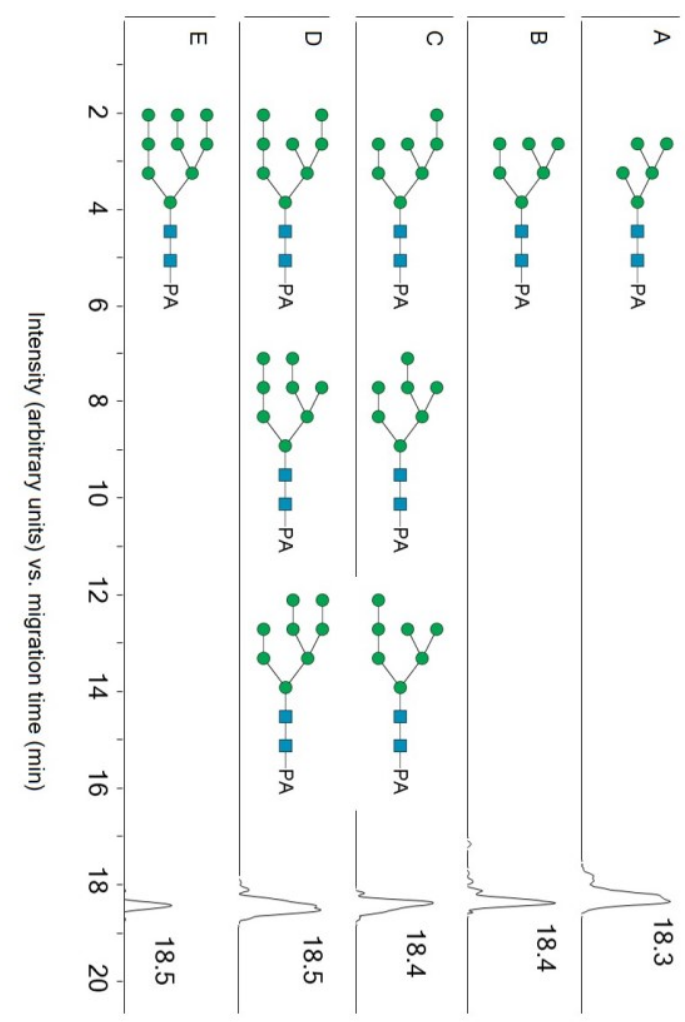

嵌 鬲

居茶志

월유.

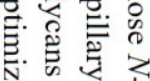

N. 40 \%

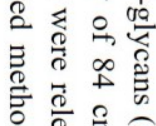

实产

क.

豆

फ ․․ㄹ.

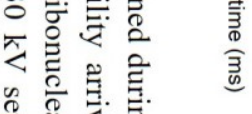

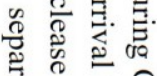

苛. 苛
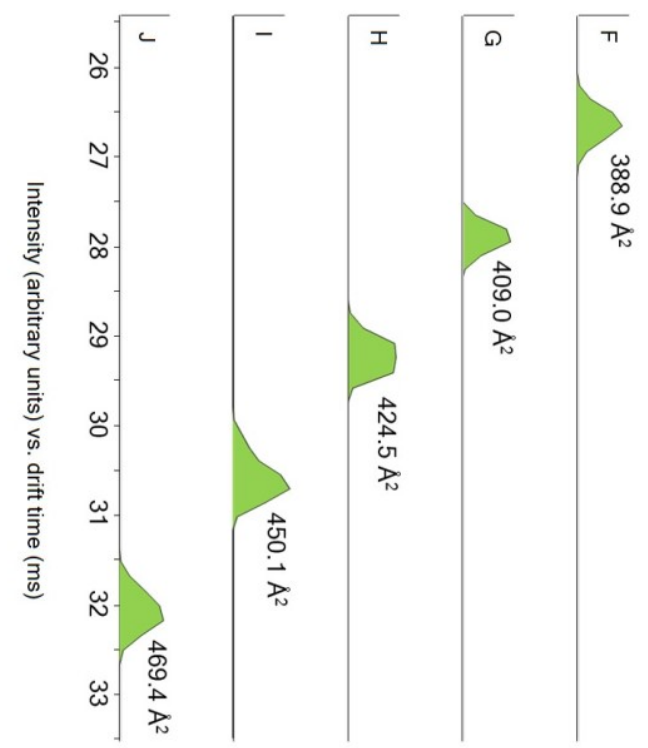
Sialylated $\mathrm{N}$-glycans, which are partially negatively charged at $\mathrm{pH}$ values above 2.9, showed a reduced retention on the strong cation exchange material and therefore a mixed weak anion and strong cation exchange trap column with diatomite $(1: 1: 2 \mathrm{~m} / \mathrm{m} / \mathrm{m})$ was used to also trap acidic glycans. The weak anion exchange material (DVB-NVP modified with piperazine substituents, which has $\mathrm{pK}_{\mathrm{a}} \mathrm{s}$ of 6 and 9), can be used to trap and elute anions under the same conditions as optimized for the strong cation exchange material.

Figure 8 shows the CZE-DTIMS-MS analysis of chemoenzymatically synthesized and PA labeled $N$-glycan standards, ${ }^{31,35}$ using strong cation exchange/weak anion sample trapping. By using blends of cation and anion exchange sorbents, both neutral and sialylated $N$-glycans derivatized with PA were concentrated simultaneously, without the need for sialic acid derivatization, and allowing analysis of all compounds in positive IMS-MS mode. Several $\mathrm{N}$-glycans were enriched on the anion/cation trap column and analyzed with CZE-IMS-MS (Fig. 8). Electrospray ionization efficiency for sialylated compounds is lower than for the nonsialylated compounds and therefore the required concentration in the sample was higher.

Ion mobility ATDs for each glycan were obtained (Fig. $8 \mathrm{H}-\mathrm{N}$ ), which provide additional separation for an improved selectivity with CCS values for identification. Furthermore, the ATDs show broad profiles and partly separated peaks, demonstrating that the $\mathrm{N}$-glycans adopt different specific conformations, which can be partially separated by DTIMS. These ATDs can very likely also be used for the identification of the glycans in complex samples by using their conformer distribution fingerprint. 


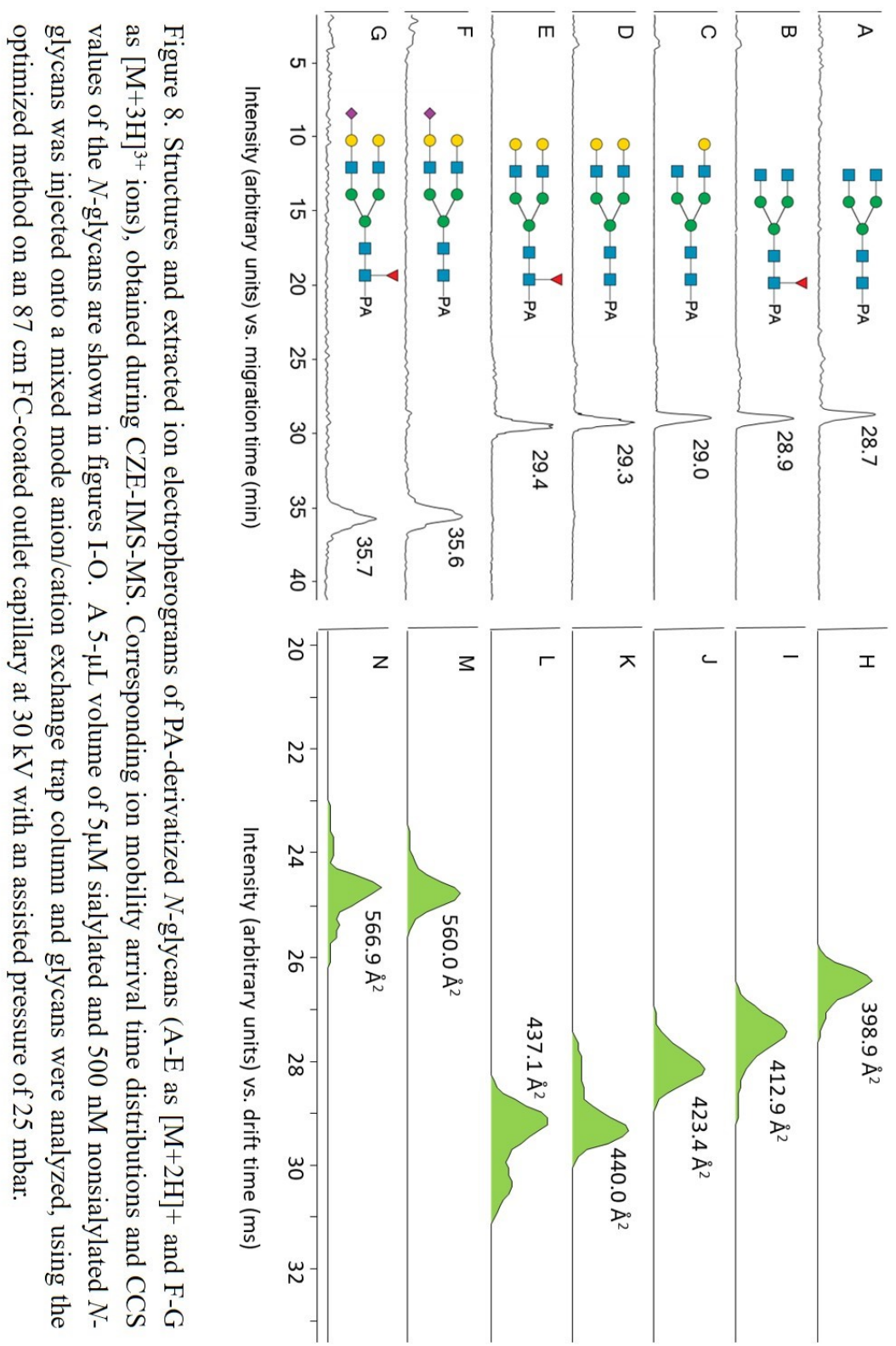




\subsection{Conclusion}

SPE sorbent blends with diatomite provided fast and easy filling of trap columns for sample trapping in CE-IMS-MS. The columns were used for up to 340 runs and remained highly permeable with consistent flow rate during their lifetime. The trap columns were applied to the analysis of neutral $\mathrm{N}$-glycans derivatized with a positive chargeable tag using a cation exchange sorbent. Acidic and neutral glycans, derivatized with a positive chargeable tag, could be enriched simultaneously by using a mixed anion/cation exchange and diatomite sorbent. Samples volumes up to $13.6 \mu \mathrm{L}$ were injected, which is a factor 1000 higher than with conventional injection methods in $\mathrm{CE}$, leading to low $\mathrm{nM}$ limits of detection for $\mathrm{N}$-glycans in positive IMS-MS mode. The described robust sample trapping can be applied broadly with different types of SPE sorbents for both anionic as cationic analytes and is expected to allow large volume injections with trap columns in $\mathrm{CE}$ to be used in routine analysis. 



\section{Identification of isomeric $N$-glycans by conformer distribution fingerprinting using IM-MS}

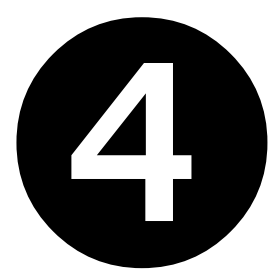

J. Sastre Toraño, O. Aizpurua-Olaizola, N. Wei, L. Tiehai, L. Unione G. Jiménez-Osés, F. Corzana, V. J. Somovilla, J.M. Falcon-Perez, G. J. Boons, Submitted for publication. 


\section{Identification of isomeric $N$-glycans by conformer distribution fingerprinting using IM-MS}

\subsection{Introduction}

Glycosylation is a posttranslational modification that has been implicated in multiple biological and disease processes. ${ }^{2,}{ }^{169-173}$ The identification of exact structures of glycans is key to understand their biology at a molecular level and for the development of bio-pharmaceuticals and biomarkers. Determination of glycan compositions in biological samples is rather straightforward and usually entails glycan release followed by a separation step, such as liquid chromatography or capillary electrophoresis, followed by accurate mass spectrometry (MS) measurements. ${ }^{174-176}$ The assignment of exact glycan structures, which requires MS/MS fragmentation experiments, is much more challenging due to the presence of multiple isomeric forms, often resulting in similar MS/MS spectra with signals of fragment ions that are difficult to univocally assign to a single structure. ${ }^{177,}{ }^{178}$ Complementary techniques, such as ion mobility spectrometry (IMS), have been combined with MS to facilitate unambiguous identification of glycans or their MS/MS derived fragments. ${ }^{27,}{ }^{179-181}$ In IMS, gas-phase ions are separated based on their mobility through a drift gas under the influence of an electric field. The measured arrival time and derived ion mobility depends on the charge, size and shape and can provide an intrinsic collision cross section value (CCS) that can be used for glycan structure assignment. ${ }^{27,28,179,182-188}$

Simple oligosaccharides usually adopt a limited number of gas phase conformations, and as a result their IMS arrival time distributions (ATDs) often show a single peak. ${ }^{189}$ In these cases, CCS values can be derived from the apex of the peak, and in general differ sufficiently to discriminate between isomeric structures. For example, it has been shown that $N$-acetyllactosamine having either an $\alpha(2,3)$ - or $\alpha(2,6)$-linked $N$-acetylneuraminic acid (Neu5Ac) can be differentiated based on CCS values. ${ }^{29}$ Larger glycans often exhibit smaller differences in CCS values, especially in the case of isomeric structures, ${ }^{190}$ and therefore it is more difficult to distinguish them only based on CCS values. 
Elegant studies have shown that ATDs of positively charged ions resemble conformational populations in the gas phase. ${ }^{189,191,192}$ Furthermore, such distributions can reveal the presence of isomeric $N$-glycans. ${ }^{193,}{ }^{194}$ The ability to determine conformational distributions (CDs) by measuring ATDs is potentially attractive for the assignment of exact isomeric glycan structures. The exploitation of CDs for this purpose, however, is hampered by a lack of well-defined $N$-glycan standards to systematically investigate the relationship between molecular structure and ATD. The recent introduction of facile chemoenzymatic synthetic methods for the preparation of $\mathrm{N}$-glycans, ${ }^{31,32}$ offers the prospect of obtaining unique collections of glycan standards for the development of new glycomic approaches such as IMS-based glycan identification.

Here, we demonstrate, for the first time, that intrinsic CD fingerprints can be obtained in ion mobility ATDs, which can be applied for glycan identification. We show that $\mathrm{CD}$ fingerprints are unique even for closely related glycans and allow, for example, to differentiate all Neu5Ac linkage-isomers of biantennary $\mathrm{N}$-glycans. Computational studies support the ATDs resemble conformational populations in the gas phase.

Complex $N$-glycans possess multiple flexible glycosidic linkages and as a result can adopt a number of distinct conformations, ${ }^{195}$ which are stabilized in the gas phase by inter-residue H-bonds. ${ }^{196-199}$ The assemble of conformational isomers is influenced by branching, ${ }^{200}$ anomeric configuration and positions of $\mathrm{N}$-acetylglucosamine (GlcNAc), ${ }^{196}$ fucosides (Fuc) and Neu5Ac residues ${ }^{201}$ as well as adduct formation ${ }^{192}$ and charge localization. The latter plays an important role in conformation stabilization and influences CCS value, ${ }^{189,202}$ in particular for small compounds in combination with a polarizable drift gas. ${ }^{203}$ 


\subsection{Experimental}

\subsubsection{Chemicals and reagents}

Fetuin from bovine serum, MS-grade formic acid and acetic acid, ammonium formate, dimethyl sulfoxide (DMSO), 2-aminoanthrallic acid (2-AA), and sodium cyanoborohydride were purchased from Sigma Aldrich Chemie NV (Zwijndrecht, The Netherlands). MS-grade acetonitrile (ACN) was acquired from Biosolve BV (Valkenswaard, The Netherlands), trifluoroacetic acid (TFA) from Argos Organics (Geel, Belgium) and PNGase F from E. coli was acquired from Roche Diagnostics International Ltd. (Basel, Switzerland). Reaction buffers of $1 \%$ NP-40, denaturation buffer $(0.5 \%$ SDS, $40 \mathrm{mM}$ dithiothreitol) and glycobuffer (50 mM Sodium Phosphate) were purchased from New England BioLabs (Ipswich, US). $\mathrm{C}_{18}$ solid phase extraction (SPE) Sep-Pak Vac (1cc) cartridges were obtained from Waters Corporation (Milford, US), porous graphitized carbon SPE Hypercarb Hypersep (1cc) cartridges from Thermo Fisher Scientific (Waltham, US) and PD Minitrap G-10 cartridges from GE Healthcare (Uppsala, Sweden). Ultra-pure water was obtained from a MilliporeSigma Synergy ${ }^{\circledR}$ water purification system (Burlington, US).

\subsubsection{Synthesis of $\boldsymbol{N}$-glycan standards}

To develop the approach, we prepared a range of symmetrical and asymmetrical bi-antennary $\mathrm{N}$-glycans 1-15 (Fig. 1) that often are found on therapeutic glycoproteins such as IgG antibodies. For example, compounds $\mathbf{3}$ and $\mathbf{5}$ are positional isomers in which a galactoside (Gal) is present at the $\alpha 6$ and $\alpha 3$ arm, respectively. Glycans 10-15 differ in the pattern of sialic acid linkage types and have either $\alpha 2,6-(\mathbf{1 0})$ or $\alpha 2,3$-linked (11) bis-sialosides or at one arm an $\alpha 2,3-$ and at the other arm an $\alpha 2,6$-linked sialoside (12 and 13). To investigate the influence of core fucosylation on ATDs, compounds were prepared with $(\mathbf{1 4}, \mathbf{1 5})$ and without this modification $(\mathbf{1 1}, \mathbf{1 0})$.

The synthesis started by treating a sialoglycopeptide (SGP) isolated from eggyolk ${ }^{204}$, 205 with PNGase $\mathrm{F}$ to remove the peptide followed by exposure to a sialidase and galactosidase to provide 1 (Scheme S1, supporting information). Treatment of the latter compound with FUT8 in the presence of GDP-Fuc and 
calf intestine alkaline phosphatase (CIAP) provided core fucosylated 2. Glycans 1 and $\mathbf{2}$ were extended at both arms by a galactosyl moiety to give $\mathbf{6}$ and $\mathbf{7}$, respectively by treatment with B4GalT1 and UDP-Gal. Branch selective extensions of the antennae were accomplished by exploiting the inherent preference of the galactosidase of E. coli and a2,6-sialyltransferase (ST6GAL1) for the 1,3-arm of $N$-glycans followed by further remodeling of the resulting asymmetrical glycans with a panel of glycosyl transferases to provide the target compounds. ${ }^{36}$

\subsection{3 $N$-glycan release and labelling}

Bovine fetuin was used as a model compound to demonstrate the structural assignment of glycans released from proteins. Bovine fetuin $(100 \mu \mathrm{g})$ was dissolved in $75 \mu \mathrm{L}$ of water with $12.5 \mu \mathrm{L}$ of denaturing buffer and heated at $100{ }^{\circ} \mathrm{C}$ for 10 minutes. After cooling to room temperature, $12.5 \mu \mathrm{L}$ of glycobuffer, $12.5 \mu \mathrm{L}$ of NP-40 solution and $2.5 \mathrm{U}$ of PNGase F were added and the mixture was incubated at $37{ }^{\circ} \mathrm{C}$ overnight. After incubation, the sample was first cleaned using a $\mathrm{C}_{18}$ solid phase extraction (SPE) cartridge, eluting the glycans with $1 \mathrm{~mL}$ of $5 \%$ ACN:95\% water with $0.05 \%$ TFA $(\% \mathrm{v} / \mathrm{v})$ and then evaporated under a stream of nitrogen. The residue was dissolved in water and $\mathrm{N}$-glycans were extracted by PGC SPE by first washing retained analytes with 1 $\mathrm{mL}$ of $0.05 \%$ TFA in water, then with $1 \mathrm{~mL} \mathrm{ACN}$ :water 5:95 (\%v/v) containing $0.05 \%$ TFA $(\% \mathrm{v} / \mathrm{v})$ and finally by eluting with $1 \mathrm{~mL}$ of ACN/water $1: 1(\mathrm{v} / \mathrm{v})$ containing $0.1 \%$ TFA. The sample was then evaporated under a stream of nitrogen and labeled by adding $10 \mu \mathrm{L}$ of water and $10 \mu \mathrm{L}$ of the labelling mixture, which contained $50 \mathrm{mg} / \mathrm{mL} 2-\mathrm{AA}$ and $60 \mathrm{mg} / \mathrm{mL}$ of sodium cyanoborohydride in 10:3 (v/v) DMSO/acetic acid solution. The solution was then incubated at $65^{\circ} \mathrm{C}$ for 2 hours. The same labelling procedure was also applied for the synthesized standards. Labeled $N$-glycans were purified by Minitrap G-10 size exclusion SPE by diluting to $100 \mu \mathrm{L}$ with water and then loading onto an equilibrated column. The column was washed with $600 \mu \mathrm{L}$ of water and then compounds were eluted with $600-\mu \mathrm{L}$ volume of water. Collected samples were evaporated under a stream of nitrogen and reconstituted in 30:70 water/ACN $(\% \mathrm{v} / \mathrm{v})$ before analysis. 


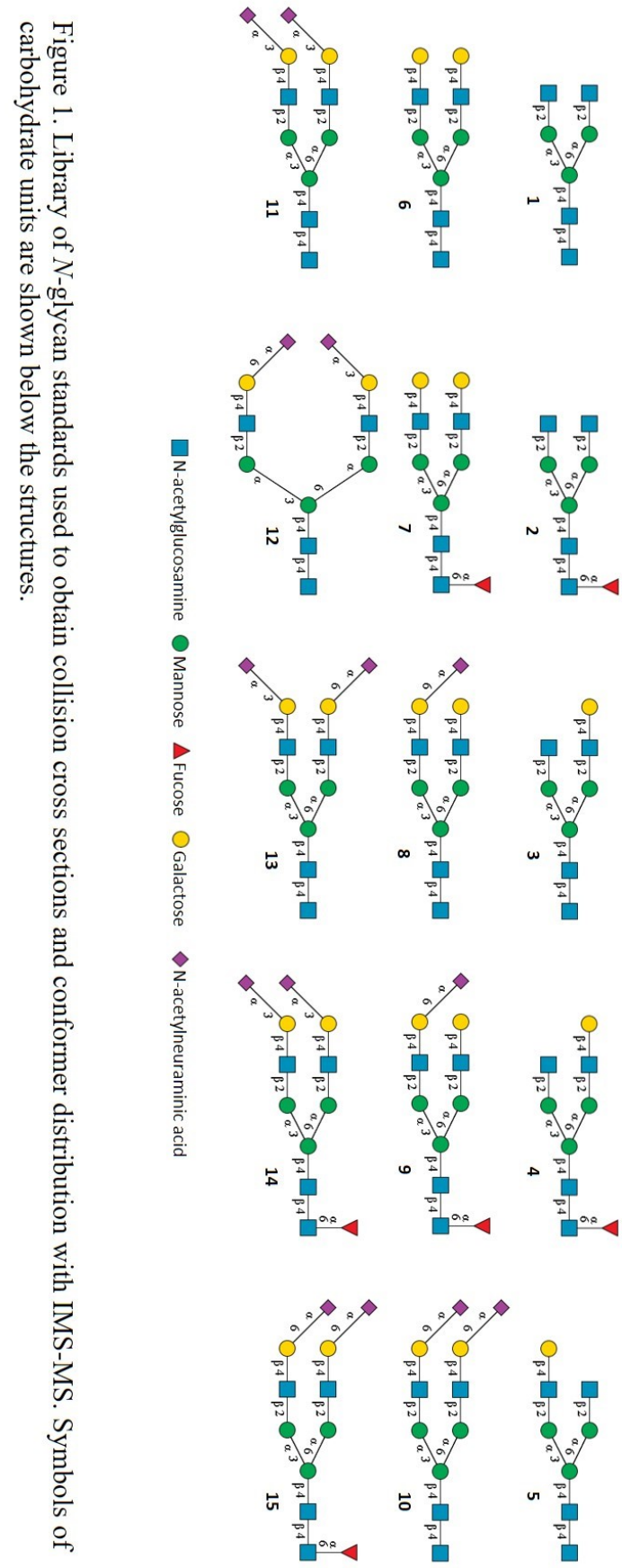




\subsubsection{IMS-QTOF analysis of $\boldsymbol{N}$-glycans}

We used a library of naturally occurring $N$-glycans (Fig. 1), with different number of galactose (Gal) and GclNAc residues on the antennae and analogs decorated with Fuc and Neu5Ac residues, including linkage regioisomers (Fig. 1, 9-12). These structures showed to adopt different, unique and stable conformations that were separated with IMS to obtain intrinsic CD fingerprints in the ATDs or converted CCS distributions (CCSD), which allowed for exact structural identification of $\mathrm{N}$-glycans. Furthermore, a computational approach was developed to obtain CCSDs for unique $N$-glycans structure, allowing for their identification without the need of an extensive collection of synthetic standards.

$\mathrm{N}$-glycan standards, both unlabeled and 2-AA labeled, were analyzed by direct infusion into an IMS-QTOF as well as by HILIC-IMS-QTOF, to obtain CCS values and ATDs. The instrument featured an Agilent 1260 Infinity LC system coupled to a $6560 \mathrm{IM}-\mathrm{QTOF}$ mass spectrometer through a jet stream electrospray ionization interface (Agilent Technologies, Santa Clara. A ZIC-HILIC column $(3 \mu \mathrm{m}, 100 \AA, 150 \mathrm{~mm} \times 2.1 \mathrm{~mm}$ ) with a guard column of $20 \mathrm{~mm} \times 2.1 \mathrm{~mm}$ (Merck Millipore, Darmstadt, Germany), maintained at a temperature of $60^{\circ} \mathrm{C}$, was used for the LC separation. Gradient elution was applied using $50 \mathrm{mM}$ ammonium formate, adjusted to $\mathrm{pH} 4.4$ with formic acid (eluent A) and 100\% ACN (eluent B). The starting composition was $30 \% \mathrm{~A}$, increasing linearly to $50 \% \mathrm{~A}$ in 20 minutes at a flow rate of $0.2 \mathrm{~mL} / \mathrm{min}$. Direct infusion experiments with standards were performed without a column, using the starting eluent composition. IMS separation was performed in the drift tube operated at an entrance voltage of $-1700 \mathrm{~V}$ and exiting voltage of $-250 \mathrm{~V}$, using nitrogen as a drift gas. For stepped field CCS calculation, the drift tube entrance voltages were varied in the -1074- $-1674 \mathrm{~V}$ range with $100 \mathrm{~V}$ increments between steps. Trap funnel pressure was maintained at 3.80 Torr and the drift tube pressure at 3.95 Torr. The maximum drift time was set at $60 \mathrm{~ms}$, using a trapping time of $20000 \mu$ s and a release time of $150 \mu$ s. Trapping funnel RF and rear funnel RF were set at $150 \mathrm{~V}$. The MS settings were a drying gas temperature of $300^{\circ} \mathrm{C}$ at a flow rate of $8 \mathrm{~L} / \mathrm{min}$, a nebulizer pressure of $40 \mathrm{psi}$, a sheath gas flow of $11 \mathrm{~L} / \mathrm{min}$ at a temperature of $350{ }^{\circ} \mathrm{C}$ and a capillary voltage of $3500 \mathrm{~V}$. 


\subsubsection{Data treatment}

Post-run mass calibration of the data was performed with the IMS-MS reprocessor software (Agilent Technologies) and multidimensional smoothing (3 points) was performed with the PNNL PreProcessor software (Pacific Nortwest National Laboratory, US). CCS single field and multi-field calibration were performed with Mass Hunter IM-MS software (Agilent Technologies). To search for glycan structures, the feature finding option of the IM-MS browser was used, using the glycan mode as isotope model, limiting charge states to 5 and ion intensities to $\geq 50$. In this way, glycan CCS values were automatically calculated by the software. Experimental glycan masses were assigned to possible compositions with the online GlycoMod software.

\subsection{Results and discussion}

\subsubsection{CCS values for glycan identification}

The synthetic glycan standards and bovine fetuin released $\mathrm{N}$-glycans were labeled with 2 -aminobenzoic acid (2-AA), ${ }^{13}$ separated by hydrophilic liquid interaction chromatography (HILIC) and the electrospray generated ions were measured with low-field drift tube IMS in nitrogen drift gas coupled to quadrupole time-of-flight MS/MS for accurate CD and CCS determination. ${ }^{206}$ Negative ion mode was used because previously it was shown that in this fashion IMS has better resolving ability. ${ }^{186}$ The labeled glycans were diluted until no concentration-dependent changes were observed in the ATDs to ensure the peak shapes were due to conformational properties of the glycans. IMS separation variables were kept constant, including the applied voltage, drift gas pressures and temperature.

The ATDs showed predominantly $[\mathrm{M}-\mathrm{H}]^{-}$ions for the smallest glycans lacking sialosides, $[\mathrm{M}-2 \mathrm{H}]^{2-}$ ions for the larger and mono-sialylated glycans and $[\mathrm{M}-3 \mathrm{H}]^{3-}$ ions for the di-sialylated glycans (Fig. 2). These results indicate that the glycans have lost protons at the acidic moieties of the sialosides and the 2-AA tag. Core fucosylated glycans $(\mathbf{2}, 4,7,9,14$ and $\mathbf{1 5})$ do not only have larger CCS values compared to their non-fucosylated counterparts $(\mathbf{1}, \mathbf{5}, \mathbf{6}, \mathbf{8}, \mathbf{1 0}$ and 11), but also 
appear at the upper level in the CCS- $m / z$ plot, following a somewhat different CCS- $m / z$ trend line compared to the other glycan classes. ${ }^{207}$ Sialylated $N$-glycans also followed a slightly different CCS- $m / z$ trend line compared to the non sialylated $\mathrm{N}$-glycans, probably due to differences in preferred conformations and flexibility of the antennae. ${ }^{201}$ It was also observed that the presence of a core Fuc and terminal Neu5Ac residues alter the CDs. ${ }^{196}$ The CCS values of specific classes of $\mathrm{N}$-glycans (e.g. fucosylated, sialylated etc.) clustered together and only differ marginally.

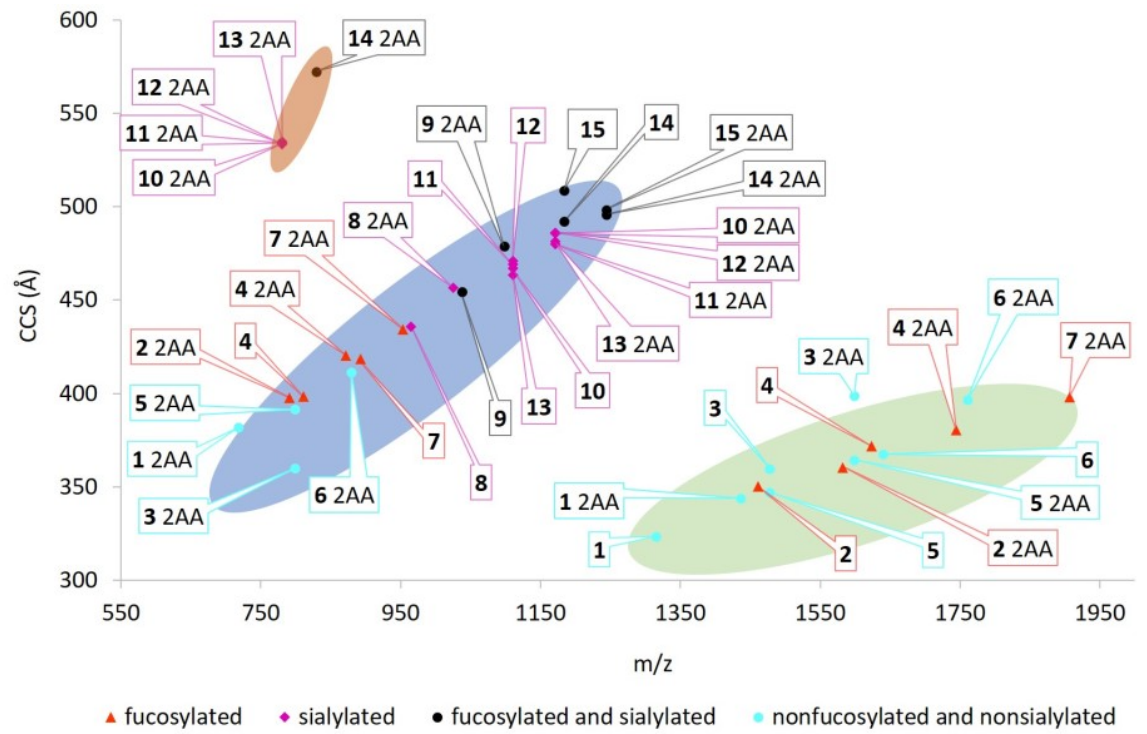

Figure 2. Conformational space plot of free and labeled (2-AA) $N$-glycan standards as $[\mathrm{M}-\mathrm{H}]$ (green marked area), $[\mathrm{M}-2 \mathrm{H}]^{2-}$ (blue marked area) and [M-3H $]^{3-}$ ions (orange marked area). Several standards showed multiple conformers at identical $\mathrm{m} / \mathrm{z}$ values, in particular the fucosylated and sialylated glycan standards, although in this figure only the CCS values from the most intense signals are visualized. 


\subsubsection{ATDs for glycan identification}

The labeled glycans exhibited distinctive ATDs (Fig. 3), which were independent of the solvent used for the analysis. These were multimodal or showed partly coinciding signals probably arising from several stable conformers having different CCS values and different peak intensities, thereby creating a unique molecular fingerprint. To confirm the presence of different conformers, ATDs were acquired using increased trapping funnel radiofrequency, which results in ion heating. Only changes in peak intensities were observed, supporting the ATD signals correspond to different CDs. It cannot be excluded that the shape of the ATDs arises from different deprotomers. However, in negative ion mode MS, charges are predominantly positioned at the acidic residues of sialic acid and 2-AA. Glycans have additional sites that can be deprotonated, however, the resulting anions are not static and acidic protons at other sites can migrate fast towards the negative charge, creating charges on multiple sites within the IMS separation time. Therefore, the ATD reflects averaged conformations that closely resemble that of an uncharged glycan. ${ }^{192}$ Thus, the charge locations on glycans, other than on the sialic acids and 2-AA tag, is expected to have a minor influence on the ATD.
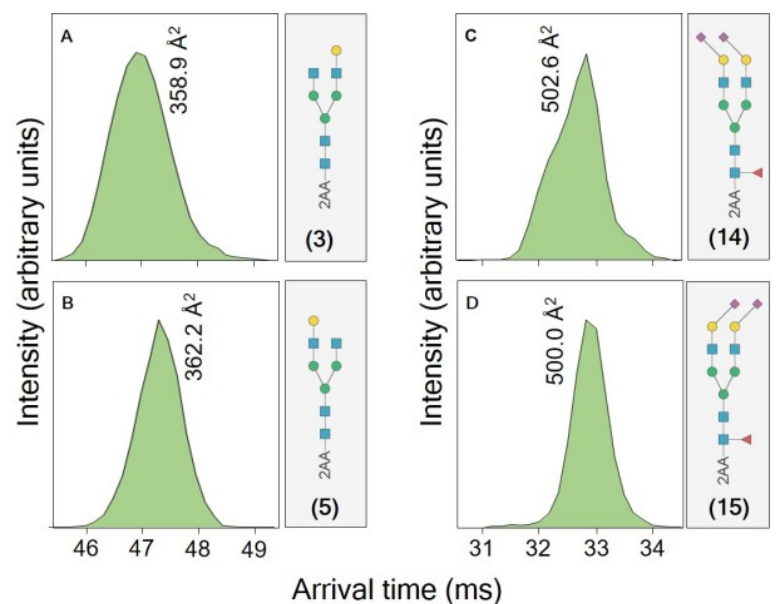

Figure 3. Arrival time distribution fingerprints and collision cross section values of 2-AA labeled $N$-glycans as $[\mathrm{M}-2 \mathrm{H}]^{2-}$ ions at $m / z 717.67$ (A), $m / z 1025.36$ (B) and $m / z 1098.39$ (C) and $m / z 1170.91$ (D). 
ATDs and CCS values (Fig. S1-S15) of each glycan were repeatable with relative standard deviations (RSDs) of $0.05-0.25 \%$ for intraday $(n=3)$ and interday CCS values $(n=3)$, using both single- and stepped-field approaches. These RSDs are in accordance with values obtained in inter-laboratory studies for other classes of molecules ${ }^{206}$ and allow for the unique intrinsic ATDs to be used, in combination with CCS and $\mathrm{m} / \mathrm{z}$ values, for unambiguous glycan identification. Additionally, the ATDs can be converted to CCS distributions ${ }^{208}$ to compare fingerprints obtained with different instruments or different separation parameters.

The ATDs can be employed to identify isomeric glycans. For example, compounds 3 and $\mathbf{5}$, which have the same $\mathrm{m} / z$ but differ in the position of Gal, have very close CCS values at the peak apex (Fig. 4). The ATDs, however, are distinctive and a broader $\mathrm{CD}$ was observed for the derivative having $\mathrm{Gal}$ on the more flexible $\alpha 6$-arm (3; Fig. 4A, B).
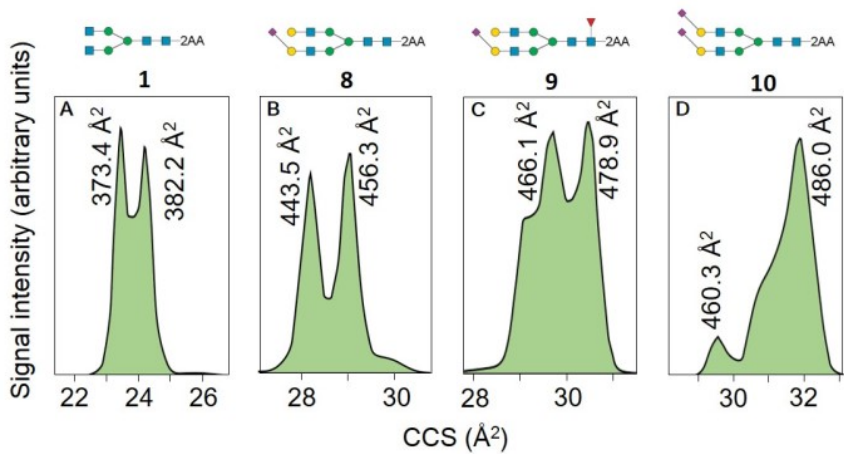

Figure 4. Arrival time distribution fingerprints and collision cross section values of 2-AA labeled $N$-glycan standards as [M-H] ions at $m / z 1598.58$ (A and B) and [M-2H $]^{2-}$ ions at $m / z 1243.94$ (C and D).

Compounds 10-13 are isomers having sialic acid residues linked to Gal in $\alpha 2,3-$ or $\alpha 2,6$-fashion covering - possible natural configurations. Their CCS values at the peak apex (Fig. 2) are very close and the $m / z$ values identical. However, the ATDs of the glycan standards as $[\mathrm{M}-2 \mathrm{H}]^{2-}$ and $[\mathrm{M}-3 \mathrm{H}]^{3-}$ ions (Fig. 5, marked in blue) are distinctive and can be employed to distinguish the various isomers without a need for demanding MS/MS fragmentation experiments. These differences likely arise from differences in conformational properties of $\alpha 2,3-$ 
and $\alpha 2,6$-linked sialosides. ${ }^{209}$ The isomers $\mathbf{1 4}$ and $\mathbf{1 5}$, which have an additional core Fuc, have close CCS values but can also be differentiated based on ATDs (Fig. 4C,D). Interestingly, the CD of these compounds differ substantially from glycans 10 and 11 (Fig. 5), lacking the core Fuc, indicating the latter functionality exerts conformational control. Indeed, a previous study has shown that a core Fuc changes specific inter-residue hydrogen bonds thereby altering conformational properties. $^{210}$
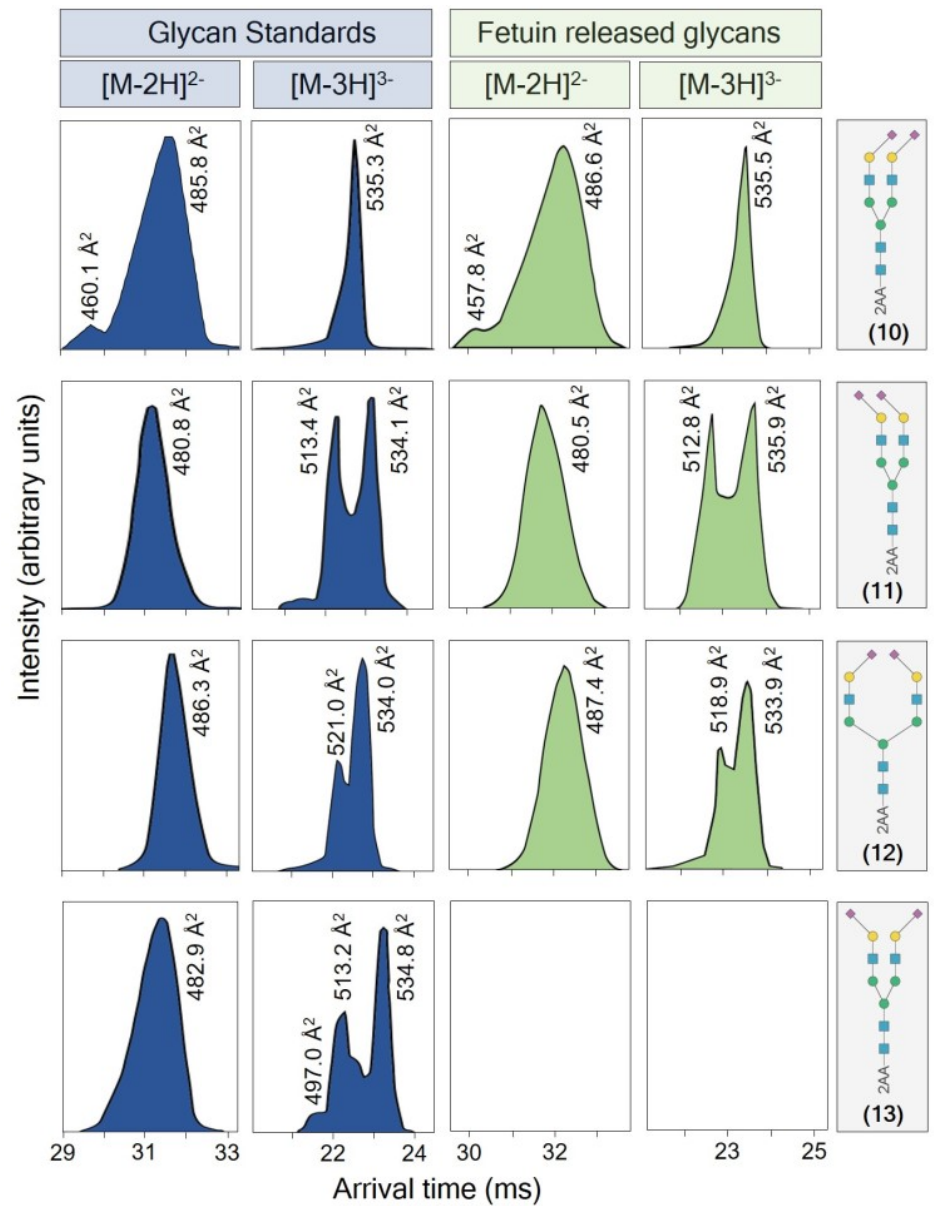

Figure 5. Arrival time/conformer distribution fingerprints as $[\mathrm{M}-2 \mathrm{H}]^{2-}$ and $[\mathrm{M}-3 \mathrm{H}]^{3-}$ ions of intact 2-AA labeled $\mathrm{N}$-glycans released from bovine fetuin (marked in green) and matching regioisomeric standards 10-13 (marked in blue), obtained with IMS-MS. 
To demonstrate the applicability of the approach for analysis of protein glycosylation, glycans released from bovine fetuin and labeled with 2-AA were analyzed by IMS-MS and the results were compared with the ATDs and CCS values of the glycan standards (Fig. S1 17). A total of 135 released $N$-glycans were detected (Table S1). The ATDs of released glycans matched with ATDs of the glycan standards with an average deviation between CCS values at the peak apex of $0.27 \%$ (Fig. S118-128). Retention times of the HILIC separated standards and the protein released glycans, assigned by ATD, matched for all compounds, confirming the assignment through ATDs and CCS values is correct.

The presence of the regioisomeric glycans 10-12 in bovine fetuin was confirmed by comparing their ATD fingerprint (Fig. 5, marked in green) with the ATDs of standards (Fig. 5, marked in blue). Compounds $\mathbf{1 2}$ and $\mathbf{1 3}$ have identical retention times in HILIC and identical $\mathrm{m} / \mathrm{z}$ values. The ATDs, however, are different and sufficiently characteristic to distinguish the compounds and to assign the exact structure of a fetuin released glycan as compound $\mathbf{1 2}$ and to exclude the presence of 13. Standard $\mathbf{1 1}$ and $\mathbf{1 3}$ are distinguished from the other isomers by a small difference in CCS values $\left(2.1 \AA^{2}\right)$ of the $[\mathrm{M}-2 \mathrm{H}]^{2-}$ ion cluster and a different ATD (Fig. 5). The difference in CCS values for the $[\mathrm{M}-3 \mathrm{H}]^{3-}$ ions is even smaller $\left(0.2\right.$ and $\left.0.7 \AA^{2}\right)$, but here again the clear difference in ATDs was used for exact structure assignment. Standards $\mathbf{1 0}$ and $\mathbf{1 2}$ also show similar CCS values $\left(0.5 \AA^{2}\right.$ difference for $[\mathrm{M}-2 \mathrm{H}]^{2-}$ and $1.3 \AA^{2}$ for $[\mathrm{M}-3 \mathrm{H}]^{3-}$ ions $)$ and ATD fingerprints were used to assign the correct structures.

We explored the possibility to obtain CCS distributions by a computational method. Isomeric unlabeled glycans $\mathbf{1 0}$ and 11, which are modified by $\alpha(2,6)-$ and $\alpha(2,3)$-linked sialosides, respectively were used as models. Firstly, lowenergy conformers for both derivatives were generated using a carbohydrate builder, ${ }^{211}$ which were subjected to $5 \mu$ sD simulations in vacuo. In this way, it is possible to circumvent the limitations of current force fields that in general fail to sample the conformational landscape due to high-energy barriers between conformers in vacuo. All MD simulations were performed using AMBER 18, ${ }^{212}$ which was implemented with the general amber force field (GAFF2) to accurately reproduce the conformational behavior of the glycans in the gas phase. ${ }^{213,} 214$ Up to 10000 frames were collected at regular intervals for each trajectory and high performance collision cross section (HPCCS) software ${ }^{215}$ was used to calculate their CCS values. For each glycan, all ensembles derived from 
the different initial MD simulations were scored, and the contribution of each ensemble to the $\mathrm{CD}$ and CCS values were scaled according to the relative energy at $25^{\circ} \mathrm{C}$ of the starting structure used in the MD simulations. Fig. $6 \mathrm{E}-6 \mathrm{~F}$ shows the resulting structural ensembles which have folded conformations to maximize the intramolecular hydrogen bonds. Gratifyingly, the shapes of the computed CDs (Fig 6, marked in blue) fit experimentally determined conformer clusters (Fig. 6, marked in green). Computed CCS values at the peak apex in the CDs are 511.5 and $537.4 \AA^{2}$ for $\mathbf{1 0}$ and $522.1 \AA^{2}$ for $\mathbf{1 1}$ of the experimental values. The deviations from the experimental values are probably caused by variance in computation, but can also be due to biased mobility measurements. ${ }^{216}$

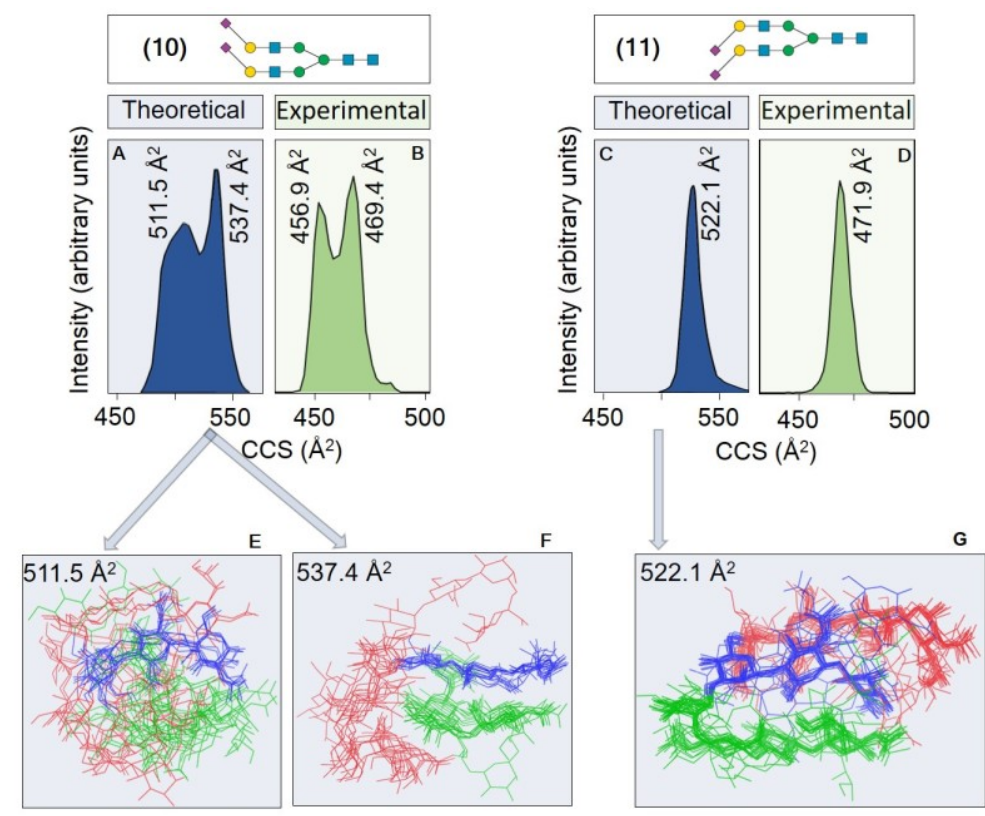

Figure 6. Theoretical CDs (A and C; marked in blue) and experimental CDs (B and D; marked in green) for the unlabeled isomers $\mathbf{1 0}$ and $\mathbf{1 1}$ as $[\mathrm{M}-2 \mathrm{H}]^{2-}$ ions. Overlay of conformational ensembles derived from MD simulations of $\mathbf{1 0}(\mathrm{E}$ and $\mathrm{F})$ and $\mathbf{1 1}(\mathrm{G})$, at CCS values that correspond to the peak apex in the CDs. Each set of structures, evenly spaced along the trajectory, have been aligned to the trisaccharide Man $\beta(1,4)$ GlcNAc $\beta(1,4)$ GlcNAc (depicted in blue). The upper branch (Man $\alpha(1,6)$ Man) is depicted in red, the lower branch (Man $\alpha(1,3)$ Man) in green. 


\subsection{Conclusion}

We have shown that assembles of glycan gas phase conformations can be resolved by IMS to obtain intrinsic CD fingerprints in the ATDs that can be exploited for the identification of isomeric $N$-glycans. The approach is facilitated by the emergence of high-resolution IMS instrumentation ${ }^{30,190}$ that makes it possible to resolve such conformers. The power of the approach was demonstrated by identifying all Neu5Ac linkage-isomers of biantennary $\mathrm{N}$-glycans. The results highlight that a database of CD fingerprints will facilitate fast identification of protein released $\mathrm{N}$-glycans, including isomers, without the need for demanding MS/MS experiments.

During the past few years, facile methods for the chemoenzymatic synthesis of highly complex glycans have become available. ${ }^{36}$ Furthermore, automation platforms have been introduced that can further speed up the preparation of these compounds. ${ }^{35}$ Thus, it is now possible to prepare sufficiently large collections of compounds for IMS-MS data base development. Unknown $N$-glycans that are not incorporated in a database, can be identified by MS/MS experiments in combination with IMS of fragment ions, ${ }^{158}$ when synthesis of possible structure candidates is not an option. In addition, we developed an approach to compute CCSDs for $\mathrm{N}$-glycan identification, and such an approach can also contribute to database development. 



\section{IMS can assign exact fucosyl position in glycans and prevent misinterpretation of MS data after gas-phase rearrangement}

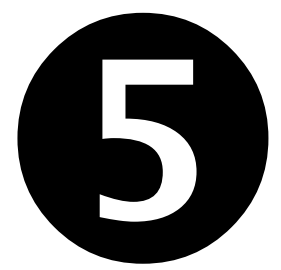

J. Sastre Toraño, I. A. Gagarinov, G. M. Vos, F. Broszeit, A. D. Srivastava, M. Palmer, J. I. Langridge, O. Aizpurua-Olaizola, V. J. Somovilla, G. J. Boons, Angewandte Chemie, International Edition, 58 (2019) 17616-17620. 


\section{IMS can assign exact fucosyl position in glycans and prevent misinterpretation of MS data after gas-phase}

rearrangement

\subsection{Introduction}

Glycosylation is the structurally most complex posttranslational modification of proteins and it plays key roles in many biological and disease processes. ${ }^{2}$ To understand these processes on a molecular level, an accurate analysis of glycan structures is essential. ${ }^{217}$ Current analytical methods generally entail glycan release, derivatization and purification, followed by chromatographic separation and matrix-assisted laser desorption/ionization (MALDI), or electrospray ionization (ESI) mass spectrometry (MS). ${ }^{8}$ Accurate mass measurement can provide glycan compositions, whereas sequence and linkage positions, which are more difficult to elucidate given the complexity and diversity of glycans, can be probed through tandem mass spectrometry (MS/MS) experiments. ${ }^{218}$

Most MS experiments are performed in positive ion mode, which leads to glycosidic bond cleavage and yields MS/MS spectra with B- and Y-type fragment ions (Fig. 1) facilitating structural assignment. ${ }^{219}$ Structure determination can, however, be erroneous due to molecular rearrangements of intact ${ }^{220}$ and fragmented ${ }^{221}$ protonated glycans. Usually, such rearrangements involve residues with rather labile glycosidic linkages such as fucosides ${ }^{222}$ that can migrate to an anomeric tag, ${ }^{223}$ sialic acid residues ${ }^{224}$ and between $N$-glycan antennae. ${ }^{225}$ The mechanism of fucosyl rearrangement is difficult to clarify by MS/MS and proposed fucose locations are mainly based on hypothetical models and theoretical calculations. ${ }^{223,226,227}$

In humans, the structural diversity of fucosylated glycans arises from thirteen fucosyl transferases that, in concert with other glycosyl transferases, create a wide variety of glycan epitopes. Fucosylated epitopes mediate many physiological and disease processes such as leukocyte adhesion during inflammation, ${ }^{228}$ 
fertilization, ${ }^{229}$ tissue development ${ }^{230-233}$ and tumor metastasis. ${ }^{234,} 235$ Therefore, determination of exact fucoside positions and affirmation of rearrangements are critical for the application of glycans as clinical biomarkers and to understand their biological roles at a molecular level.

Here, we report a general approach to determine the exact positions of fucosyl residues in structurally complex glycans based on the combined use of ionmobility spectrometry (IMS)-MS and well-defined oligosaccharide standards. IMS can separate gas-phase ions based on their mobility through a buffer gas under the influence of a weak electric field, resulting in different ion arrival times at the end of the mobility cell. IMS arrival time distributions (ATD), which can be used to derive collision cross sections (CCS) values of ions, depend on the charge, size and shape of the ions, making IMS very suitable for the separation of different ion isomers and conformers. ${ }^{28}$ We anticipated that fucosyl migration would yield isomeric fragment ions that can be distinguished by their ATD in IMS. ${ }^{27,} 183$ Furthermore, we expected that MS/MS of well-defined oligosaccharides with fucosyl residues at different but clearly defined sites (1-11, Fig 1B-D), would reveal positions to which fucose can migrate (Fig. 1C). This study provides mechanistic insight into fucosyl rearrangement and it is shown that migration occurs only to nucleophilic amides and amines of GlcNAc, Neu5Ac and anomeric tags. This information will make it possible to determine ATDs of fragments having native and rearranged fucosyl residues.

\subsection{Experimental}

\subsubsection{Chemicals and reagents}

MS-grade acetic acid, dimethyl sulfoxide (DMSO), 2-aminobenzamide (2-AB), and sodium cyanoborohydride were purchased from Sigma-Aldrich Chemie NV (Zwijndrecht, The Netherlands). MS-grade acetonitrile (ACN) was acquired from Biosolve BV (Valkenswaard, The Netherlands), trifluoroacetic acid (TFA) from Argos Organics (Geel, Belgium), and porous graphitized carbon (PGC) solidphase extraction (SPE) Hypercarb Hypersep (1cc) cartridges from Thermo Fisher Scientific (Waltham, US). Ultra-pure water was obtained from a Millipore Sigma Synergy ${ }^{\circledR}$ water purification system (Burlington, US). 


\subsection{2 $\mathrm{N}$-glycan labelling}

Glycan standards were dissolved in $10 \mu \mathrm{L}$ water, labeled by adding $10 \mu \mathrm{L}$ of the labelling mixture containing $50 \mathrm{mg} / \mathrm{mL} 2-\mathrm{AB}$ and $60 \mathrm{mg} / \mathrm{mL}$ of sodium cyanoborohydride in $10: 3(\mathrm{v} / \mathrm{v}) \mathrm{DMSO} /$ acetic acid and incubation at $65^{\circ} \mathrm{C}$ for 2 hours. Labeled $N$-glycans were purified by diluting the sample to $1 \mathrm{ml}$ with water and performing PGC SPE by first washing retained analytes with $1 \mathrm{ml}$ of $0.05 \%$ TFA in water, then with $1 \mathrm{ml} \mathrm{ACN}$ :water 5:95 (\%v/v) containing $0.05 \%$ TFA $(\% \mathrm{v} / \mathrm{v})$ and finally by eluting with $1 \mathrm{ml}$ of $\mathrm{ACN} / \mathrm{H}_{2} \mathrm{O} 1: 1(\mathrm{v} / \mathrm{v})$ containing $0.1 \% \mathrm{TFA}(\% \mathrm{v} / \mathrm{v})$. Collected samples were evaporated under a stream of nitrogen and reconstituted in $0.1 \%$ formic acid/acetonitrile $1 / 4(\mathrm{v} / \mathrm{v} \%)$ before analysis.

A library of well-defined glycan compounds was used to elucidate the fucose rearrangement location with MS and to visualize fragments with migrated fucose residues with IMS. The library (Fig. 1) consisted of complex $\mathrm{N}$-glycans, fucosylated trisaccharide and several sialosyl-fucosyl oligo- $N$-acetyllactosamines standards (S-F oligo-LacNAcs), as part of naturally occurring polysaccharides. All standards were labeled at the reducing end with $2-\mathrm{AB}$, unless otherwise specified.

\subsubsection{IMS-QTOF analysis of glycan standards}

Standards (Fig. 1) were analyzed on an Agilent 6560 drift tube IMS (DTIMS)quadrupole time-off-flight (Q-TOF) MS instrument (Agilent Technologies, Santa Clara, CA, US). The system featured ESI to produce positive ions which were introduced in the drift tube filled with nitrogen gas for DTIMS. After DTIMS separation (with a resolution of $\sim 60 \Omega / \Delta \Omega$ ), selected ions were fragmented in the collision cell through collision induced dissociation (CID) to obtain detailed structural information. In addition to CID, fragment ions of S-F oligo-LacNAcs were also obtained from in-source dissociation to obtain high-resolution ATDs of fragment ions. 


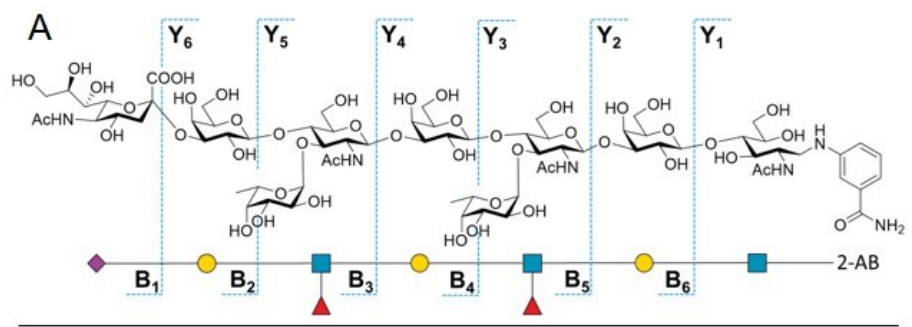

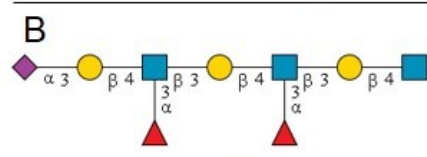

1

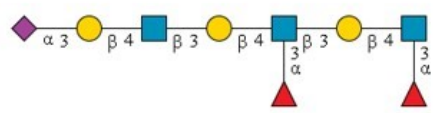

3

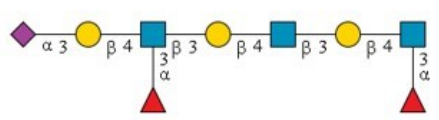

5

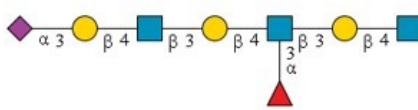

2

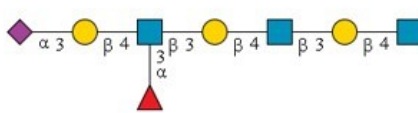

4

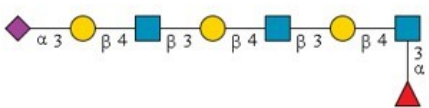

6

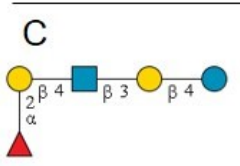

7

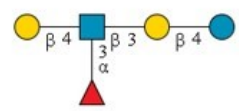

8

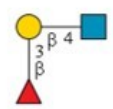

9

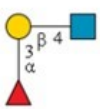

10

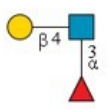

11
$\mathrm{N}$-acetylglucosamine

Glucose $\triangle$ Fucose

$\mathrm{N}$-acetylneuraminic acid

Galactose

Figure 1. Library of oligosaccharide standards used for establishing fucosyl rearrangements in glycans with IMS-MS. (A) Structure of sialosyl-fucosyl oligo- $N$-acetyllactosamine with $\alpha 1,3$ linked fucose on the central and terminal $N$-acetylglucosamines. The compound is derivatized with 2 -aminobenzamide (2-AB) at the reducing end. Symbols of the carbohydrate units are explained at the bottom. Annotation of fragment ions (B- and Y-type) according to the commonly used nomenclature, with the exception that only fragments of the sialosyl oligo-LacNac chain are annotated, without taking into account fucosyl residues, in order to have a uniform annotation between the various sialosyl-fucosyl oligo- $N$-acetyllactosamine compounds. (B) Sialosyl-fucosyl oligo- $N$-acetyllactosamine standards. (C) Fragment standards of sialosylfucosyl oligo- $N$-acetyllactosamines. 
As in-source fragmentation of larger glycans is more complicated, biantennary $\mathrm{N}$-glycan standards, containing either antennae or core fucosylation, were analyzed with travelling wave IMS (TWIMS)-MS on a Select Series cyclic IMS (cIMS; Waters, Milford, US), which has the geometry ESI-Q-cIMS-TOF. The observed IMS resolution scales with the square root of the number of passes of the cIM, with the system also containing a pre-IMS CID cell, allowing for arrival time measurement of fragment ions from complex glycans. Precursor ions were selected in the quadrupole, fragmented in the trap collision cell, the resulting fragment ions were subjected to 3 passes of the cIM (which corresponds to an IMS resolution of $\sim 110 \Omega / \Delta \Omega$ ) and ions mass measured in the TOF.

\subsection{Results and discussion}

To identify products formed during gas-phase fucosyl rearrangement, labeled oligosaccharide standards 1-6 $6^{236}$ (Fig.1B) were fragmented by MS/MS using lowenergy collision induced dissociation (CID)/MS. What makes these standards attractive is that they have the same linear tri-LacNAc backbone, modified by different but well-defined patterns of fucosylation, making it possible to unambiguously assign fragment ions arising from the parent compound and fucosyl migration. Furthermore, compounds 1-6 are important constituents of $\mathrm{N}$ - and $\mathrm{O}$-glycans as well as glycolipids and contain $\mathrm{N}$-acetyl neuraminic acid (Neu5Ac) residues to which fucosyl can migrate.

\subsubsection{Determination of fucoside migration positions with MS/MS}

The fragmentation spectra of the protonated standards, $[\mathrm{M}+\mathrm{H}]^{+} \mathbf{1 - 6}$ showed several B- and Y-ions derived from the parent compound, but also fragment ions arising from intramolecular fucosyl migration. For example, the spectrum of compound 1, which has fucosides at the middle and terminal $N$-acetylglucosamine (GlcNAc) residue (Fig. 1A and 1B), showed fucosyl residues on $\mathrm{Y}_{1}, \mathrm{Y}_{2}$ and $\mathrm{Y}_{4}$ fragment ions (Fig. 2) and even two fucosyl residues on an $\mathrm{Y}_{2}$ ion (Fig. 2). However, no more fucosyl residues than were originally present were observed in the MS/MS spectra, excluding intermolecular migrations. 


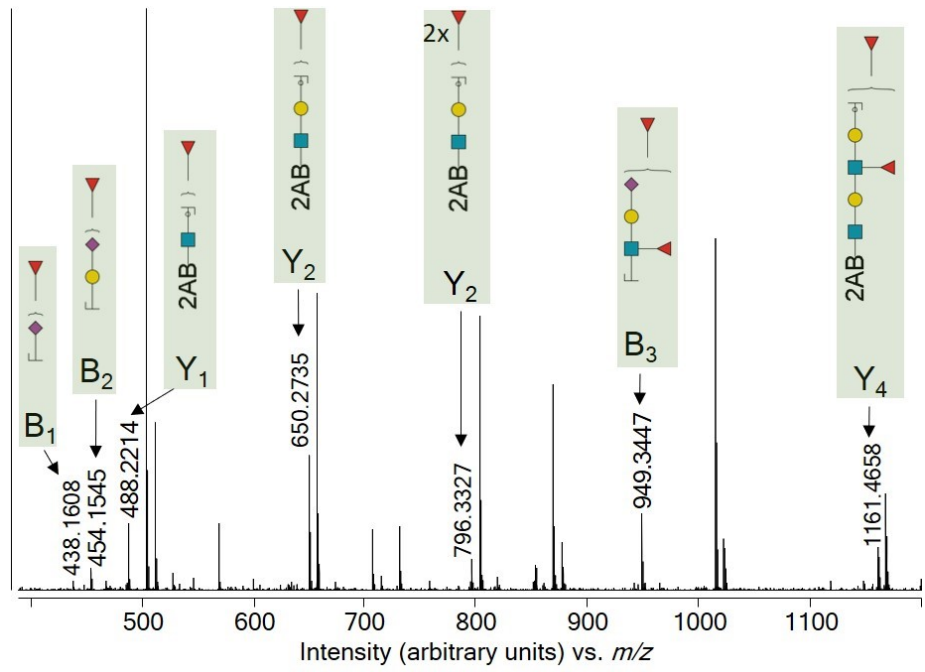

Figure 2. MS/MS of singly charged $[\mathrm{M}+\mathrm{H}]^{+}$2-AB labeled sialosyl-difucosyl-oligo- $N$-acetyl lactosamine with fucosides on the middle and terminal $N$-acetylglucosamine (compound 1, Fig. 1B) at $\mathrm{m} / \mathrm{z}$ 1817.69. Several fragment ions originating from fucosyl rearrangements (highlighted in green) were detected.

Fucosides were also observed on $\mathrm{B}_{1}, \mathrm{~B}_{2}$ and $\mathrm{B}_{3}$ ions (Fig. 2) demonstrating migration to Neu5Ac, which previously was proposed to involve an anhydrofucosyl intermediate migrating to the acetamido moiety of sialic acid. ${ }^{224}$ This functional group is also present on GlcNAc, and therefore we expect a similar migration will occur to this residue. To confirm this mode of rearrangement, Y4-like standards 7 and $\mathbf{8}$ (Fig. 1C) which have a benzyl at the anomeric center, were analyzed by CID/MS. Upon fragmentation of compound $\mathbf{8}$, which has a lactose moiety at the reducing end, no fucosyl rearrangement was observed towards the reducing end or other carbohydrate moieties, even at a high activation energy, indicating that fucosides do not migrate to hydroxyls, although this was previously proposed as a possible mode of rearrangement. ${ }^{227}$ On the contrary, when a similar experiment was performed with compound 7 , which has a GlcNAc without a native fucosyl residue (Fig. 1C), a fucosyl residue was observed on the $\mathrm{B}_{2} / \mathrm{Y}_{3}$ ion (GlcNAc), supporting migration to acetamido residues. Furthermore, when the anomeric benzyl tag of compound 7 was replaced by 2-AB, additional $Y_{1}, Y_{2}$ and $Y_{3}$ fragment ions were observed, which could only 
be assigned to migration to this tag. ${ }^{219}$ Based on these observations, we conclude that proton mediated fucosyl rearrangement results in compounds that are modified at one of the somewhat nucleophilic amide moieties (Fig. 3). Additionally, migration to the secondary amine of reductive aminated glycans is possible, ${ }^{223}$ as demonstrated by the analysis of standard 7 modified by an aniline tag. These intramolecular rearrangements can occur stepwise, which provides a rationale for two migrated fucosyl residues on some of the $\mathrm{Y}_{2}$ fragment ions.

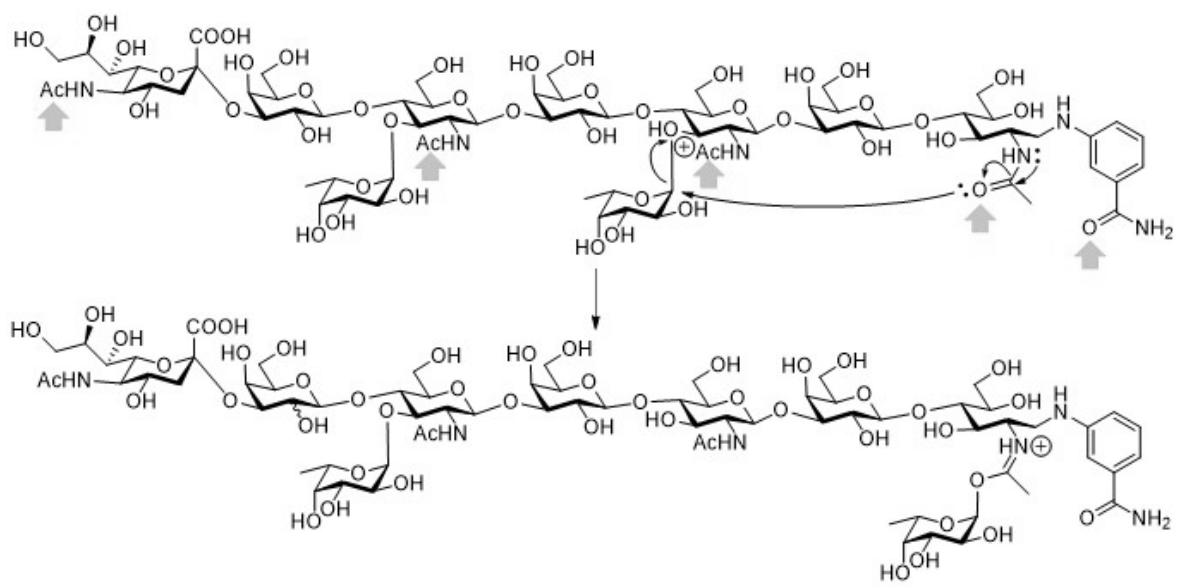

Figure 3. Proposed mechanism for proton mediated fucose migration to the 2-AB tag as well as Neu5Ac and GlcNAc residues in sialosyl-fucosyl oligo- $N$-acetyl lactosamine. Fucosyl residues may rearrange to both oxygen as well as nitrogen of acetamido moieties although oxygen is more nucleophilic. ${ }^{237}$ Furthermore, the rearrangement as shown for the first GlcNAc residue can also occur at other migration locations (marked with arrows).

\subsubsection{Identification of MS/MS fragments with IMS}

Fucosyl migration to different positions of an oligo-LacNAc backbone will yield several positional isomeric fragment ions, and we anticipated that these can be resolved by IMS. ${ }^{238,239}$ Thus, fragments arising from glycans 1-6, which have a native 1,3-linked as well as migrated fucosyl residues, were examined with drift tube IMS (DTIMS, with a resolution of $\sim 60 \Omega / \Delta \Omega$ ) after in-source fragmentation to obtain linkage-specific ATDs. The ATDs of $\mathrm{Y}_{2}$ ions, which have native linked fucoside on GlcNAc, showed a single peak (Fig. 4B), while the ATDs of the isomeric $\mathrm{Y}_{2}$ ions with rearranged fucose exhibited several peaks (Fig. 4C) that 
belong to isomers with this residue on either the acetamido moiety of a GlcNAc moiety or the 2-AB tag. Differences in ATDs between fragments having native and rearranged fucosyl residues were observed on Y-type ions as well as on other fragments, such as $\mathrm{B}_{3}$ ions (Fig. 5), allowing discrimination of these fragment ions by DTIMS.

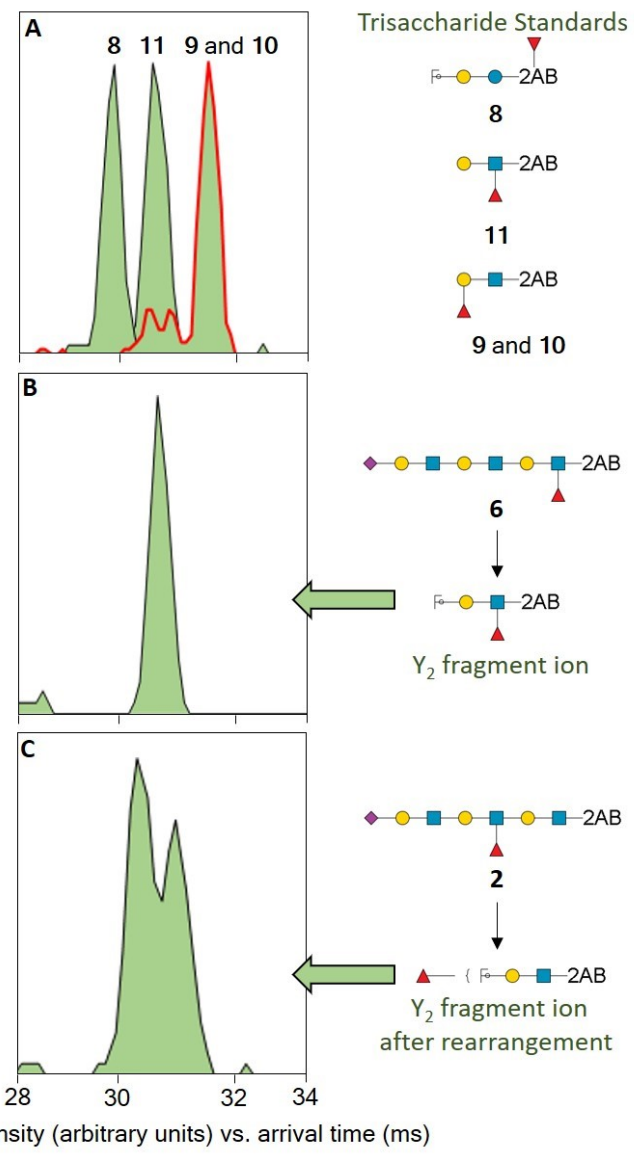

Figure 4. Intensity normalized DTIMS ATDs of $Y_{2}$ fragment ions with native or rearranged fucosides, and $\mathrm{Y}_{2}$-like standards with differently linked fucosides. (A) ATDs with separated peaks of 2-AB fucosylated lactose (obtained from 8 at $\mathrm{m} / \mathrm{z} 609.248$ ) and acetyllactosamines with differently linked fucosides (standards $\mathbf{9 ,} \mathbf{1 0}$ and 11 at $m / z$ 650.279); (B) ATD of an $\mathrm{Y}_{2}$ fragment ion (at $m / z$ 650.277) from insource fragmentation of standard $\mathbf{6}$, showing one peak for a fragment with a native fucoside. (C) $\mathrm{Y}_{2}$ fragment ion (at $m / z$ 650.2788) after in-source fragmentation of standard 2, showing 2 peaks for a fragment with rearranged fucoside. ATDs from standards in panel A were used to identify the peaks in figure $\mathrm{B}$ and $\mathrm{C}$.

To assign the peaks in the ATDs to specific glycan structures and further evaluate previously reported rearrangement mechanisms, three fucosylated trisaccharide standards (compounds 9-11, Fig. 1) were analyzed by DTIMS. The ATD of 11, having an $\alpha 1,3$ linked fucoside at GlcNAc (Fig. 4A, 11), exhibited an identical profile as those of an $\mathrm{Y}_{2}$ fragment ion having native linked fucoside (Fig. 4B, 6), 
confirming the $\mathrm{Y}_{2}$ fragment ion identity. The ATDs of standards $\mathbf{9}$ and $\mathbf{1 0}$, which have fucoside linked $\alpha$ - or $\beta(1,3)$ to Gal, showed a major peak (Fig. 4A, 9 and 10), which is absent in the ATD of the oligo-LacNAc standards with a rearranged fucose residue (Fig. 4C), excluding fucosyl rearrangement to the cleaved glycosidic linkage side (C-3 on $\mathrm{Gal}$ ), which was previously proposed as a mode of migration. ${ }^{226}$ Standards 9 and $\mathbf{1 0}$ (Fig.1) however, exhibited two additional signals that match the arrival times of fragments having rearranged fucose residues (Fig. 4C), confirming that rearrangements not only occur in MS upon fragmentation but also in intact glycans. ${ }^{220}$ The analysis of a fragment derived from compound $\mathbf{8}$ (Fig. 1), in which fucose had migrated to the 2-AB tag, showed a single peak with short arrival time (Fig. 4A, 8), indicating that the fragment peak derived from the oligo LacNAc standards with the shortest arrival time (Fig. 4C) corresponds to a fragment having a fucosyl residue on the 2-AB tag. The other major peak in the ATD should then correspond to a fragment with a fucosyl residue on the acetamido moiety of GlcNAc. These results highlight that ATDs can be assigned to fragment ions with native and migrated fucosyl residues. Importantly, once the ATDs of such fragments are known, the structure of similar unknown compounds can be elucidated without a need for further synthetic standards.

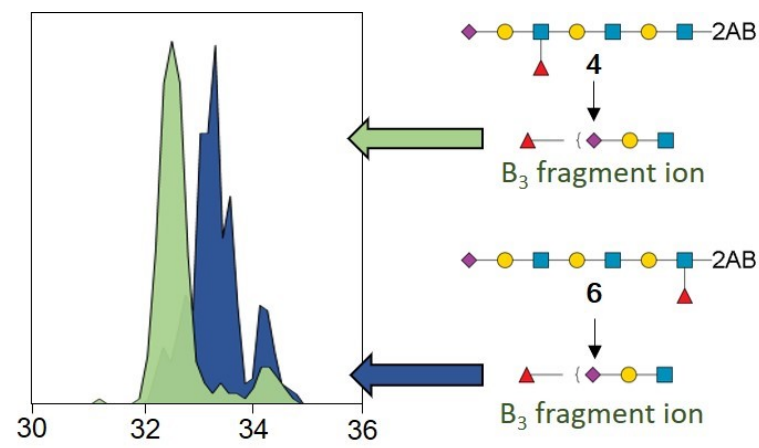

Intensity (arbitrary units) vs. arrival time (ms)

Figure 5. Intensity normalized DTIMS ATDs of $\mathrm{B}_{3}$ fragment ions from standard 6 (at $\mathrm{m} / \mathrm{z} 803.2909$ ) and 4 (at $m / z$ 803.2890), which contains a sialyl Lewis ${ }^{x}$ epitope. The ATD of an ion with native fucoside on $\mathrm{N}$-acetylglucosamine (green signal) is easily distinguishable from an ion with a rearranged fucosyl residue on $\mathrm{N}$-acetylglucosamine and $\mathrm{N}$-acetylneuraminic acid residues (blue signal). 


\subsubsection{Cyclic IMS of $N$-glycan fragment ions}

To demonstrate the applicability of IMS-MS to determine exact positions of fucosides in glycans, two biantennary $\mathrm{N}$-glycans, containing either $\mathrm{Le}^{\mathrm{x}}$ epitopes or modified by core fucosylation (compounds $\mathbf{1 2}$ and 13, ${ }^{36}$ respectively; Fig. 6), were analyzed with IMS-MS. Since in-source fragmentation of larger glycans is more complicated, the standards were analyzed with travelling wave IMS (TWIMS)-MS on a linear and on a cyclic IMS (cIMS) instrument, which has the geometry ESI-Q-cIMS-TOF and contains both a pre-IMS and post-IMS CID cell. The pre-IMS allows for the ATD measurement of fragment ions from glycans. ${ }^{30}$ The $\mathrm{N}$-glycans were observed in the MS spectrum as double-charged sodium adducts $\left([\mathrm{M}+2 \mathrm{Na}]^{2+}\right.$ and $\left.[\mathrm{M}+\mathrm{H}+\mathrm{Na}]^{2+}\right)$. No fucosyl migration was observed in adducts containing two sodium ions, whereas the presence of a proton facilitated migration, supporting a rearrangement mechanism mediated by a mobile proton with poor charge fixation.223, 226, 227 Furthermore, no fucosyl migration was observed in protonated glycans from the core to an antenna, although this rearrangement cannot be excluded in other glycan structures.

The fragmentation spectra of protonated $\mathrm{N}$-glycans $[\mathrm{M}+\mathrm{H}+\mathrm{Na}]^{2+}$ showed sodium adducts of $\mathrm{Y}_{4 \alpha} / \mathrm{Y}_{3 \beta}$ and $\mathrm{Y}_{4 \alpha} / \mathrm{Y}_{4 \beta}$ fragments containing fucose for both $N$-glycans (12 and 13), which leads to the correct identification of core fucosylation in $\mathbf{1 3}$ but to an erroneous structural assignment of the antennae fucosylated glycan $\mathbf{1 2}$. Here, TWIMS can provide a definitive answer about the exact fucoside position. ATDs obtained with linear and cyclic TWIMS instruments with 1 pass were similar and showed the ATD reproducibility, with an increase in cIM passes resulting in improved ATD resolution. The cIM ATDs at 3 passes of fragments having native fucoside (from standard 13), are dominated by one major signal that originates from the native fucosylated fragment, with additional minor peaks (Fig. 6A and 6B, green signals), originating from fucosyl rearrangements to the acetamido moieties of GlcNAc residues and 2-AB tag. On the contrary, the ATDs of fragments that can only arise from rearranged fucoside residues (from standard 12), show multiple, broad and partially resolved peaks, revealing the presence of different positional isomers (Fig. 6A and 6B, blue signal) that match arrival times of the minor peaks of the native fucosylated fragment (green signal). The presence of relatively strong signals of several isomers allowed to discriminate between $\mathrm{N}$-glycans with native core fucosylation and those with rearranged fucosides on the core structure. 

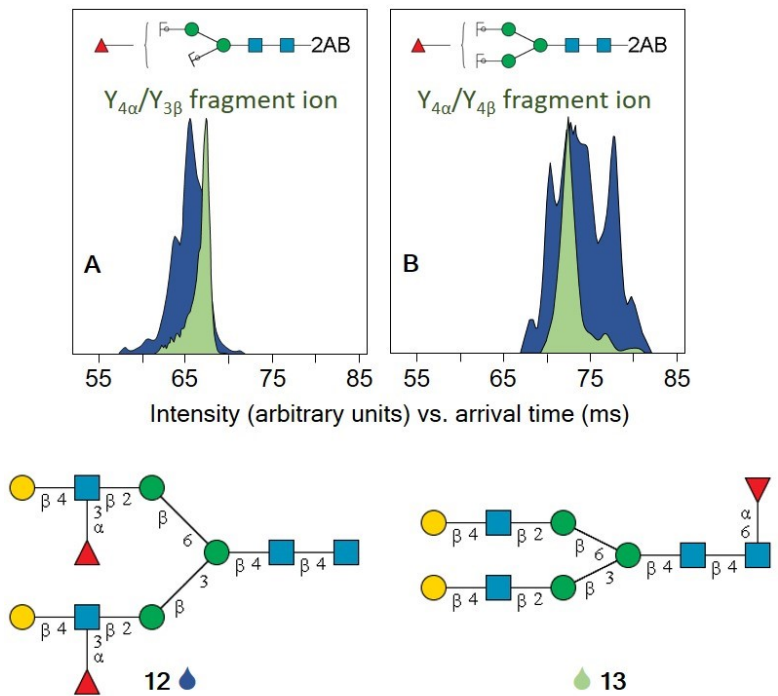

Figure 6. Intensity normalized TWIMS ATDs of sodium-adducted fragment ions from 2-AB labeled $N$-glycans with core fucosylation $\left(13,[\mathrm{M}+\mathrm{H}+\mathrm{Na}]^{2+}\right.$ at $\left.\mathrm{m} / \mathrm{z} 965.3577\right)$ or antennae fucosylation (12, $[\mathrm{M}+\mathrm{H}+\mathrm{Na}]^{2+}$ at $m / z$ 1038.3866). Precursor ions were selected in the quadrupole, fragmented in the trap collision cell, the resulting fragment ions were subjected to 3 passes of the cIM (which corresponds to an IMS resolution of $\sim 110 \Omega / \Delta \Omega$ ) with mass measurement in the TOF. ATDs of $Y_{4 \alpha} / Y_{4 \beta}(A)$ and $Y_{4 \alpha} / Y_{3 \beta}$ (B) fragment ions show that sodium-adducted fragment ions with native $\alpha(1,6)$ linked core fucose (green signal) can be discriminated from fragment ions originating from rearranged fucosides on the $\underline{N}$-acetylglucosamine and 2 -AB tag (blue signal).

\subsection{Conclusion}

IMS-MS of well-defined oligosaccharides has demonstrated that proton mediated fucosyl migration occurs intramolecularly to acetamido moieties of Neu5Ac and GlcNAc residues as well as nucleophilic sites of the 2-AB tag. Contrary to previous reports, no rearrangement to hydroxyls was observed, which limits the number of positions for fucosyl migration. This new mechanistic insight enables the straightforward characterization of diagnostic Y- and B-type fragment ions arising from native and rearranged fucosyl residues with IMS. MS/MS fragments that have rearranged fucosides can be identified by the presence of multiple peaks in the ATD or by a shift in arrival time and CCS value with respect to welldefined fragment-like standards. The described strategy can now be applied broadly, and we anticipate that a comprehensive database of ATDs and CCS 
values of fragment ions derived from native and rearranged fucosides can be generated by analyzing a limited set of well-defined oligosaccharides with branched structures modified by various types of Lewis- and blood group antigens. Such a database will facilitate the fast and unambiguous assignment of fucosylation sites of unknown glycans without the need for additional synthetic standards. The set of compounds described here has already provided diagnostic ions that can confirm the presence of a sialyl Lewis ${ }^{\mathrm{x}}$ motif and identify core fucosylation. It is expected that a database of ATDs and CCS values combined with multi-stage IMS and MS instrumentation will also enable de novo sequencing of glycans. ${ }^{179}$ Similar strategies can be applied for the identification of sites of sulfation in oligosaccharides ${ }^{240}$ and phosphorylation in peptides ${ }^{241}$ to prevent erroneous structure elucidation due to rearrangement 



\section{Summary and Conclusions}

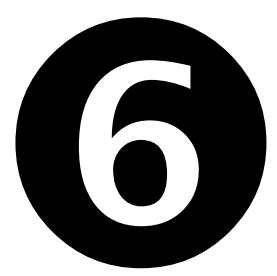




\section{Summary and conclusions}

Glycosylation is structurally the most complex posttranslational modification of proteins, playing key roles in many biological and disease processes. To understand the biology of glycans and glycoconjugates and to develop biologicals for the treatment of these diseases, it is essential to determine exact glycan structures. In this thesis, new electrophoretic analysis approaches are described for the separation and identification of glycans, based on their mobility in the liquid and gas phase. A new capillary electrophoresis (CE) method, using large volume injection for sensitive analysis, and ion mobility spectrometry (IMS) methods for exact structure assignment, are presented.

Chapter 1 provides an overview of the structure of glycans, sample preparation and the possibilities for analysis with liquid chromatography, mass spectrometry (MS), ion mobility spectrometry and CE. CE played an important role in developments in several fields of the life sciences and is nowadays mainly used for the analysis of both large and small molecules in applications where $\mathrm{CE}$ performs better than or is complementary to liquid chromatographic techniques.

\subsection{Capillary electrophoresis}

In chapter 2, principles of different electromigration techniques, such as capillary isoelectric focusing (CIEF), capillary gel (CGE) and capillary zone electrophoresis (CZE), are described and recent developments in instrumentation, with an emphasis on mass spectrometry (MS) coupling and microchip CE, are discussed. The impact of CE in life sciences is shown with the most noticeable applications over the past few decades. In this context, current practice for the characterization of biologicals (therapeutic proteins) is shown with CIEF, CGE and CZE using different detection techniques, including MS.

The application of CGE and CZE, in combination with laser induced fluorescence detection and CZE-MS is demonstrated for the analysis of proteins and released glycans for the characterization of biologicals and glycan biomarker discovery. The large number of CE applications published on these topics in recent years clearly demonstrates $\mathrm{CE}$ as an established technique in this field. 
Despite all the improvements in the CE field, detection of low abundant glycans with CZE still poses a problem due to the low nL-range injection volumes in CZE. Fritless packed solid-phase extraction (SPE) trap columns have been applied to increase the injection volume in CZE, but this approach has not yet found its way in routine analysis. This is due to problems like caking and wedging of SPE particles, leading to void spaces and irreproducible and incomplete filling of trap columns during preparation. The formation of a dense cake and compression of particles increase backpressure over time, which leads to irreproducible results, current break downs, impermeable columns and short trap column durability. Chapter 3 describes the application of in-line sample trapping using SPE sorbents blended with diatomite to ensure an easy and fast fabrication of trap columns and yielding an incompressible and permeable chromatographic cake. Diatomite consist of natural amorphous silica, which forms intricately shaped and highly porous particles. It is used as a filter aid to form highly permeable and incompressible layers in filters, as stationary phases for liquid and gas chromatography and as an anticaking agent and glidant in the pharmaceutical and food/feed industry. The combination of diatomite with different types of SPE sorbents allowed for smooth and consistent filling of trap columns. Furthermore, higher and sustained flow rates were obtained, without affecting injection, elution and other flushing procedures over time, allowing the use of a trap column for more than 340 injections.

Trap columns with both cation and anion exchange particles were applied to CEMS analysis of neutral and sialylated glycans derivatized with a positive chargeable tag. Compounds were eluted using an eluent with high $\mathrm{pH}$ and high salt concentration. To concentrate the glycans in the eluent prior to CZE, a transient isotachophoresis method was used. The concentration was achieved by using ammonium ions in the eluent as leading electrolyte and protons in an acetic acid background electrolyte as terminating electrolyte. These electrolytes allowed for narrower separation zones and improved CZE separation after sample injections of up to $13.6 \mu \mathrm{L}$, which is a factor 1000 higher than with conventional $\mathrm{CE}$ injection methods. The higher injection volumes enabled the detection of low $\mathrm{nM}$ concentrations for $\mathrm{N}$-glycans with IMS-MS, using an injection volume of $10 \mu \mathrm{L}$.

The possibility to combine large volume injections in $\mathrm{CE}$ with modern nano-flow interfaces for MS analysis, makes it possible to bring CE-MS to the same level 
as LC-MS, in terms of sensitivity. CE offers different separation characteristics and selectivity in comparison to hydrophilic interaction and porous graphitized carbon chromatography, which are currently the most used separation techniques in these fields in combination with MS. It is expected that the application of highly sensitive CE-IMS-MS will, in comparison to LC-MS, reveal the presence of additional glycans in biological samples. The combination of SPE blends with diatomite for trapping columns in $\mathrm{CE}$ can be used with different types of sorbents and for different classes of analytes. We therefore expect this approach will also find its use in other life science fields.

\subsection{Ion mobility-mass spectrometry}

MS has become indispensable for glycan detection and identification, as it offers good detection sensitivity in combination with a high degree of certainty about the composition of the analyte. Other detection techniques, like laser induced fluorescence detection, can offer a better detection sensitivity, but lack the identity certainty that MS offers. On the other hand, exact structural assignment of $\mathrm{N}$-glycans by mass spectrometry (MS) alone is also challenging, given their high structural complexity and the presence of numerous isomers. Here, IMS can play an important role. The combination of IMS with MS has made a significant contribution in various fields of the life sciences, in terms of compound identification. In metabolomics and lipidomics, collision cross section (CCS) values are used to identify a large range of compounds, while in glycomics the application, up to now, is mostly limited to the identification of small polysaccharides. This is largely due to the small differences in CCS values of larger carbohydrates, such as $\mathrm{N}$-glycans, and the presence of isomeric structures.

Chapter 4 shows a new glycan identification strategy with IMS, using the different glycan conformers that are present in the gas phase. Glycans can adopt different specific and stable conformations in the gas-phase, which depend on the branching and linkage of the different carbohydrate residues. These conformations are measured with IMS to obtain intrinsic arrival time distribution (ATD) fingerprints which, in conjunction with MS, are used for the assignment of glycans with close CCS values. We assigned exact structures of proteinderived $\mathrm{N}$-glycans, including all possible Neu5Ac linkage-isomers of a group of biantennary $\mathrm{N}$-glycans, using an ATD database. Such a database will allow the fast identification of $\mathrm{N}$-glycans, including isomers, without the need for MS/MS 
experiments, which will significantly reduce data processing time. This approach can also be applied to other types of biomolecules that adopt various conformations in the gas-phase and have close CCS values for isomeric structures.

For unknown glycans that are not yet incorporated in the ATD database, we developed an approach to compute ATDs for $N$-glycan identification based on molecular dynamics simulations. Similar ATDs were obtained for computed and IMS-Neu5Ac linkage isomers, demonstrating the possibility to assign exact structures of glycans that are not yet available in the database. In addition, the unknown $N$-glycans can also be identified by MS/MS experiments in combination with IMS of fragment ions. Chapter 5 shows the exact structure assignment of fucosylated $\mathrm{N}$-glycans, based on ATDs of MS/MS fragments which are obtained from well-defined glycan standards. The fucosylation of glycans leads to diverse structures and is associated with many biological and disease processes. The exact determination of fucoside positions by tandem mass spectrometry (MS/MS) however, is complicated because rearrangements in the gas phase lead to erroneous structural assignments. In chapter 5 we demonstrate that the combined use of IMS-MS and well-defined synthetic glycan standards can prevent both misinterpretation of MS/MS spectra as well as incorrect structural assignments of fucosylated glycans. We show that fucosyl residues do not migrate to hydroxyl groups but to acetamido moieties of $\mathrm{N}$-acetylneuraminic acid as well as to $\mathrm{N}$-acetylglucosamine residues and nucleophilic sites of an anomeric tag, yielding specific isomeric fragment ions. This mechanistic insight enables the characterization of unique ATDs of the isomers which can be used to accurately determine fucosyl positions in glycans. These results, in turn, facilitate unambiguous discrimination between MS/MS fragments arising from parent compounds and those that occur due to rearranged fucosyl residues, preventing misinterpretation of MS/MS spectra.

This approach can be applied broadly, using an extensive database of ATDs and CCS values of glycan fragment ions. This database can be generated by analyzing a limited set of well-defined glycans with different branching and linkage as well as positions of carbohydrate residues along the glycan structure. Such a database, combined with multi-stage MS and IMS, will facilitate the fast and unambiguous exact structure assignment without the need for additional synthetic standards, enabling de novo sequencing of $\mathrm{N}$-glycans. 



\section{Samenvatting}

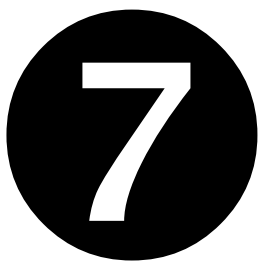




\section{Samenvatting}

Glycanen spelen een belangrijke rol in verschillende biologische- en ziekteprocessen. Om de biologie van glycanen en glycoconjugaten te begrijpen en deze kennis toe te passen in de ontwikkeling van biologische geneesmiddelen, is het essentieel om exacte glycaanstructuren te bepalen. In dit proefschrift worden nieuwe elektroforetische analysemethodieken beschreven voor de scheiding en identificatie van glycanen, gebaseerd op hun elektroforetische mobiliteit in de vloeistof- en gasfase. Er wordt een nieuwe capillaire elektroforese (CE) methode gepresenteerd, die gebruik maakt van grote injectievolumes voor gevoeligere analyse. Vervolgens worden twee nieuwe methodieken voor exacte structuurtoewijzing gepresenteerd, gebaseerd op ionenmobiliteitsspectrometrie (IMS).

In hoofdstuk 1 wordt een overzicht gegeven van de structuuropbouw van verschillende glycanen, de laatste ontwikkelingen op het gebied van de opwerking vanuit complexe monsters en de mogelijkheden om glycanen te analyseren met o.a. capillaire elektroforese (CE), vloeistofchromatografie en IMS, gekoppeld aan massaspectrometrie (MS).

Hoofdstuk 2 beschrijft de ontwikkelingen en applicatie van CE in de levenswetenschappen. De techniek wordt tegenwoordig gebruikt voor de analyse van zowel grote als kleine moleculen in toepassingen waar het beter presteert of complementair is aan vloeistofchromatografische technieken. In hoofdstuk 2 worden principes van verschillende elektromigratietechnieken getoond, in het bijzonder van capillair iso-elektrisch focusseren (CIEF), capillaire gel- (CGE) en capillaire zone-elektroforese (CZE). Recente instrumentele ontwikkelingen worden behandeld, met een nadruk op microchip CE en MS. Daarnaast wordt met gebruik van toepassingen de rol van $\mathrm{CE}$ aangetoond voor de karakterisering van therapeutische eiwitten met CIEF, CGE en CZE i.c.m. verschillende detectietechnieken, waaronder MS. Vervolgens wordt de toepassing van CGE en CZE(-MS) beschreven voor de analyse van glycanen op eiwitten, bij de karakterisering van farmaceutische eiwitten en bij het analyseren van diagnostische componenten in biologische monsters. Het grote aantal CE(-MS)toepassingen dat de afgelopen jaren voor deze onderwerpen is gepubliceerd toont duidelijk de gevestigde rol van $\mathrm{CE}$ in de levenswetenschappen aan. 
Door het gebruik van lage (nanoliter) injectievolumes in conventionele CE is de detectie van lage glycaanconcentraties nog steeds een probleem. Diverse oplossingen zijn hiervoor aangedragen, waaronder fritloze vaste fase extractie (VFE) kolommen. VFE kolommen zijn in het verleden toegepast om het injectievolume in CZE-MS te vergroten. Deze kolommen worden echter niet gebruikt in routine-analyses, vanwege het kleven en vastklemmen van het kolommateriaal, wat leidt tot holle ruimtes, onvolledige vulling van de kolommen en niet-reproduceerbare resultaten. De vorming van een dichte laag en het samendrukken van deeltjes verhogen de tegendruk in de loop van de tijd, wat leidt tot stroomonderbrekingen in de $\mathrm{CE}$ en verstopte kolommen met daardoor een korte levensduur. Hoofdstuk 3 beschrijft de toepassing van VFE deeltjes gemengd met diatomeeënaarde om een gemakkelijke en snelle constructie van kolommen te garanderen. Deze combinatie levert een niet-samendrukbare en doordringbare deeltjeslaag op, die hogere en herhaalbare vloeistofstroomsnelheden mogelijk maakt. Op deze wijze kunnen grote volumes in CE worden geïnjecteerd. De combinatie van diatomeeënaarde met verschillende soorten VFE materialen zorgt er voor dat kolommen gedurende meer dan 340 injecties gebruikt kunnen worden, zonder verlies van herhaalbaarheid. De kolommen zijn toegepast voor de analyse van positief gelabelde glycanen, door een gecombineerde kation- en anionenuitwisselingskolom te gebruiken om de analieten te concentreren. Een isotachoforese methode werd gebruikt om de glycanen na elutie te concentreren alvorens deze te scheiden m.b.v. CZE. Dit gebeurde door gebruik te maken van ammoniumionen in het eluens als leidend elektrolyt en protonen in het azijnzuur elektrolyt als eindelektrolyt. Na de concentratiestap kunnen glycanen met CZE verder worden gescheiden. Deze strategie maakt het mogelijk om genoeg gevoeligheid te verkrijgen voor IMS-MS-karakterisering van $\mathrm{N}$-glycanen door monsterinjecties tot $13.6 \mu \mathrm{L}$ te gebruiken. Dit injectievolume is een factor 1000 hoger dan bij conventionele hydrodynamische injectiemethoden in CE en biedt lage $\mathrm{nM}$ detectielimieten met CE-IMS-MS. De beschreven strategie kan breed worden toegepast met verschillende VFE materialen voor verschillende componentgroepen en zullen het mogelijk maken grote-volume injecties in CE te gebruiken voor routinematig gebruik.

De exacte structuurtoewijzing van $N$-glycanen met MS is uitdagend door de grote structurele complexiteit en de vele isomeren. Hoofdstuk 4 laat zien dat de combinatie van ionenmobiliteit (IM)-MS en goed gedefinieerde synthetische glycanen kan worden gebruikt voor een eenduidige toewijzing van isomere 
glycaanstructuren. Glycanen kunnen verschillende specifieke en stabiele conformaties aannemen in de gasfase, afhankelijk van vertakking en koppeling van de verschillende suikergroepen. Deze conformaties kunnen worden gemeten met IMS om een aankomsttijd verdeling (ATV) te verkrijgen die als uniek profiel kan worden gebruikt om, in combinatie met MS, glycanen te identificeren. Met deze conformatie verdelingen (CV's) kunnen exacte structuren van glycanen afkomstig van eiwitten worden toegewezen, waaronder die van isomeren. Daarnaast wordt een strategie beschreven voor het berekenen van CV profielen op basis van moleculaire dynamica simulaties. Vergelijkbare CV's werden verkregen voor berekende en gemeten isomeren, wat de waarde van berekende CV's voor glycaanidentificatie aantoont. De toepassing van CV-profielen maakt een snelle en eenduidige identificatie van glycaanstructuren mogelijk, terwijl de gegevensverwerkingstijd aanzienlijk wordt verkort.

Hoofdstuk 5 toont de exacte structuuropheldering van gefucosyleerde $N$-glycanen m.b.v. ATV-en van MS/MS-fragmenten die zijn verkregen met goedgedefinieerde glycaanstandaarden. De fucosylering van glycanen leidt tot verschillende structuren, die geassocieerd worden met veel biologische- en ziekteprocessen. De exacte bepaling van fucosideposities met MS/MS-spectra is uitdagend omdat omleggingen in de gasfase tot foutieve structuurtoewijzingen leiden. In hoofdstuk 5 wordt aangetoond hoe het gecombineerd gebruik van MS, IMS en goed-gedefinieerde synthetische glycaanstandaarden een verkeerde interpretatie van MS/MS-spectra en onjuiste structuurtoewijzingen van gefucosyleerde glycanen kan voorkomen. Er wordt aangetoond dat fucosylgroepen niet naar hydroxylgroepen migreren, maar naar siaalzuren, $N$-acetylglucosaminegroepen en nucleofiele delen van het gebruikte derivatiseringslabel. Deze omleggingen leveren specifieke isomere fragmentionen met unieke ATV-en op die kunnen worden gebruikt om nauwkeurig fucosylposities in glycanen te bepalen. Op deze wijze kunnen MS/MS-fragmenten voortkomend uit moederverbindingen en afkomstig van omleggingen van fucosylgroepen worden onderscheiden en kan een verkeerde interpretatie van MS/MS-spectra worden voorkomen. 




\section{Curriculum Vitae}

Javier Sastre Toraño was born on August 6,1973 in Utrecht. After finishing secondary school at the Niels Stensen College in Utrecht, he studied analytical chemistry at the HU University of applied sciences Utrecht. After graduating in 1995, he started his professional career in the pharmaceutical laboratory of Tergooi Hospital, followed by a ten-year stay in the pharmaceutical and toxicological laboratory of the Academic Medical Center in Amsterdam. In 2005 he joined the biomedical analysis group of Professor G. J. de Jong and Professor G.W. Somsen at Utrecht University. After ten years, Javier started at the same university in the Medicinal Chemistry and Chemical Biology group of Professor R. Pieters and Professor R.M.J. Liskamp and subsequently the Chemical Biology and Drug Discovery group of Professor G.J. Boons. In 2018, Javier started his $\mathrm{PhD}$ trajectory in this group, which led to this thesis. 



\section{List of publications}

Sastre Toraño, J., Aizpurua-Olaizola, O., Wei, N., Li, T., Unione, L., JiménezOsés, G., Corzana, F., Somovilla, V.J., Falcon-Perez J.M. \& Boons, G.J. (2020). Identification of Isomeric N-glycans by Conformer Distribution Fingerprinting using Ion Mobility-Mass Spectrometry. Submitted for publication.

Güngör, E., Brouwer, P., Dijkhuizen, L., Shaffar, D., Nierop, K., De Vos, R., Sastre Toraño, J., van der Meer, I. \& Schluepmann, H. (2020). Azolla ferns testify: Seed plants and ferns share a common ancestor for leucoanthocyanidin reductase enzymes. New Phytol., DOI: 10.1111/nph.16896.

Liu, Y., Scrivano, L., Peterson, J.D., Fens, M.H.A.M., Beltrán Hernández, I., Mesquita, B., Sastre Torano, J., Hennink, W.E., van Nostrum, C.F. \& Oliveira, S. (2020). EGFR targeted nanobody functionalized polymeric micelles loaded with mTHPC for selective photodynamic therapy. Mol. Pharm., 17 (4):12761292.

Sastre Torano, J., Gagarinov, I. A., Vos, G. M., Broszeit, F., Srivastava, A. D., Palmer, M., Langridge, J. I., Aizpurua-Olaizola, O., Somovilla, V. J. \& Boons, G. J. (2019). Ion-mobility spectrometry can assign exact fucosyl positions in glycans and prevent misinterpretation of mass-spectrometry data after gas-phase rearrangement. Angew. Chem., Int. Ed. Engl., 58 (49): 17616-17620.

Sastre Torano, J.*, Ramautar, R. \& de Jong, G. (2019). Advances in capillary electrophoresis for the life sciences. J. Chromatogr. B: Anal. Technol. Biomed. Life Sci., 1118-1119: 116-136.

Gagarinov, I. A., Li, T., Wei, N., Sastre Torano, J., de Vries, R. P., Wolfert, M. A. \& Boons, G. J. (2019). Protecting-group-controlled enzymatic glycosylation of oligo- $N$-acetyllactosamine derivatives. Angew. Chem., Int. Ed. Engl., 58 (31): 10547-10552. 
Jansen, J., Jansen, K., Neven, E., Poesen, R., Othman, A., van Mil, A., Sluijter, J., Sastre Torano, J., Zaal, E. A., Berkers, C. R., Esser, D., Wichers, H. J., van Ede, K., van Duursen, M., Burtey, S., Verhaar, M. C., Meijers, B. \& Masereeuw, R. (2019). Remote sensing and signaling in kidney proximal tubules stimulates gut microbiome-derived organic anion secretion. Proc. Natl. Acad. Sci. U. S. A., 116 (32): 16105-16110.

Van der Made, T. K., Fedecostante, M., Scotcher, D., Rostami-Hodjegan, A., Sastre Torano, J., Middel, I., Koster, A. S., Gerritsen, K. G., Jankowski, V., Jankowski, J., Hoenderop, J. G. J., Masereeuw, R. \& Galetin, A. (2019). Quantitative translation of microfluidic transporter in vitro data to in vivo reveals impaired albumin-facilitated indoxyl sulfate secretion in chronic kidney disease. Mol. Pharm., 16 (11): 4551-4562.

Shi, H., Leonhard, W. N., Sijbrandi, N. J., van Steenbergen, M. J., Fens, M., van de Dikkenberg, J. B., Sastre Torano, J., Peters, D. J. M., Hennink, W. E. \& Kok, R. J. (2019). Folate-dactolisib conjugates for targeting tubular cells in polycystic kidneys. J. Control. Release, 293: 113-125.

De Groof, T. W. M., Mashayekhi, V., Fan, T. S., Bergkamp, N. D., Sastre Torano, J., van Senten, J. R., Heukers, R., Smit, M. J. \& Oliveira, S. (2019). Nanobody-targeted photodynamic therapy selectively kills viral GPCRexpressing glioblastoma cells. Mol. Pharm., 16 (7): 3145-3156.

Martinez-Jothar, L., Doulkeridou, S., Schiffelers, R. M., Sastre Torano, J., Oliveira, S., van Nostrum, C. F. \& Hennink, W. E. (2018). Insights into maleimide-thiol conjugation chemistry: Conditions for efficient surface functionalization of nanoparticles for receptor targeting. J. Control. Release, 282: 101-109.

Kordalivand, N., Li, D., Beztsinna, N., Sastre Torano, J., Mastrobattista, E., van Nostrum, C. F., Hennink, W. E. \& Vermonden, T. (2018). Polyethyleneimine coated nanogels for the intracellular delivery of RNase A for cancer therapy. Chem. Eng. J., 340: 32-41. 
Chevtchik, N. V., Mihajlovic, M., Fedecostante, M., Bolhuis-Versteeg, L., Sastre Torano, J., Masereeuw, R. \& Stamatialis, D. (2018). A bioartificial kidney device with polarized secretion of immune modulators. J. Tissue Eng. Regen. Med., 12 (7): 1670-1678.

Aizpurua-Olaizola, O., Sastre Torano, J., Pukin, A., Fu, O., Boons, G. J., de Jong, G. J. \& Pieters, R. J. (2018). Affinity capillary electrophoresis for the assessment of binding affinity of carbohydrate-based cholera toxin inhibitors. Electrophoresis, 39 (2): 344-347.

Aizpurua-Olaizola, O., Sastre Toraño, J., Falcon-Perez, J. M., Williams, C., Reichardt, N. \& Boons, G. J. (2018). Mass spectrometry for glycan biomarker discovery. TrAC, Trends Anal. Chem., 100: 7-14.

van Haren, M. J., Taig, R., Kuppens, J., Sastre Torano, J., Moret, E. E., Parsons, R. B., Sartini, D., Emanuelli, M. \& Martin, N. I. (2017). Inhibitors of nicotinamide $N$-methyltransferase designed to mimic the methylation reaction transition state. Org. Biomol. Chem., 15 (31): 6656-6667.

Sevšek, A., Sastre Toraño, J., Quarles van Ufford, L., Moret, E. E., Pieters, R. J. \& Martin, N. I. (2017). Orthoester functionalized $N$-guanidino derivatives of 1,5-dideoxy-1,5-imino-d-xylitol as $\mathrm{pH}$-responsive inhibitors of $\beta$ glucocerebrosidase. Med. Chem. Comm., 8 (11): 2050-2054.

Mackus, M., van de Loo, A., Raasveld, S. J., Hogewoning, A., Sastre Torano, J., Flesch, F. M., Korte-Bouws, G. A. H., van Neer, R. H. P., Wang, X., Nguyen, T. T., Brookhuis, K. A., Kraneveld, A. D., Garssen, J. \& Verster, J. C. (2017). Biomarkers of the alcohol hangover state: Ethyl glucuronide (EtG) and ethyl sulfate (EtS). Hum. Psychopharmacol., 32 (5).

Kleijn, L. H. J., Vlieg, H. C., Wood, T. M., Sastre Torano, J., Janssen, B. J. C. \& Martin, N. I. (2017). A High-Resolution Crystal Structure that Reveals Molecular Details of Target Recognition by the Calcium-Dependent Lipopeptide Antibiotic Laspartomycin C. Angew. Chem., Int. Ed., 56 (52): 16546-16549. 
Gagarinov, I. A., Li, T., Sastre Torano, J., Caval, T., Srivastava, A. D., Kruijtzer, J. A., Heck, A. J. \& Boons, G. J. (2017). Chemoenzymatic Approach for the Preparation of Asymmetric Bi-, Tri-, and Tetra-Antennary $\mathrm{N}$-Glycans from a Common Precursor. J. Am. Chem. Soc., 139 (2): 1011-1018.

van Haren, M. J., Sastre Torano, J., Sartini, D., Emanuelli, M., Parsons, R. B. \& Martin, N. I. (2016). A Rapid and Efficient Assay for the Characterization of Substrates and Inhibitors of Nicotinamide $N$-Methyltransferase. Biochemistry, 55 (37): 5307-5315.

Sevsek, A., Celan, M., Erjavec, B., Quarles van Ufford, L., Sastre Torano, J., Moret, E. E., Pieters, R. J. \& Martin, N. I. (2016). Bicyclic isoureas derived from 1-deoxynojirimycin are potent inhibitors of beta-glucocerebrosidase. Org. Biomol. Chem., 14 (37): 8670-8673.

Prior, A., Sanchez-Hernandez, L., Sastre Torano, J., Marina, M. L., de Jong, G. J. \& Somsen, G. W. (2016). Enantioselective analysis of proteinogenic amino acids in cerebrospinal fluid by capillary electrophoresis-mass spectrometry. Electrophoresis, 37 (17-18): 2410-2419.

Naksuriya, O., van Steenbergen, M. J., Sastre Torano, J., Okonogi, S. \& Hennink, W. E. (2016). A kinetic degradation study of curcumin in its free form and loaded in polymeric micelles. AAPS J., 18 (3): 777-787.

Dymek, K., Panarese, V., Herremans, E., Cantre, D., Schoo, R., Sastre Torano, J., Schluepmann, H., Wadso, L., Verboven, P., Nicolai, B. M., Dejmek, P. \& Gomez Galindo, F. (2016). Investigation of the metabolic consequences of impregnating spinach leaves with trehalose and applying a pulsed electric field. Bioelectrochemistry, 112: 153-157.

Shirangi, M., Sastre Torano, J., Sellergren, B., Hennink, W. E., Somsen, G. W. \& van Nostrum, C. F. (2015). Methyleneation of peptides by N,N,N,Ntetramethylethylenediamine (TEMED) under conditions used for free radical polymerization: a mechanistic study. Bioconjug. Chem., 26 (1): 90-100. 
Jordan, N. Y., Mimpen, J. Y., van den Bogaard, W. J., Flesch, F. M., van de Meent, M. H. \& Sastre Torano, J.* (2015). Analysis of caffeine and paraxanthine in human saliva with ultra-high-performance liquid chromatography for CYP1A2 phenotyping. J. Chromatogr. B: Anal. Technol. Biomed. Life Sci., 995-996: 70-73.

Medina-Casanellas, S., Tak, Y. H., Benavente, F., Sanz-Nebot, V., Sastre Torano, J., Somsen, G. W. \& de Jong, G. J. (2014). Evaluation of fritless solidphase extraction coupled on-line with capillary electrophoresis-mass spectrometry for the analysis of opioid peptides in cerebrospinal fluid. Electrophoresis, 35 (20): 2996-3002.

Moreno-Gonzalez, D., Sastre Torano, J., Gamiz-Gracia, L., Garcia-Campana, A. M., de Jong, G. J. \& Somsen, G. W. (2013). Micellar electrokinetic chromatography-electrospray ionization mass spectrometry employing a volatile surfactant for the analysis of amino acids in human urine. Electrophoresis, 34 (18): 2615-2622.

Tak, Y. H., Sastre Torano, J., Somsen, G. W. \& de Jong, G. J. (2012). Optimization of in-line fritless solid-phase extraction for capillary electrophoresis-mass spectrometry. J. Chromatogr. A, 1267: 138-143.

Sastre Torano, J.*, Delatte, T. L., Schluepmann, H., Smeekens, S. C., de Jong, G. J. \& Somsen, G. W. (2012). Determination of trehalose-6-phosphate in Arabidopsis thaliana seedlings by hydrophilic-interaction liquid chromatography-mass spectrometry. Anal. Bioanal. Chem., 403 (5): 1353-1360.

Coimbra, M., Isacchi, B., van Bloois, L., Sastre Torano, J., Ket, A., Wu, X., Broere, F., Metselaar, J. M., Rijcken, C. J., Storm, G., Bilia, R. \& Schiffelers, R. M. (2011). Improving solubility and chemical stability of natural compounds for medicinal use by incorporation into liposomes. Int. J. Pharm., 416 (2): 433-442.

Vinkers, C. H., Korte-Bouws, G. A., Sastre Torano, J., Mirza, N. R., Nielsen, E. O., Ahring, P. K., de Jong, G. J. \& Olivier, B. (2010). The rapid hydrolysis of chlordiazepoxide to demoxepam may affect the outcome of chronic osmotic minipump studies. Psychopharmacology 208 (4): 555-562. 
Ramautar, R., Sastre Torano, J., Somsen, G. W. \& de Jong, G. J. (2010). Evaluation of $\mathrm{CE}$ methods for global metabolic profiling of urine. Electrophoresis, 31 (14): 2319-2327.

Somsen, G. W., Tak, Y. H., Sastre Torano, J., Jongen, P. M. \& de Jong, G. J. (2009). Determination of oversulfated chondroitin sulfate and dermatan sulfate impurities in heparin by capillary electrophoresis. J. Chromatogr. A, 1216 (18): 4107-4112.

Silvertand, L. H., Sastre Torano, J., de Jong, G. J. \& van Bennekom, W. P. (2009). Development and characterization of cIEF-MALDI-TOF MS for protein analysis. Electrophoresis, 30 (10): 1828-1835.

Silvertand, L. H., Sastre Torano, J., van Bennekom, W. P. \& de Jong, G. J. (2008). Recent developments in capillary isoelectric focusing. J. Chromatogr. A, 1204 (2): 157-170.

Silvertand, L. H., Sastre Torano, J., de Jong, G. J. \& van Bennekom, W. P. (2008). Improved repeatability and matrix-assisted desorption/ionization - time of flight mass spectrometry compatibility in capillary isoelectric focusing. Electrophoresis, 29 (10): 1985-1996.

Catai, J. R., Sastre Torano, J., Jongen, P. M., de Jong, G. J. \& Somsen, G. W. (2007). Analysis of recombinant human growth hormone by capillary electrophoresis with bilayer-coated capillaries using UV and MS detection. $J$. Chromatogr. B: Anal. Technol. Biomed. Life Sci., 852 (1-2): 160-166.

Catai, J. R., Sastre Torano, J., de Jong, G. J. \& Somsen, G. W. (2007). Capillary electrophoresis-mass spectrometry of proteins at medium $\mathrm{pH}$ using bilayercoated capillaries. Analyst, 132 (1): 75-81.

Catai, J. R., Sastre Torano, J., de Jong, G. J. \& Somsen, G. W. (2006). Efficient and highly reproducible capillary electrophoresis-mass spectrometry of peptides using Polybrene-poly(vinyl sulfonate)-coated capillaries. Electrophoresis, 27 (11): 2091-2099. 
Van Kan, H. J. M., Groeneveld, G. J., Sastre Torano, J., Spieksma, M., Van den Berg, L. H. \& Guchelaar, H. J. (2004). Correlation between riluzole clearance and CYP1A2 activity in patients with amyotrophic lateral sclerosis. Br. J. Clin. Pharmacol., 57 (3): 367-368.

van Kan, H. J., Spieksma, M., Groeneveld, G. J., Sastre Torano, J., van den Berg, L. H. \& Guchelaar, H. J. (2004). A validated HPLC assay to monitor riluzole plasma or serum concentrations in patients with amyotrophic lateral sclerosis. Biomed. Chromatogr., 18 (9): 723-726.

Wu, Y. H., Feenstra, M. G., Zhou, J. N., Liu, R. Y., Sastre Torano, J., Van Kan, H. J., Fischer, D. F., Ravid, R. \& Swaab, D. F. (2003). Molecular changes underlying reduced pineal melatonin levels in Alzheimer disease: alterations in preclinical and clinical stages. J. Clin. Endocrinol. Metab., 88 (12): 5898-5906.

Sastre Torano, J.* \& van Kan, H. J. (2003). Simultaneous determination of the tobacco smoke uptake parameters nicotine, cotinine and thiocyanate in urine, saliva and hair, using gas chromatography-mass spectrometry for characterisation of smoking status of recently exposed subjects. Analyst, 128 (7): 838-843.

Merkus, P., Guchelaar, H. J., Van Rijn-Bikker, P. C., Sastre Torano, J., Bosch, D. A. \& Merkus, F. W. H. M. (2002). Nasal drug delivery to the cerebrospinal fluid: transport of a lipophilic compound. Br. J. Clin. Pharmacol., 54: 560.

Kwadijk, S. \& Sastre Torano, J.* (2002). High-performance liquid chromatographic method with ultraviolet detection for the determination of dapsone and its hydroxylated metabolite in human plasma. Biomed. Chromatogr., 16 (3): 203-208.

Sastre Torano, J., Vermes, A. \& Guchelaar, H. J. (2001). Simultaneous determination of flucytosine and fluorouracil in human plasma by highperformance liquid chromatography. Biomed. Chromatogr., 15 (2): 89-94. 
Sastre Torano, J.* \& Hattum, S. (2001). Quantitative analysis of active compounds in pharmaceutical preparations by use of attenuated total-reflection Fourier transform mid-infrared spectrophotometry and the internal standard method. Fresenius' J. Anal. Chem., 371 (4): 532-535.

Groeneveld, G. J., van Kan, H. J., Sastre Torano, J., Veldink, J. H., Guchelaar, H. J., Wokke, J. H. \& van den Berg, L. H. (2001). Inter- and intraindividual variability of riluzole serum concentrations in patients with ALS. J. Neurol. Sci., 191 (1-2): 121-125.

Sastre Torano, J., Rijn-Bikker, P., Merkus, P. \& Guchelaar, H. J. (2000). Quantitative determination of melatonin in human plasma and cerebrospinal fluid with high-performance liquid chromatography and fluorescence detection. Biomed. Chromatogr., 14 (5): 306-310.

Sastre Torano, J., Verbon, A. \& Guchelaar, H. J. (1999). Quantitative determination of thalidomide in human serum with high-performance liquid chromatography using protein precipitation with trichloroacetic acid and ultraviolet detection. J. Chromatogr. B, 734 (2): 203-210.

Sastre Torano, J. \& Guchelaar, H. J. (1998). Quantitative determination of the macrolide antibiotics erythromycin, roxithromycin, azithromycin and clarithromycin in human serum by high-performance liquid chromatography using pre-column derivatization with 9-fluorenylmethyloxycarbonyl chloride and fluorescence detection. J. Chromatogr. B, 720 (1-2): 89-97. 




\section{Reference list}

[1] Varki, A. \& Sharon, N. (2009). Historical background and overview. In Varki, A., Cummings, R. D., Esko, J. D., Freeze, H. H., Stanley, P., Bertozzi, C. R., Hart, G. W. \& Etzler, M. E. (eds) Essentials of Glycobiology, pp. 1-22. Cold Spring Harbor (NY): Cold Spring Harbor Laboratory Press.

[2] Varki, A. (2017). Biological roles of glycans. Glycobiology, 27 (1): 3-49.

[3] Knezevic, A., Gornik, O., Polasek, O., Pucic, M., Redzic, I., Novokmet, M., Rudd, P. M., Wright, A. F., Campbell, H., Rudan, I., et al. (2010). Effects of aging, body mass index, plasma lipid profiles, and smoking on human plasma N-glycans. Glycobiology, 20 (8): 959-969.

[4] Svarovsky, S. S. \& Joshi, L. (2014). Cancer glycan biomarkers and their detection - past, present and future. Anal. Methods, 6 (12): 3918-3936.

[5] Dalziel, M., Crispin, M., Scanlan, C. N., Zitzmann, N. \& Dwek, R. A. (2014). Emerging principles for the therapeutic exploitation of glycosylation. Science, 343 (6166): 37.

[6] Reusch, D. \& Tejada, M. L. (2015). Fc glycans of therapeutic antibodies as critical quality attributes. Glycobiology, 25 (12): 1325-1334.

[7] Reusch, D., Haberger, M., Kailich, T., Heidenreich, A. K., Kampe, M., Bulau, P. \& Wuhrer, M. (2014). High-throughput glycosylation analysis of therapeutic immunoglobulin $\mathrm{G}$ by capillary gel electrophoresis using a DNA analyzer. $m A b s, 6$ (1): 185-196.

[8] Aizpurua-Olaizola, O., Sastre Toraño, J., Falcon-Perez, J. M., Williams, C., Reichardt, N. \& Boons, G. J. (2018). Mass spectrometry for glycan biomarker discovery. TrAC,Trends Anal. Chem., 100: 7-14.

[9] Sastre Torano, J., Ramautar, R. \& de Jong, G. (2019). Advances in capillary electrophoresis for the life sciences. J. Chromatogr. B: Anal. Technol. Biomed. Life Sci., 1118-1119: 116-136.

[10] Gaunitz, S., Nagy, G., Pohl, N. L. \& Novotny, M. V. (2017). Recent advances in the analysis of complex glycoproteins. Anal. Chem., 89 (1): 389-413.

[11] Karlsson, N. G., Jin, C., Rojas-Macias, M. A. \& Adamczyk, B. (2017). Next generation O-linked glycomics. Trends Glycosci. Glycotechnol., 29 (166): E35E46. 
[12] Fukuda, M., Kondo, T. \& Osawa, T. (1976). Studies on hydrazinolysis of glycoproteins - cor structures of oligosaccharides obtained from porcine thyroglobulin and pineapple stem bromelain. J. Biochem., 80 (6): 1223-1232.

[13] Ruhaak, L. R., Zauner, G., Huhn, C., Bruggink, C., Deelder, A. M. \& Wuhrer, M. (2010). Glycan labeling strategies and their use in identification and quantification. Anal. Bioanal. Chem., 397 (8): 3457-3481.

[14] Zhang, Y. W., Zhao, M. Z., Liu, J. X., Zhou, Y. L. \& Zhang, X. X. (2015). Double-layer poly(vinyl alcohol)-coated capillary for highly sensitive and stable capillary electrophoresis and capillary electrophoresis with mass spectrometry glycan analysis. J. Sep. Sci., 38 (3): 475-482.

[15] Hennion, M. C. (2000). Porous graphitic carbon: liquid chromatography. In Wilson, I. D. (ed.) Encyclopedia of Separation Science, pp. 3937-3946. Oxford: Academic Press.

[16] Selman, M. H., Hemayatkar, M., Deelder, A. M. \& Wuhrer, M. (2011). Cotton HILIC SPE microtips for microscale purification and enrichment of glycans and glycopeptides. Anal. Chem., 83 (7): 2492-2499.

[17] Alley, W. R., Mann, B. F. \& Novotny, M. V. (2013). High-sensitivity Analytical Approaches for the Structural Characterization of Glycoproteins. Chemical Reviews, 113 (4): 2668-2732.

[18] Veillon, L., Huang, Y. F., Peng, W. J., Dong, X., Cho, B. G. \& Mechref, Y. (2017). Characterization of isomeric glycan structures by LC-MS/MS Electrophoresis, 38 (17): 2100-2114.

[19] Vreeker, G. C. M. \& Wuhrer, M. (2017). Reversed-phase separation methods for glycan analysis. Analytical and Bioanalytical Chemistry, 409 (2): 359-378.

[20] Zauner, G., Deelder, A. M. \& Wuhrer, M. (2011). Recent advances in hydrophilic interaction liquid chromatography (HILIC) for structural glycomics. Electrophoresis, 32 (24): 3456-3466.

[21] Song, T., Aldredge, D. \& Lebrilla, C. B. (2015). A method for in-depth structural annotation of human serum glycans that yields biological variations. Anal. Chem., 87 (15): 7754-7762.

[22] Schwedler, C., Kaup, M., Weiz, S., Hoppe, M., Braicu, E. I., Sehouli, J., Hoppe, B., Tauber, R., Berger, M. \& Blanchard, V. (2014). Identification of 34 N-glycan isomers in human serum by capillary electrophoresis coupled with laser-induced fluorescence allows improving glycan biomarker discovery. Anal. Bioanal. Chem., 406 (28): 7185-7193.

[23] Jarvas, G., Guttman, A., Miękus, N., Bączek, T., Jeong, S., Chung, D. S., Pätoprstý, V., Masár, M., Hutta, M., Datinská, V., et al. (2020). Practical sample 
pretreatment techniques coupled with capillary electrophoresis for real samples in complex matrices. TrAC, Trends Anal. Chem., 122.

[24] Breadmore, M. C., Grochocki, W., Kalsoom, U., Alves, M. N., Phung, S. C., Rokh, M. T., Cabot, J. M., Ghiasvand, A., Li, F., Shallan, A. I., et al. (2019). Recent advances in enhancing the sensitivity of electrophoresis and electrochromatography in capillaries and microchips (2016-2018). Electrophoresis, 40 (1): 17-39.

[25] Ramautar, R., Somsen, G. W. \& de Jong, G. J. (2016). Developments in coupled solid-phase extraction-capillary electrophoresis 2013-2015. Electrophoresis, 37 (1): $35-44$.

[26] May, J. C. \& McLean, J. A. (2015). Ion mobility-mass spectrometry: timedispersive instrumentation. Anal. Chem., 87 (3): 1422-1436.

[27] Gray, C. J., Thomas, B., Upton, R., Migas, L. G., Eyers, C. E., Barran, P. E. \& Flitsch, S. L. (2016). Applications of ion mobility mass spectrometry for high throughput, high resolution glycan analysis. Biochim. Biophys. Acta, 1860 (8): 1688-1709.

[28] Hofmann, J. \& Pagel, K. (2017). Glycan analysis by ion mobility-mass spectrometry. Angew. Chem., Int. Ed., 56 (29): 8342-8349.

[29] Guttman, M. \& Lee, K. K. (2016). Site-specific mapping of sialic acid linkage isomers by ion mobility spectrometry. Anal. Chem., 88 (10): 5212-5217.

[30] Giles, K., Ujma, J., Wildgoose, J., Pringle, S., Richardson, K., Langridge, D. \& Green, M. (2019). A cyclic ion mobility-mass spectrometry system. Anal. Chem., 91: 8564-8573.

[31] Wang, Z., Chinoy, Z. S., Ambre, S. G., Peng, W., McBride, R., de Vries, R. P., Glushka, J., Paulson, J. C. \& Boons, G. J. (2013). A general strategy for the chemoenzymatic synthesis of asymmetrically branched N-glycans. Science, 341 (6144): 379-383.

[32] Li, T., Huang, M., Liu, L., Wang, S., Moremen, K. W. \& Boons, G. J. (2016). Divergent Chemoenzymatic Synthesis of Asymmetrical-Core-Fucosylated and Core-Unmodified N-Glycans. Chemistry, 22 (52): 18742-18746.

[33] Gagarinov, I. A., Li, T., Sastre Torano, J., Caval, T., Srivastava, A. D., Kruijtzer, J. A., Heck, A. J. \& Boons, G. J. (2017). Chemoenzymatic Approach for the Preparation of Asymmetric Bi-, Tri-, and Tetra-Antennary N-Glycans from a Common Precursor. J. Am. Chem. Soc., 139 (2): 1011-1018.

[34] Prudden, A. R., Liu, L., Capicciotti, C. J., Wolfert, M. A., Wang, S., Gao, Z. W., Meng, L., Moremen, K. W. \& Boons, G. J. (2017). Synthesis of asymmetrical multiantennary human milk oligosaccharides. Proc. Natl. Acad. Sci. U. S. A., 114 (27): 6954-6959. 
[35] Li, T. H., Liu, L., Wei, N., Yang, J. Y., Chapla, D. G., Moremen, K. W. \& Boons, G. J. (2019). An automated platform for the enzyme-mediated assembly of complex oligosaccharides. Nat. Chem., 11 (3): 229-236.

[36] Liu, L., Prudden, A. R., Capicciotti, C. J., Bosman, G. P., Yang, J. Y., Chapla, D. G., Moremen, K. W. \& Boons, G. J. (2019). Streamlining the chemoenzymatic synthesis of complex $\mathrm{N}$-glycans by a stop and go strategy. Nat. Chem., 11 (2): 161-169.

[37] Schmitt-Kopplin, P. (2016). Capillary electrophoresis : methods and protocols. New York: Humana Press.

[38] Vesterberg, O. (1989). History of electrophoretic methods. J. Chromatogr., 480: 3-19.

[39] Tiselius, A. (1937). A new apparatus for electrophoretic analysis of colloidal mixtures. Trans. Faraday Soc., 33 (1): 524-530.

[40] Martin, A. J. P. (1942, Unpublished results). Unpublished manuscript.

[41] Hjertén, S. (1967). Free zone electrophoresis. Chromatogr. Rev., 9 (2): 122-219.

[42] Everaerts, F. M., Beckers, J. L., Verheggen, T. P. E. M. \& Beckers, J. L. (1976). Isotachophoresis: theory, instrumentation and applications. Amsterdam: Elsevier.

[43] Jorgenson, J. W. \& Lukacs, K. D. (1981). Zone electrophoresis in open-tubular glass-capillaries. Analytical Chemistry, 53 (8): 1298-1302.

[44] de Jong, G. J. (2016). Capillary electrophoresis - mass spectrometry (CE-MS) : principles and applications. Weinheim: Wiley-VCH.

[45] Terabe, S., Otsuka, K., Ichikawa, K., Tsuchiya, A. \& Ando, T. (1984). Electronic separations with micellar solutions and open-tubular capillaries. Anal. Chem., 56 (1): 111-113.

[46] Silva, M. (2013). Micellar electrokinetic chromatography: A review of methodological and instrumental innovations focusing on practical aspects. Electrophoresis, 34 (1): 141-158.

[47] Sänger - van de Griend, C. E., Hedeland, Y. \& Pettersson., C. (2013). Chromatogr. Today, May/June: 32-37.

[48] Pretorius, V., Hopkins, B. J. \& Schieke, J. D. (1974). Electro-osmosis - New concept for high-speed liquid-chromatography. J. Chromatogr., 99 (NOV6): 23 30 .

[49] Tsuda, T., Nomura, K. \& Nakagawa, G. (1982). Open-tubular microcapillary liquid-chromatography with electroosmosis flow using a UV detector. $J$. Chromatogr., 248 (2): 241-247. 
[50] Knox, J. H. \& Grant, I. H. (1987). Miniaturizing in pressure and electroendosmotically driven liquid-chromatography - Some theoretical considerations. Chromatographia, 24: 135-143.

[51] Horvath, J. \& Dolnik, V. (2001). Polymer wall coatings for capillary electrophoresis. Electrophoresis, 22 (4): 644-655.

[52] Hajba, L. \& Guttman, A. (2017). Recent advances in column coatings for capillary electrophoresis of proteins. TrAC,Trends Anal. Chem., 90: 38-44.

[53] Garza, S., Chang, S. \& Moini, M. (2007). Simplifying capillary electrophoresismass spectrometry operation: Eliminating capillary derivatization by using selfcoating background electrolytes. J. Chromatogr. A, 1159 (1-2): 14-21.

[54] Huhn, C., Ramautar, R., Wuhrer, M. \& Somsen, G. W. (2010). Relevance and use of capillary coatings in capillary electrophoresis-mass spectrometry. Analytical and bioanalytical chemistry, 396 (1): 297-314.

[55] Manz, A., Harrison, D. J., Verpoorte, E. M. J., Fettinger, J. C., Paulus, A., Ludi, H. \& Widmer, H. M. (1992). Planer chips technology for miniaturization and integration of separation techniques into monitoring systems - Capillary electrophoresis on a chip. J. Chrom., 593 (1-2): 253-258.

[56] Jacobson, S. C., Hergenroder, R., Koutny, L. B. \& Ramsey, J. M. (1994). Highspeed separations on a microchip. Anal. Chem., 66 (7): 1114-1118.

[57] Han, H. L., Livingston, E. \& Chen, X. Y. (2011). High throughput profiling of charge heterogeneity in antibodies by microchip electrophoresis. Anal. Chem., 83 (21): 8184-8191.

[58] Dawod, M., Arvin, N. E. \& Kennedy, R. T. (2017). Recent advances in protein analysis by capillary and microchip electrophoresis. Analyst, 142 (11): 18471866.

[59] Redman, E. A., Batz, N. G., Mellors, J. S. \& Ramsey, J. M. (2015). Integrated microfluidic capillary electrophoresis-electrospray ionization devices with online MS detection for the separation and characterization of intact monoclonal antibody variants. Anal. Chem., 87 (4): 2264-2272.

[60] Redman, E. A., Mellors, J. S., Starkey, J. A. \& Ramsey, J. M. (2016). Characterization of intact antibody drug conjugate variants using microfluidic capillary electrophoresis-mass spectrometry. Anal. Chem., 88 (4): 2220-2226.

[61] Ruizmartinez, M. C., Berka, J., Belenkii, A., Foret, F., Miller, A. W. \& Karger, B. L. (1993). DNA-sequencing by capillary electrophoresis with replaceable linear polyacrilamide and laser-induced fluorescence detection. Anal. Chem., 65 (20): 2851-2858. 
[62] Swerdlow, H. \& Gesteland, R. (1990). Capillary gel-electrophoresis for rapid, high-resolution DNA sequencing. Nucleic Acids Res., 18 (6): 1415-1419.

[63] Zagursky, R. J. \& McCormick, R. M. (1990). DNA sequencing report - DNA sequencing separations in capillary gels on a modified commercial DNA sequencing instrument. Biotechniques, 9 (1): 74-79.

[64] Swerdlow, H., Wu, S., Harke, H. \& Dovichi, N. J. (1990). Capillary gelelectrophoresis for DNA sequencing - laser-induced fluorescence detection with the sheath flow cuvette. J. Chromatogr., 516 (1): 61-67.

[65] Dovichi, N. J. \& Zhang, J. Z. (2000). How capillary electrophoresis sequenced the human genome. Ang. Chem., Int. Ed., 39 (24): 4463-4468.

[66] Szekrenyes, A., Park, S. S., Santos, M., Lew, C., Jones, A., Haxo, T., Kimzey, M., Pourkaveh, S., Szabo, Z., Sosic, Z., et al. (2016). Multi-Site N-glycan mapping study 1: Capillary electrophoresis - laser induced fluorescence. $m A b s$, 8 (1): $56-64$.

[67] Kilar, F. (2003). Recent applications of capillary isoelectric focusing. Electrophoresis, 24 (22-23): 3908-3916.

[68] Shimura, K. (2009). Recent advances in IEF in capillary tubes and microchips. Electrophoresis, 30 (1): 11-28.

[69] Mao, Q. L. \& Pawliszyn, J. (1999). Capillary isoelectric focusing with whole column imaging detection for analysis of proteins and peptides. J. Biochem. Biophys. Methods, 39 (1-2): 93-110.

[70] Dai, J., Lamp, J., Xia, Q. W. \& Zhang, Y. R. (2018). Capillary isoelectric focusing-mass spectrometry method for the separation and online characterization of intact monoclonal antibody charge variants. Anal. Chem., 90 (3): 2246-2254.

[71] Liu, H. C., Zhang, L. H., Zhu, G. J., Zhang, W. B. \& Zhang, Y. K. (2004). An etched porous interface for on-line capillary electrophoresis-based twodimensional separation system. Anal. Chem., 76 (21): 6506-6512.

[72] Dole, M., Mack, L. L. \& Hines, R. L. (1968). Molecular beams of macroions. J. Chem. Phys., 49 (5): 2240-2249.

[73] Yamashita, M. \& Fenn, J. B. (1984). Electrospray ion-source - another variation on the free-jet theme. J. Phys. Chem., 88 (20): 4451-4459.

[74] Olivares, J. A., Nguyen, N. T., Yonker, C. R. \& Smith, R. D. (1987). online mass-spectrometric detection for capillary zone electrophoresis. Anal. Chem., 59 (8): 1230-1232. 
[75] Smith, R. D., Barinaga, C. J. \& Udseth, H. R. (1988). Improved Electrospray Ionization Interface for Capillary Zone Electrophoresis - Mass-Spectrometry. Anal. Chem., 60 (18): 1948-1952.

[76] Hommerson, P., Khan, A. M., de Jong, G. J. \& Somsen, G. W. (2011). Ionization techniques in capillary electrophoresis-mass spectrometry: principles, design, and application. Mass Spectrom. Rev., 30 (6): 1096-1120.

[77] Soga, T., Igarashi, K., Ito, C., Mizobuchi, K., Zimmermann, H. P. \& Tomita, M. (2009). Metabolomic profiling of anionic metabolites by capillary electrophoresis mass spectrometry. Anal. Chem., 81 (15): 6165-6174.

[78] Causon, T. J., Maringer, L., Buchberger, W. \& Klampfl, C. W. (2014). Addition of reagents to the sheath liquid: a novel concept in capillary electrophoresismass spectrometry. J. Chromatogr. A, 1343: 182-187.

[79] do Lago, C. L., Vidal, D. T., Francisco, K. J. \& dos Santos, V. B. (2014). A simple approach to compensate the suction caused by the electrospray ionization source in capillary electrophoresis-mass spectrometry systems. Electrophoresis, 35 (16): 2412-2416

[80] Eriksson, J. H., Mol, R., Somsen, G. W., Hinrichs, W. L., Frijlink, H. W. \& de Jong, G. J. (2004). Feasibility of nonvolatile buffers in capillary electrophoresiselectrospray ionization-mass spectrometry of proteins. Electrophoresis, 25 (1): 43-49.

[81] Chien, C. T., Li, F. A., Huang, J. L. \& Her, G. R. (2007). CE-MS of antihistamines using nonvolatile phosphate buffer. Electrophoresis, 28 (9): 1454-1560.

[82] Gottardo, R., Miksik, I., Aturki, Z., Sorio, D., Seri, C., Fanali, S. \& Tagliaro, F. (2012). Analysis of drugs of forensic interest with capillary zone electrophoresis/time-of-flight mass spectrometry based on the use of nonvolatile buffers. Electrophoresis, 33 (4): 599-606.

[83] Gonzalez-Ruiz, V., Codesido, S., Rudaz, S. \& Schappler, J. (2018). Evolution in the design of a low sheath-flow interface for CE-MS and application to biological samples. Electrophoresis, 39 (5-6): 853-861.

[84] Gonzalez-Ruiz, V., Codesido, S., Far, J., Rudaz, S. \& Schappler, J. (2016). Evaluation of a new low sheath-flow interface for CE-MS. Electrophoresis, 37 (7-8): 936-946.

[85] Moini, M. (2007). Simplifying CE-MS operation. 2. Interfacing low-flow separation techniques to mass spectrometry using a porous tip. Anal. Chem., 79 (11): 4241-4246.

[86] Yin, Y., Li, G., Guan, Y. \& Huang, G. (2016). Sheathless interface to match flow rate of capillary electrophoresis with electrospray mass spectrometry using regular-sized capillary. Rapid Commun Mass Spectrom, 30 Suppl 1: 68-72. 
[87] Haselberg, R., de Jong, G. J. \& Somsen, G. W. (2013). Low-flow sheathless capillary electrophoresis-mass spectrometry for sensitive glycoform profiling of intact pharmaceutical proteins. Anal. Chem., 85 (4): 2289-2296.

[88] Haselberg, R., Ratnayake, C. K., de Jong, G. J. \& Somsen, G. W. (2010). Performance of a sheathless porous tip sprayer for capillary electrophoresiselectrospray ionization-mass spectrometry of intact proteins. J. Chromatogr. A, 1217 (48): 7605-11.

[89] Ramautar, R., Busnel, J. M., Deelder, A. M. \& Mayboroda, O. A. (2012). Enhancing the coverage of the urinary metabolome by sheathless capillary electrophoresis-mass spectrometry. Anal. Chem., 84 (2): 885-892.

[90] Lee, E. D., Muck, W., Henion, J. D. \& Covey, T. R. (1989). Liquid junction coupling for capillary zone electrophoresis/ion spray mass spectrometry. Biomed. Environ. Mass Spectrom., 18 (9): 844-850.

[91] Maxwell, E. J., Zhong, X., Zhang, H., van Zeijl, N. \& Chen, D. D. (2010). Decoupling CE and ESI for a more robust interface with MS. Electrophoresis, 31 (7): 1130-1137.

[92] Maxwell, E. J., Zhong, X. F. \& Chen, D. D. Y. (2010). Asymmetrical emitter geometries for increased range of stable electrospray flow rates. Anal. Chem., 82 (20): 8377-8381.

[93] Zhong, X., Maxwell, E. J., Ratnayake, C., Mack, S. \& Chen, D. D. (2011). Flowthrough microvial facilitating interface of capillary isoelectric focusing and electrospray ionization mass spectrometry. Anal. Chem., 83 (22): 8748-8755.

[94] Sun, L., Zhu, G., Zhang, Z., Mou, S. \& Dovichi, N. J. (2015). Third-generation electrokinetically pumped sheath-flow nanospray interface with improved stability and sensitivity for automated capillary zone electrophoresis-mass spectrometry analysis of complex proteome digests. J. Proteome Res., 14 (5): $2312-2321$.

[95] Batz, N. G., Mellors, J. S., Alarie, J. P. \& Ramsey, J. M. (2014). Chemical vapor deposition of aminopropyl silanes in microfluidic channels for highly efficient microchip capillary electrophoresis-electrospray ionization-mass spectrometry. Anal. Chem., 86 (7): 3493-3500.

[96] Khatri, K., Klein, J. A., Haserick, J. R., Leon, D. R., Costello, C. E., McComb, M. E. \& Zaia, J. (2017). Microfluidic capillary electrophoresis-mass spectrometry for analysis of monosaccharides, oligosaccharides, and glycopeptides. Anal. Chem., 89 (12): 6645-6655.

[97] Silvertand, L. H., Sastre Torano, J., de Jong, G. J. \& van Bennekom, W. P. (2009). Development and characterization of cIEF-MALDI-TOF MS for protein analysis. Electrophoresis, 30 (10): 1828-1835. 
[98] Busnel, J. M., Josserand, J., Lion, N. \& Girault, H. H. (2009). Iontophoretic fraction collection for coupling capillary zone electrophoresis with matrixassisted laser desorption/ionization mass spectrometry. Anal. Chem., 81 (10): 3867-3872.

[99] Wang, J., Ma, M., Chen, R. \& Li, L. (2008). Enhanced neuropeptide profiling via capillary electrophoresis off-line coupled with MALDI FTMS. Anal. Chem., 80 (16): 6168-6177.

[100] Tycova, A., Vido, M., Kovarikova, P. \& Foret, F. (2016). Interface-free capillary electrophoresis-mass spectrometry system with nanospray ionization-Analysis of dexrazoxane in blood plasma. J. Chromatogr. A, 1466: 173-179.

[101] Krenkova, J., Kleparnik, K., Grym, J., Luksch, J. \& Foret, F. (2016). Selfaligning subatmospheric hybrid liquid junction electrospray interface for capillary electrophoresis. Electrophoresis, 37 (3): 414-417.

[102] Fekete, S., Guillarme, D., Sandra, P. \& Sandra, K. (2016). Chromatographic, electrophoretic, and mass spectrometric methods for the analytical characterization of protein biopharmaceuticals. Anal. Chem., 88 (1): 480-507.

[103] Moritz, B., Schnaible, V., Kiessig, S., Heyne, A., Wild, M., Finkler, C., Christians, S., Mueller, K., Zhang, L., Furuya, K., et al. (2015). Evaluation of capillary zone electrophoresis for charge heterogeneity testing of monoclonal antibodies. J. Chromatogr. B: Anal. Technol. Biomed. Life Sci., 983-984: 10110.

[104] Beck, A., Wagner-Rousset, E., Ayoub, D., Van Dorsselaer, A. \& SanglierCianferani, S. (2013). Characterization of Therapeutic Antibodies and Related Products. Anal. Chem., 85 (2): 715-736.

[105] Salas-Solano, O., Tomlinson, B., Du, S., Parker, M., Strahan, A. \& Ma, S. (2006). Optimization and validation of a quantitative capillary electrophoresis sodium dodecyl sulfate method for quality control and stability monitoring of monoclonal antibodies. Anal. Chem., 78 (18): 6583-6594.

[106] Han, M., Phan, D., Nightlinger, N., Taylor, L., Jankhah, S., Woodruff, B., Yates, Z., Freeman, S., Guo, A., Balland, A., et al. (2006). Optimization of CE-SDS method for antibody separation based on multi-users experimental practices. Chromatographia, 64 (5-6): 335-342.

[107] Esterman, A. L., Katiyar, A. \& Krishnamurthy, G. (2016). Implementation of USP antibody standard for system suitability in capillary electrophoresis sodium dodecyl sulfate (CE-SDS) for release and stability methods. J. Pharm. Biomed. Anal., 128: 447-454.

[108] Yin, S., Pastuskovas, C. V., Khawli, L. A. \& Stults, J. T. (2013). Characterization of therapeutic monoclonal antibodies reveals differences between in vitro and in vivo time-course studies. Pharm. Res., 30 (1): 167-178. 
[109] Szekely, A., Szekrenyes, A., Kerekgyarto, M., Balogh, A., Kadas, J., Lazar, J., Guttman, A., Kurucz, I. \& Takacs, L. (2014). Multicapillary SDS-gel electrophoresis for the analysis of fluorescently labeled mAb preparations: A high throughput quality control process for the production of QuantiPlasma and PlasmaScan mAb libraries. Electrophoresis, 35 (15): 2155-2162.

[110] Kubota, K., Kobayashi, N., Yabuta, M., Ohara, M., Naito, T., Kubo, T. \& Otsuka, K. (2017). Identification and characterization of a thermally cleaved fragment of monoclonal antibody-A detected by sodium dodecyl sulfatecapillary gel electrophoresis. J. Pharm. Biomed. Anal., 140: 98-104.

[111] Smith, M. T., Zhang, S., Adams, T., DiPaolo, B. \& Dally, J. (2017). Establishment and validation of a microfluidic capillary gel electrophoresis platform method for purity analysis of therapeutic monoclonal antibodies. Electrophoresis, 38 (9-10): 1353-1365.

[112] Tamizi, E. \& Jouyban, A. (2015). The potential of the capillary electrophoresis techniques for quality control of biopharmaceuticals-A review. Electrophoresis, 36 (6): 831-858.

[113] Fekete, S., Gassner, A. L., Rudaz, S., Schappler, J. \& Guillarme, D. (2013). Analytical strategies for the characterization of therapeutic monoclonal antibodies. TrAC,Trends Anal. Chem., 42: 74-83.

[114] Suba, D., Urbanyi, Z. \& Salgo, A. (2015). Capillary isoelectric focusing method development and validation for investigation of recombinant therapeutic monoclonal antibody. J. Pharm. Biomed. Anal., 114: 53-61.

[115] Wu, Z. G., Zhou, P., Li, X. X., Wang, H., Luo, D. L., Qiao, H. Y., Ke, X. \& Huang, J. (2013). Structural characterization of a recombinant fusion protein by instrumental analysis and molecular modeling. Plos One, 8 (3): 1-8.

[116] Salas-Solano, O., Babu, K., Park, S. S., Zhang, X. F., Zhang, L., Sosic, Z., Boumajny, B., Zeng, M., Cheng, K. C., Reed-Bogan, A., et al. (2011). Intercompany study to evaluate the robustness of capillary isoelectric focusing technology for the analysis of monoclonal antibodies. Chromatographia, 73 (1112): 1137-1144.

[117] Kinoshita, M., Nakatsuji, Y., Suzuki, S., Hayakawa, T. \& Kakehi, K. (2013). Quality assurance of monoclonal antibody pharmaceuticals based on their charge variants using microchip isoelectric focusing method. J. Chrom. A, 1309: 76-83.

[118] Vincents, B., von Pawel-Rammingen, U., Bjorck, L. \& Abrahamson, M. (2004). Enzymatic characterization of the streptococcal endopeptidase, IdeS, reveals that it is a cysteine protease with strict specificity for IgG cleavage due to exosite binding. Biochemistry, 43 (49): 15540-15549. 
[119] Han, M., Rock, B. M., Pearson, J. T. \& Rock, D. A. (2016). Intact mass analysis of monoclonal antibodies by capillary electrophoresis-Mass spectrometry. $J$. Chromatogr. B: Anal. Technol. Biomed. Life Sci., 1011: 24-32.

[120] Biacchi, M., Gahoual, R., Said, N., Beck, A., Leize-Wagner, E. \& Francois, Y. N. (2015). Glycoform separation and characterization of cetuximab variants by middle-up off-line capillary zone electrophoresis-UV/electrospray ionizationMS. Anal. Chem., 87 (12): 6240-6250.

[121] Suba, D., Urbanyi, Z. \& Salgo, A. (2016). Method development and qualification of capillary zone electrophoresis for investigation of therapeutic monoclonal antibody quality. J. Chromatogr. B: Anal. Technol. Biomed. Life Sci., 1032: 224-229.

[122] Bush, D. R., Zang, L., Belov, A. M., Ivanov, A. R. \& Kargert, B. L. (2016). High resolution CZE-MS quantitative characterization of intact biopharmaceutical proteins: proteoforms of interferon-beta 1. Anal. Chem., 88 (2): 1138-1146.

[123] Biacchi, M., Bhajun, R., Said, N., Beck, A., Francois, Y. N. \& Leize-Wagner, E. (2014). Analysis of monoclonal antibody by a novel CE-UV/MALDI-MS interface. Electrophoresis, 35 (20): 2986-2995.

[124] Taichrib, A., Pelzing, M., Pellegrino, C., Rossi, M. \& Neususs, C. (2011). High resolution TOF MS coupled to $\mathrm{CE}$ for the analysis of isotopically resolved intact proteins. J. Proteomics, 74 (7): 958-966.

[125] Haselberg, R., Brinks, V., Hawe, A., de Jong, G. J. \& Somsen, G. W. (2011). Capillary electrophoresis-mass spectrometry using noncovalently coated capillaries for the analysis of biopharmaceuticals. Anal. Bioanal. Chem., 400 (1): 295-303.

[126] Redman, E. A., Mellors, J. S., Starkey, J. A. \& Ramsey, J. M. (2016). Characterization of intact antibody drug conjugate variants using microfluidic capillary electrophoresis-mass spectrometry. Analytical Chemistry, 88 (4): 2220-2226.

[127] Said, N., Gahoual, R., Kuhn, L., Beck, A., Francois, Y. N. \& Leize-Wagner, E. (2016). Structural characterization of antibody drug conjugate by a combination of intact, middle-up and bottom-up techniques using sheathless capillary electrophoresis - Tandem mass spectrometry as nanoESI infusion platform and separation method. Anal. Chim. Acta, 918: 50-59.

[128] Laroy, W., Contreras, R. \& Callewaert, N. (2006). Glycome mapping on DNA sequencing equipment. Nat. Protoc., 1 (1): 397-405.

[129] Durney, B. C., Crihfield, C. L. \& Holland, L. A. (2015). Capillary electrophoresis applied to DNA: determining and harnessing sequence and structure to advance bioanalyses (2009-2014). Anal. Bioanal. Chem., 407 (23): 6923-6938. 
[130] Beneito-Cambra, M., Anres, P., Vial, J., Gareil, P. \& Delaunay, N. (2016). Stability and effectiveness of linear polyacrylamide capillary coating to suppress EOF in acidic media in the presence of surfactants, ionic liquids and organic modifiers. Talanta, 150: 546-552.

[131] Belder, D., Deege, A., Husmann, H., Kohler, F. \& Ludwig, M. (2001). Crosslinked poly(vinyl alcohol) as permanent hydrophilic column coating for capillary electrophoresis. Electrophoresis, 22 (17): 3813-3818.

[132] Liu, J. P., Shirota, O. \& Novotny, M. V. (1992). Sensitive, Laser-Assisted Determination of Complex Oligosaccharide Mixtures Separated by Capillary Gel-Electrophoresis at High-Resolution. Anal. Chem., 64 (8): 973-975.

[133] Klockow, A., Widmer, H. M., Amado, R. \& Paulus, A. (1994). Capillary Electrophoresis of Ants Labeled Oligosaccharide Ladders and Complex Carbohydrates. Fresenius' J. Anal. Chem., 350 (7-9): 415-425.

[134] Kerekgyarto, M. \& Guttman, A. (2014). Toward the generation of an aminonaphthalene trisulfonate labeled N-glycan database for capillary gel electrophoresis analysis of carbohydrates. Electrophoresis, 35 (15): 2222-2228.

[135] Callewaert, N., Geysens, S., Molemans, P. \& Contreras, R. (2001). Ultrasensitive profiling and sequencing of N-linked oligosaccharides using standard DNA-sequencing equipment. Glycobiology, 11 (4): 275-281.

[136] Fang, M., Zhao, Y. P., Zhou, F. G., Lu, L. G., Qi, P., Wang, H., Zhou, K., Sun, S. H., Chen, C. Y. \& Gao, C. F. (2010). N-glycan based models improve diagnostic efficacies in hepatitis B virus-related hepatocellular carcinoma. Int. J. Cancer, 127 (1): 148-159.

[137] Zhao, Y. P., Xu, X. Y., Fang, M., Wang, H., You, Q., Yi, C. H., Ji, J., Gu, X., Zhou, P. T., Cheng, C., et al. (2014). Decreased core-fucosylation contributes to malignancy in gastric cancer. PLoS One, 9 (4): e94536.

[138] Zhao, Y. P., Ruan, C. P., Wang, H., Hu, Z. Q., Fang, M., Gu, X., Ji, J., Zhao, J. Y. \& Gao, C. F. (2012). Identification and assessment of new biomarkers for colorectal cancer with serum N-glycan profiling. Cancer, 118 (3): 639-650.

[139] Moginger, U., Grunewald, S., Hennig, R., Kuo, C. W., Schirmeister, F., Voth, H., Rapp, E., Khoo, K. H., Seeberger, P. H., Simon, J. C., et al. (2018). Alterations of the human skin $\mathrm{N}$ - and $\mathrm{O}$-glycome in basal cell carcinoma and squamous cell carcinoma. Front. Oncol., 8: 70.

[140] Mitra, I., Snyder, C. M., Zhou, X., Campos, M. I., Alley, W. R., Jr., Novotny, M. V. \& Jacobson, S. C. (2016). Structural characterization of serum N-glycans by methylamidation, fluorescent labeling, and analysis by microchip electrophoresis. Anal. Chem., 88 (18): 8965-8671.

[141] Snyder, C. M., Alley, W. R., Jr., Campos, M. I., Svoboda, M., Goetz, J. A., Vasseur, J. A., Jacobson, S. C. \& Novotny, M. V. (2016). Complementary 
glycomic analyses of sera derived from colorectal cancer patients by MALDITOF-MS and microchip electrophoresis. Anal. Chem., 88 (19): 9597-9605.

[142] Guttman, A. (2013). Capillary electrophoresis in the N-glycosylation analysis of biopharmaceuticals. TrAC,Trends Anal. Chem., 48: 132-143.

[143] Szabo, Z., Guttman, A., Bones, J. \& Karger, B. L. (2011). Rapid high-resolution characterization of functionally important monoclonal antibody $\mathrm{N}$-glycans by capillary electrophoresis. Anal. Chem., 83 (13): 5329-5336.

[144] Schwarzer, J., Rapp, E. \& Reichl, U. (2008). N-glycan analysis by CGE-LIF: profiling influenza A virus hemagglutinin $\mathrm{N}$-glycosylation during vaccine production. Electrophoresis, 29 (20): 4203-4214.

[145] Snyder, C. M., Zhou, X., Karty, J. A., Fonslow, B. R., Novotny, M. V. \& Jacobson, S. C. (2017). Capillary electrophoresis-mass spectrometry for direct structural identification of serum N-glycans. J. Chromatogr. A, 1523: 127-139.

[146] Bunz, S. C., Rapp, E. \& Neususs, C. (2013). Capillary electrophoresis/mass spectrometry of APTS-labeled glycans for the identification of unknown glycan species in capillary electrophoresis/laser-induced fluorescence systems. Anal. Chem., 85 (21): 10218-10224.

[147] Jayo, R. G., Li, J. \& Chen, D. D. (2012). Capillary electrophoresis mass spectrometry for the characterization of $\mathrm{O}$-acetylated $\mathrm{N}$-glycans from fish serum. Anal. Chem., 84 (20): 8756-8762.

[148] Jayo, R. G., Thaysen-Andersen, M., Lindenburg, P. W., Haselberg, R., Hankemeier, T., Ramautar, R. \& Chen, D. D. (2014). Simple capillary electrophoresis-mass spectrometry method for complex glycan analysis using a flow-through microvial interface. Anal. Chem., 86 (13): 6479-6486.

[149] Langan, T. J. \& Holland, L. A. (2012). Capillary electrophoresis coupled to electrospray mass spectrometry through a coaxial sheath flow interface and semi-permanent phospholipid coating for the determination of oligosaccharides labeled with 1-aminopyrene-3,6,8-trisulfonic acid. Electrophoresis, 33 (4): 607 613.

[150] Khan, S., Liu, J., Szabo, Z., Kunnummal, B., Han, X., Ouyang, Y., Linhardt, R. J. \& Xia, Q. (2018). On-line capillary electrophoresis/laser-induced fluorescence/mass spectrometry analysis of glycans labeled with Teal fluorescent dye using an electrokinetic sheath liquid pump-based nanospray ion source. Rapid Commun. Mass Spectrom., 32 (11): 882-888.

[151] Jooss, K., Sommer, J., Bunz, S. C. \& Neususs, C. (2014). In-line SPE-CE using a fritless bead string design--application for the analysis of organic sulfonates including inline SPE-CE-MS for APTS-labeled glycans. Electrophoresis, 35 (9): 1236-1243. 
[152] Yuan, J., Hashii, N., Kawasaki, N., Itoh, S., Kawanishi, T. \& Hayakawa, T. (2005). Isotope tag method for quantitative analysis of carbohydrates by liquid chromatography-mass spectrometry. J. Chromatogr. A, 1067 (1-2): 145-152.

[153] Varadi, C., Mittermayr, S., Millan-Martin, S. \& Bones, J. (2016). Quantitative twoplex glycan analysis using (12)C6 and (13)C6 stable isotope 2-aminobenzoic acid labelling and capillary electrophoresis mass spectrometry. Anal. Bioanal. Chem., 408 (30): 8691-8700.

[154] Hahne, H., Neubert, P., Kuhn, K., Etienne, C., Bomgarden, R., Rogers, J. C. \& Kuster, B. (2012). Carbonyl-reactive tandem mass tags for the proteome-wide quantification of N-linked glycans. Anal. Chem., 84 (8): 3716-3724.

[155] Zhong, X., Chen, Z., Snovida, S., Liu, Y., Rogers, J. C. \& Li, L. (2015). Capillary electrophoresis-electrospray ionization-mass spectrometry for quantitative analysis of glycans labeled with multiplex carbonyl-reactive tandem mass tags. Anal. Chem., 87 (13): 6527-6534.

[156] Dovichi, N. J. \& Zhang, J. (2000). How capillary electrophoresis sequenced the human genome. Angew. Chem., Int. Ed. Engl., 39 (24): 4463-4468.

[157] Lageveen-Kammeijer, G. S. M., de Haan, N., Mohaupt, P., Wagt, S., Filius, M., Nouta, J., Falck, D. \& Wuhrer, M. (2019). Highly sensitive CE-ESI-MS analysis of N-glycans from complex biological samples. Nat. Commun., 10 (1): 2137.

[158] Sastre Torano, J., Gagarinov, I. A., Vos, G. M., Broszeit, F., Srivastava, A. D., Palmer, M., Langridge, J. I., Aizpurua-Olaizola, O., Somovilla, V. J. \& Boons, G. J. (2019). Ion-mobility spectrometry can assign exact fucosyl positions in glycans and prevent misinterpretation of mass-spectrometry data after gas-phase rearrangement. Angew. Chem., Int. Ed. Engl., 58 (49): 17616-17620.

[159] Slampova, A., Mala, Z. \& Gebauer, P. (2019). Recent progress of sample stacking in capillary electrophoresis (2016-2018). Electrophoresis, 40 (1): 4054.

[160] Medina-Casanellas, S., Tak, Y. H., Benavente, F., Sanz-Nebot, V., Sastre Torano, J., Somsen, G. W. \& de Jong, G. J. (2014). Evaluation of fritless solidphase extraction coupled on-line with capillary electrophoresis-mass spectrometry for the analysis of opioid peptides in cerebrospinal fluid. Electrophoresis, 35 (20): 2996-3002.

[161] Tak, Y. H., Sastre Torano, J., Somsen, G. W. \& de Jong, G. J. (2012). Optimization of in-line fritless solid-phase extraction for capillary electrophoresis-mass spectrometry. J. Chromatogr. A, 1267: 138-143.

[162] Cummins, A. B. (1942). Clarifying efficiency of diatomaceous filter aids. Ind. Eng. Chem., 34 (4): 403-411. 
[163] Peng, S. X., Branch, T. M. \& King, S. L. (2001). Fully automated 96-well liquidliquid extraction for analysis of biological samples by liquid chromatography with tandem mass spectrometry. Anal. Chem., 73 (3): 708-714.

[164] James, A. T. \& Martin, A. J. (1952). Gas-liquid partition chromatography; the separation and micro-estimation of volatile fatty acids from formic acid to dodecanoic acid. Biochem. J., 50 (5): 679-90.

[165] Whistler, R. L. \& Durso, D. F. (1950). Chromatographic Separation of Sugars on Charcoal. J. Am. Chem. Soc., 72 (2): 677-679.

[166] Howard, G. A. \& Martin, A. J. P. (1950). The separation of the C12-C18 fatty acids by reversed-phase partition chromatography. Biochem. J., 46 (5): 532-538.

[167] Federal Regulations (annual edition) - Title 21 - Food and Drugs - Part 573 Food additives permitted in feed and drinking water of animals-Section 573.340 - Diatomaceous earth. . (2001). Administration, F. a. D.: U.S. Government Publishing Office.

[168] Bočker, P., Gebauer, P. \& Deml, M. (1981). Migration behaviour of the hydrogen ion and its role in isotachophoresis of cations. J. Chromatogr. A, 217: 209-224.

[169] Cummings, R. D. \& Pierce, J. M. (2014). The challenge and promise of glycomics. Chem. Biol., 21 (1): 1-15.

[170] Wolfert, M. A. \& Boons, G. J. (2013). Adaptive immune activation: glycosylation does matter. Nat Chem Biol, 9 (12): 776-84.

[171] Scott, H. \& Panin, V. M. (2014). The role of protein N-glycosylation in neural transmission. Glycobiology, 24 (5): 407-417.

[172] Dalziel, M., Crispin, M., Scanlan, C. N., Zitzmann, N. \& Dwek, R. A. (2014). Emerging principles for the therapeutic exploitation of glycosylation. Science, 343 (6166): 1235681.

[173] Hudak, J. E. \& Bertozzi, C. R. (2014). Glycotherapy: new advances inspire a reemergence of glycans in medicine. Chem. Biol., 21 (1): 16-37.

[174] Aizpurua-Olaizola, O., Torano, J. S., Falcon-Perez, J. M., Williams, C., Reichardt, N. \& Boons, G. J. (2018). Mass spectrometry for glycan biomarker discovery. TrAC, Trends Anal. Chem., 100: 7-14.

[175] Alley, W. R., Jr., Mann, B. F. \& Novotny, M. V. (2013). High-sensitivity analytical approaches for the structural characterization of glycoproteins. Chem. Rev., 113 (4): 2668-2732.

[176] Dotz, V., Haselberg, R., Shubhakar, A., Kozak, R. P., Falck, D., Rombouts, Y., Reusch, D., Somsen, G. W., Fernandes, D. L. \& Wuhrer, M. (2015). Mass 
spectrometry for glycosylation analysis of biopharmaceuticals. TrAC, Trends Anal. Chem., 73: 1-9.

[177] Ruhaak, L. R., Xu, G., Li, Q., Goonatilleke, E. \& Lebrilla, C. B. (2018). Mass spectrometry approaches to glycomic and glycoproteomic analyses. Chem. Rev., 118 (17): 7886-7930.

[178] Gray, C. J., Migas, L. G., Barran, P. E., Pagel, K., Seeberger, P. H., Eyers, C. E., Boons, G. J., Pohl, N. L. B., Compagnon, I., Widmalm, G., et al. (2019). Advancing solutions to the carbohydrate sequencing challenge. J. Am. Chem. Soc., 141 (37): 14463-14479.

[179] Both, P., Green, A. P., Gray, C. J., Sardzik, R., Voglmeir, J., Fontana, C., Austeri, M., Rejzek, M., Richardson, D., Field, R. A., et al. (2014). Discrimination of epimeric glycans and glycopeptides using IM-MS and its potential for carbohydrate sequencing. Nat. Chem., 6 (1): 65-74.

[180] Plasencia, M. D., Isailovic, D., Merenbloom, S. I., Mechref, Y., Novotny, M. V. \& Clemmer, D. E. (2008). Resolving and assigning N-linked glycan structural isomers from ovalbumin by IMS-MS. J. Am. Soc. Mass Spectrom., 19 (11): 1706-1715.

[181] Zhu, F., Lee, S., Valentine, S. J., Reilly, J. P. \& Clemmer, D. E. (2012). Mannose7 glycan isomer characterization by IMS-MS/MS analysis. J. Am. Soc. Mass Spectrom., 23 (12): 2158-2166.

[182] Hoftmann, J., Stuckmann, A., Crispin, M., Harvey, D. J., Page, K. \& Struwe, W. B. (2017). Identification of lewis and blood group carbohydrate epitopes by ion mobility-tandem-mass spectrometry fingerprinting. Anal. Chem., 89 (4): 23182325 .

[183] Harvey, D. J., Watanabe, Y., Allen, J. D., Rudd, P., Pagel, K., Crispin, M. \& Struwe, W. B. (2018). Collision cross sections and ion mobility separation of fragment ions from complex N-glycans. J. Am. Soc. Mass Spectrom., 29 (6): $1250-1261$.

[184] Pagel, K. \& Harvey, D. J. (2013). Ion mobility-mass spectrometry of complex carbohydrates: collision cross sections of sodiated N-linked glycans. Anal. Chem., 85 (10): 5138-5145.

[185] Struwe, W. B., Benesch, J. L., Harvey, D. J. \& Pagel, K. (2015). Collision cross sections of high-mannose N-glycans in commonly observed adduct states-identification of gas-phase conformers unique to [M-H](-) ions. Analyst, 140 (20): 6799-6803.

[186] Hofmann, J., Hahm, H. S., Seeberger, P. H. \& Pagel, K. (2015). Identification of carbohydrate anomers using ion mobility-mass spectrometry. Nature, 526 (7572): 241-244. 
[187] Hofmann, J., Struwe, W. B., Scarff, C. A., Scrivens, J. H., Harvey, D. J. \& Pagel, K. (2014). Estimating collision cross sections of negatively charged N-glycans using traveling wave ion mobility-mass spectrometry. Anal. Chem., 86 (21): 10789-10795.

[188] Struwe, W. B., Pagel, K., Benesch, J. L., Harvey, D. J. \& Campbell, M. P. (2016). GlycoMob: an ion mobility-mass spectrometry collision cross section database for glycomics. Glycoconjugate J., 33 (3): 399-404.

[189] Re, S., Watabe, S., Nishima, W., Muneyuki, E., Yamaguchi, Y., MacKerell, A. D., Jr. \& Sugita, Y. (2018). Characterization of Conformational Ensembles of Protonated N-glycans in the Gas-Phase. Sci. Rep., 8 (1): 1644.

[190] May, J. C., Goodwin, C. R., Lareau, N. M., Leaptrot, K. L., Morris, C. B., Kurulugama, R. T., Mordehai, A., Klein, C., Barry, W., Darland, E., et al. (2014). Conformational ordering of biomolecules in the gas phase: nitrogen collision cross sections measured on a prototype high resolution drift tube ion mobility-mass spectrometer. Anal. Chem., 86 (4): 2107-2116.

[191] Yamaguchi, Y., Nishima, W., Re, S. \& Sugita, Y. (2012). Confident identification of isomeric N-glycan structures by combined ion mobility mass spectrometry and hydrophilic interaction liquid chromatography. Rapid Commun. Mass Spectrom., 26 (24): 2877-2884.

[192] Struwe, W. B., Baldauf, C., Hofmann, J., Rudd, P. M. \& Pagel, K. (2016). Ion mobility separation of deprotonated oligosaccharide isomers - evidence for gasphase charge migration. Chem. Commun. (Cambridge, U. K.), 52 (83): 1235312356.

[193] Harvey, D. J., Crispin, M., Bonomelli, C. \& Scrivens, J. H. (2015). Ion mobility mass spectrometry for ion recovery and clean-up of MS and MS/MS spectra obtained from low abundance viral samples. J. Am. Soc. Mass Spectrom., 26 (10): 1754-1767.

[194] Manz, C., Grabarics, M., Hoberg, F., Pugini, M., Stuckmann, A., Struwe, W. B. \& Pagel, K. (2019). Separation of isomeric glycans by ion mobility spectrometry - the impact of fluorescent labelling. Analyst, 144 (17): 5292-5298.

[195] Re, S., Nishima, W., Miyashita, N. \& Sugita, Y. (2012). Conformational flexibility of N-glycans in solution studied by REMD simulations. Biophys. Rev., 4 (3): 179-187.

[196] Nishima, W., Miyashita, N., Yamaguchi, Y., Sugita, Y. \& Re, S. (2012). Effect of bisecting GlcNAc and core fucosylation on conformational properties of biantennary complex-type N-glycans in solution. J. Phys. Chem. B, 116 (29): 8504-8512.

[197] Almond, A., Petersen, B. O. \& Duus, J. O. (2004). Oligosaccharides implicated in recognition are predicted to have relatively ordered structures. Biochemistry, 43 (19): 5853-5863. 
[198] Almond, A. (2005). Towards understanding the interaction between oligosaccharides and water molecules. Carbohydr. Res., 340 (5): 907-920.

[199] Woods, R. J., Pathiaseril, A., Wormald, M. R., Edge, C. J. \& Dwek, R. A. (1998). The high degree of internal flexibility observed for an oligomannose oligosaccharide does not alter the overall topology of the molecule. Eur. $J$. Biochem., 258 (2): 372-386.

[200] Montreuil, J. (1984). Spatial conformation of glycans and glycoproteins. Biol. Cell, 51 (2): 115-131.

[201] Guillot, A., Dauchez, M., Belloy, N., Jonquet, J., Duca, L., Romier, B., Maurice, P., Debelle, L., Martiny, L., Durlach, V., et al. (2016). Impact of sialic acids on the molecular dynamic of bi-antennary and tri-antennary glycans. Sci. Rep., 6.

[202] Jin, L., Barran, P. E., Deakin, J. A., Lyon, M. \& Uhrin, D. (2005). Conformation of glycosaminoglycans by ion mobility mass spectrometry and molecular modelling. Phys. Chem. Chem. Phys., 7 (19): 3464-3471.

[203] Warnke, S., Seo, J., Boschmans, J., Sobott, F., Scrivens, J. H., Bleiholder, C., Bowers, M. T., Gewinner, S., Schollkopf, W., Pagel, K., et al. (2015). Protomers of benzocaine: solvent and permittivity dependence. J Am Chem Soc, 137 (12): 4236-42.

[204] Seko, A., Koketsu, M., Nishizono, M., Enoki, Y., Ibrahim, H. R., Juneja, L. R., Kim, M. \& Yamamoto, T. (1997). Occurrence of a sialylglycopeptide and free sialylglycans in hen's egg yolk. Biochim. Biophys. Acta, 1335 (1-2): 23-32.

[205] Liu, L., Prudden, A. R., Bosman, G. P. \& Boons, G. J. (2017). Improved isolation and characterization procedure of sialylglycopeptide from egg yolk powder. Carbohydr. Res., 452: 122-128.

[206] Stow, S. M., Causon, T. J., Zheng, X., Kurulugama, R. T., Mairinger, T., May, J. C., Rennie, E. E., Baker, E. S., Smith, R. D., McLean, J. A., et al. (2017). An Interlaboratory Evaluation of Drift Tube Ion Mobility-Mass Spectrometry Collision Cross Section Measurements. Anal. Chem., 89 (17): 9048-9055.

[207] Harvey, D. J., Scarff, C. A., Edgeworth, M., Pagel, K., Thalassinos, K., Struwe, W. B., Crispin, M. \& Scrivens, J. H. (2016). Travelling-wave ion mobility mass spectrometry and negative ion fragmentation of hybrid and complex N-glycans. J. Mass Spectrom., 51 (11): 1064-1079.

[208] Marchand, A., Livet, S., Rosu, F. \& Gabelica, V. (2017). Drift tube ion mobility: how to reconstruct collision cross section distributions from arrival time distributions? Anal. Chem., 89 (23): 12674-12681.

[209] De Leoz, M. L. A., Simon-Manso, Y., Woods, R. J. \& Stein, S. E. (2019). Crossring fragmentation patterns in the tandem mass spectra of underivatized 
sialylated oligosaccharides and their special suitability for spectrum library searching. J. Am. Soc. Mass. Spectrom., 30 (3): 426-438.

[210] Andre, S., Kozar, T., Kojima, S., Unverzagt, C. \& Gabius, H. J. (2009). From structural to functional glycomics: core substitutions as molecular switches for shape and lectin affinity of N-glycans. Biol. Chem., 390 (7): 557-565.

[211] Woods, R. J. (2013). GLYCAM web. GLYCAM web, http://glycam.org Complex Carbohydrate Research Center, University of Georgia, Athens, GA. Available at: http://glycam.org.

[212] Case, D. A., Brozell, S. R., Cerutti, D. S., Cheatham III, D. E., Cruzeiro, V. W. D., Darden, T. A., Duke, R. E., Ghoreishi, D., Gohlke, H., Goetz, A. W., et al. (2018). AMBER. San Fr. 2018: AMBER, Univ. California.

[213] Corzana, F., Busto, J. H., Jimenez-Oses, G., Asensio, J. L., Jimenez-Barbero, J., Peregrina, J. M. \& Avenoza, A. (2006). New insights into alpha-GalNAc-Ser motif: influence of hydrogen bonding versus solvent interactions on the preferred conformation. J. Am. Chem. Soc., 128 (45): 14640-14648.

[214] Corzana, F., Busto, J. H., Jimenez-Oses, G., Garcia de Luis, M., Asensio, J. L., Jimenez-Barbero, J., Peregrina, J. M. \& Avenoza, A. (2007). Serine versus threonine glycosylation: the methyl group causes a drastic alteration on the carbohydrate orientation and on the surrounding water shell. J. Am. Chem. Soc., 129 (30): 9458-9467.

[215] Zanotto, L., Heerdt, G., Souza, P. C. T., Araujo, G. \& Skaf, M. S. (2018). High performance collision cross section calculation-HPCCS. J. Comput. Chem., 39 (21): 1675-1681.

[216] Gabelica, V., Shvartsburg, A. A., Afonso, C., Barran, P., Benesch, J. L. P., Bleiholder, C., Bowers, M. T., Bilbao, A., Bush, M. F., Campbell, J. L., et al. (2019). Recommendations for reporting ion mobility mass spectrometry measurements. Mass Spectrom. Rev., 38 (3): 291-320.

[217] Gaunitz, S., Nagy, G., Pohl, N. L. B. \& Noyotny, M. V. (2017). Recent advances in the analysis of complex glycoproteins. Anal. Chem., 89 (1): 389-413.

[218] Han, L. \& Costello, C. E. (2013). Mass spectrometry of glycans. Biochemistry (Moscow), 78 (7): 710-720.

[219] Kuster, B., Naven, T. J. \& Harvey, D. J. (1996). Effect of the reducing-terminal substituents on the high energy collision-induced dissociation matrix-assisted laser desorption/ionization mass spectra of oligosaccharides. Rapid Commun. Mass Spectrom., 10 (13): 1645-1651.

[220] Mucha, E., Lettow, M., Marianski, M., Thomas, D. A., Struwe, W. B., Harvey, D. J., Meijer, G., Seeberger, P. H., von Helden, G. \& Pagel, K. (2018). Fucose migration in intact protonated glycan ions: A universal phenomenon in mass spectrometry. Angew. Chem., Int. Ed., 57 (25): 7440-7443. 
[221] Wuhrer, M., Deelder, A. M. \& van der Burgt, Y. E. (2011). Mass spectrometric glycan rearrangements. Mass Spectrom. Rev., 30 (4): 664-680.

[222] BeMiller, J. N. (1967). Acid-catalyzed hydrolysis of glycosides. $A d v$. Carbohydr. Chem., 22: 25-108.

[223] Harvey, D. J., Mattu, T. S., Wormald, M. R., Royle, L., Dwek, R. A. \& Rudd, P. M. (2002). "Internal residue loss": Rearrangements occurring during the fragmentation of carbohydrates derivatized at the reducing terminus. Anal. Chem., 74 (4): 734-740.

[224] Ernst, B., Muller, D. R. \& Richter, W. J. (1997). False sugar sequence ions in electrospray tandem mass spectrometry of underivatized sialyl-Lewis-type oligosaccharides. Int. J. Mass Spectrom. Ion Processes, 160 (1-3): 283-290.

[225] Wuhrer, M., Koeleman, C. A., Hokke, C. H. \& Deelder, A. M. (2006). Mass spectrometry of proton adducts of fucosylated N-glycans: fucose transfer between antennae gives rise to misleading fragments. Rapid Commun. Mass Spectrom., 20 (11): 1747-1754.

[226] Ma, Y. L., Vedernikova, I., Van den Heuvel, H. \& Claeys, M. (2000). Internal glucose residue loss in protonated O-diglycosyl flavonoids upon low-energy collision-induced dissociation. J. Am. Soc. Mass Spectrom., 11 (2): 136-144.

[227] Franz, A. H. \& Lebrilla, C. B. (2002). Evidence for long-range glycosyl transfer reactions in the gas phase. J. Am. Soc. Mass Spectrom., 13 (4): 325-37.

[228] Li, J., Hsu, H.-C., Mountz, J. D. \& Allen, J. G. (2018). Unmasking Fucosylation: from Cell Adhesion to Immune System Regulation and Diseases. Cell Chemical Biology, 25 (5): 499-512.

[229] Pang, P.-C., Chiu, P. C. N., Lee, C.-L., Chang, L.-Y., Panico, M., Morris, H. R., Haslam, S. M., Khoo, K.-H., Clark, G. F., Yeung, W. S. B., et al. (2011). Human Sperm Binding Is Mediated by the Sialyl-Lewis $<$ sup $>\mathrm{X}</$ sup $>$ Oligosaccharide on the Zona Pellucida. Science, 333 (6050): 1761-1764.

[230] Becker, D. J. \& Lowe, J. B. (2003). Fucose: biosynthesis and biological function in mammals. Glycobiology, 13 (7): 41R-53R.

[231] Ma, B., Simala-Grant, J. L. \& Taylor, D. E. (2006). Fucosylation in prokaryotes and eukaryotes. Glycobiology, 16 (12): 158R-184R.

[232] Solter, D. \& Knowles, B. B. (1978). Monoclonal antibody defining a stagespecific mouse embryonic antigen (SSEA-1). Proc. Natl. Acad. Sci. U. S. A., 75 (11): 5565-5569.

[233] Muramatsu, T. \& Muramatsu, H. (2004). Carbohydrate antigens expressed on stem cells and early embryonic cells. Glycoconjugate J., 21 (1-2): 41-45. 
[234] Fukuda, M. (1996). Possible Roles of Tumor-associated Carbohydrate Antigens. Cancer Research, 56 (10): 2237-2244.

[235] Staudacher, E. (1999). Fucose in N-glycans: from plant to man. Biochim. Biophys. Acta, Gen. Subj., 1473 (1): 216-236.

[236] Gagarinov, I. A., Li, T., Wei, N., Sastre Torano, J., de Vries, R. P., Wolfert, M. A. \& Boons, G. J. (2019). Protecting-group-controlled enzymatic glycosylation of oligo-N-acetyllactosamine derivatives. Angew. Chem., Int. Ed. Engl., 58 (31): 10547-10552.

[237] Fraenkel, G. \& Franconi, C. (1960). Protonation of amides. J. Am. Chem. Soc., 82 (17): 4478-4483.

[238] Manz, C. \& Pagel, K. (2018). Glycan analysis by ion mobility-mass spectrometry and gas-phase spectroscopy. Curr. Opin. Chem. Biol., 42: 16-24.

[239] Harvey, D. J. \& Struwe, W. B. (2018). Structural studies of fucosylated Nglycans by ion mobility mass spectrometry and collision-induced fragmentation of negative ions. J. Am. Soc. Mass Spectrom., 29 (6): 1179-1193.

[240] Kenny, D. T., Issa, S. M. \& Karlsson, N. G. (2011). Sulfate migration in oligosaccharides induced by negative ion mode ion trap collision-induced dissociation. Rapid Commun. Mass Spectrom., 25 (18): 2611-2618.

[241] Potel, C. M., Lemeer, S. \& Heck, A. J. R. (2019). Phosphopeptide fragmentation and site localization by mass spectrometry: An update. Anal. Chem., 91 (1): 126141. 
